BNL

Informal Report

$D O E / C H / 00016-T 42$

\title{
Composite Metal-hydrogen Electrodes for Metal-Hydrogen Batteries
}

\author{
CRADA No. BNL-C-94-03 \\ Final Report \\ M. W. Ruckman', H. Wiesmann², Myron Strongin ${ }^{1}$, \\ Kwo Young ${ }^{3}$ and M. Fetcenko ${ }^{3}$ \\ 'Physics Department, Brookhaven National Laboratory \\ 2Department of Applied Science, Brookhaven National Laboratory \\ Upton, NY, 11973 \\ ${ }^{3}$ Ovonic Battery Co. (A wholly owned subsidiary of \\ Energy Conversion Devices (ECD) \\ Troy, MI, 48084
}

April 1997

This research was performed under the auspices of the U.S. Department of Energy under Contract No. DE-AC02-76CH00016. 


\section{DISCLAIMER}

Portions of this document may be illegible in electronic image products. Images are produced from the best available original document. 


\section{DISCLAIMER}

This report was prepared as an account of work sponsored by an agency of the United States Government. Neither the United States Government nor any agency thereof, nor any of their employees, nor any of their contractors, subcontractors, or their employees makes any warranty, express or implied, or assumes any legal liability or responsibility for the accuracy, completeness, or usefulness of any information, apparatus, product or process disclosed, or represents that its use would not infringe privately owned rights. Reference herein to any specific commercial product, process or service by trade name, trademark, manufacturer, or otherwise, does not necessarily constitute or imply its endorsement, recommendation, or favoring by the United States Government or any agency thereof. The views and opinions of the authors expressed herein do not necessarily state or reflect those of the United States Government or any agency, contractor, or subcontractor thereof. 


\section{Abstract}

The purpose of this project is to develop and conduct a feasibility study of metallic thin films (multilayered and alloy composition) produced by advanced sputtering techniques for use as anodes in Ni-metal hydrogen batteries. The anodes could be incorporated in thin film solid state Ni-metal hydrogen batteries that would be deposited as distinct anode, electrolyte and cathode layers in thin film devices. The materials could also be incorporated in secondary consumer batteries (i.e. type $\operatorname{AF}(4 / 3$ or $4 / 5)$ ) which use electrodes in the form of tapes. The project was based on pioneering studies of hydrogen uptake by ultra-thin $\mathrm{Pd}$-capped $\mathrm{Nb}$ films, these studies suggested that materials with metal-hydrogen ratios exceeding those of commercially available metal hydride materials and fast hydrogen charging and discharging kinetics could be produced. The project initially concentrated on gas phase and electrochemical studies of $\mathrm{Pd}$-capped niobium films in laboratory-scale NiMH cells. This extended the pioneering work to the wet electrochemical environment of NiMH batteries and exploited advanced synchrotron radiation techniques not available during the earlier work to conduct in-situ studies of such materials during hydrogen charging and discharging. Although batteries with fast charging kinetics and hydrogen-metal ratios approaching unity could be fabricated, it was found that oxidation, cracking and corrosion in aqueous solutions made pure $\mathrm{Nb}$ films and multilayers poor candidates for battery application. The project emphasis shifted to alloy films based on known elemental materials used for NiMH batteries. Although commercial $\mathrm{NiMH}$ anode materials contain many metals, it was found that $0.24 \mu \mathrm{m}$ thick sputtered $\mathrm{Zr}$ $\mathrm{Ni}$ films cycled at least 50 times with charging efficiencies exceeding $95 \%$ and $[\mathrm{H}] /[\mathrm{M}]$ ratios of 0.7-1.0. Multilayered or thicker $\mathrm{Zr}-\mathrm{Ni}$ films could be candidates for a thin film NiMH battery that may have practical applications as an integrated power source for modern electronic devices. 


\section{Table of Contents}

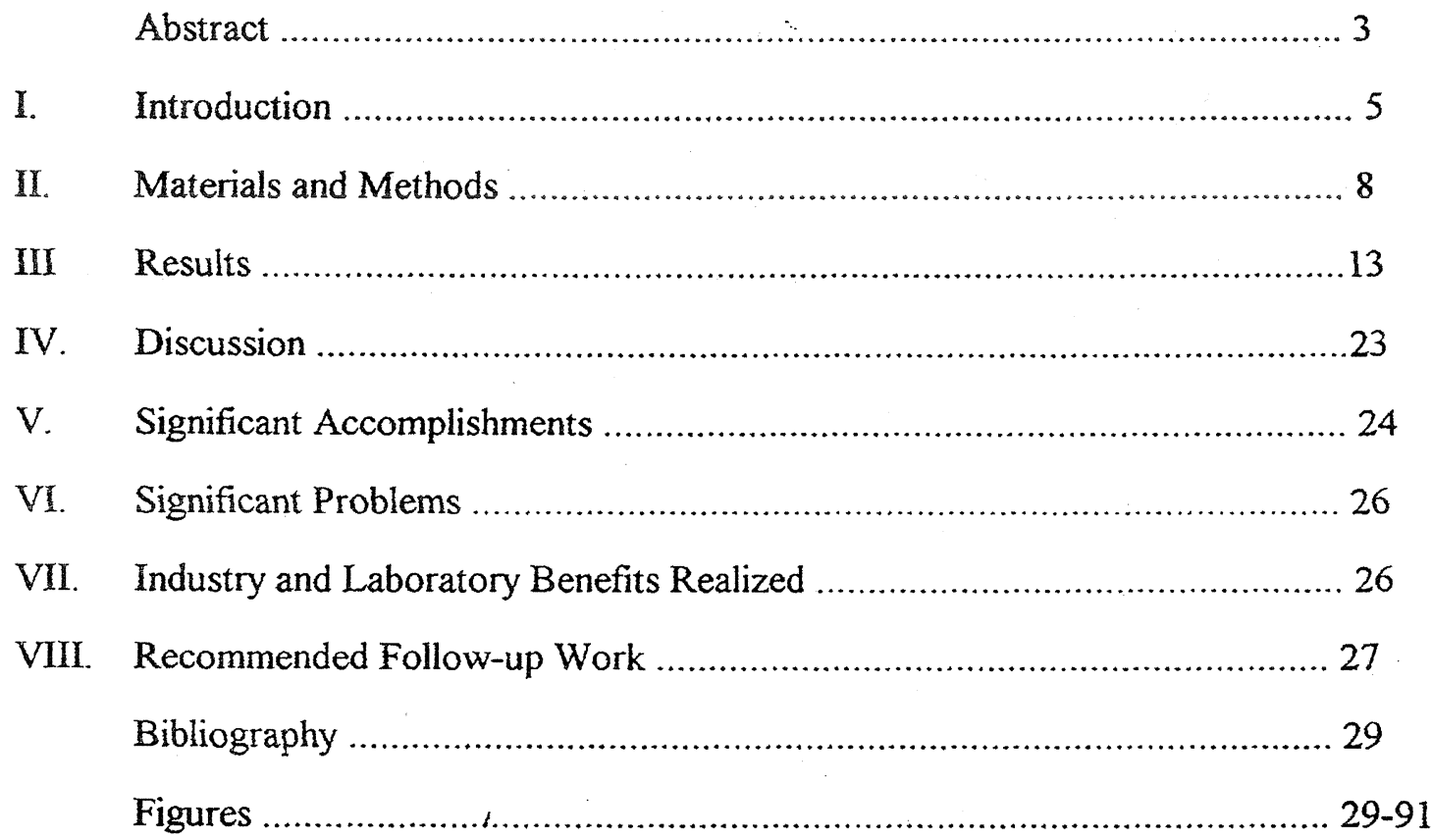




\section{Introduction}

The global market for consumer batteries exceeds 10 billion dollars per annum. Batteries power a wide array of consumer and industrial products. There is a demonstrated need for improved batteries whose energy characteristics significantly exceed those of current designs and whose environmental impacts are reduced. Available battery systems lack the energy storage capacity, charging time and durability desired for many applications like electric vehicles. The most popular and practical battery systems (e.g. lead-acid or NiCd) use heavy metals like lead or cadmium which present significant problems for waste disposal and recycling. Significant investment in research and. development of new battery technologies is on-going around the world.

One promising new battery system (Ovshinsky (1993)) is the nickel-metal hydride or NiMH cell. NiMH batteries do not contain heavy metals, do not operate at elevated temperatures, do not use pyrophoric chemicals but do show sufficient energy density and other essential performance criteria that strongly suggest further development. In fact $\mathrm{NiMH}$ battery technology is sufficiently promising to consider its use in practical electric vehicles (EVs). NiMH batteries do not consume or generate electrolyte to produce electricity and in the chemical state, store hydrogen in the anode as a solid metal hydride. The NiMH battery resembles the NiCd cell in that it uses the same cathode, NiOOH, and $\mathrm{KOH}$ electrolyte but differs in that the metal hydride replaces the $\mathrm{Cd}$ anode and as previously mentioned, is neutral to the electrolyte. In the $\mathrm{NiCd}$ cell, the discharge reaction results in the oxidation of $\mathrm{Cd}_{\text {to }} \mathrm{Cd}^{2+}$ and the reduction of $\mathrm{Ni}$ from the trivalent to divalent state. In NiMH batteries, the hydrogen stored in the metal hydride is oxidized to produce water while the cathode is reduced. NiMH battery performance depends on the hydrogen capacity and charging or discharging characteristics of the hydrogen storing medium.

Two experimental findings about the hydrogen storage characteristics of thin metal films inspired this project, namely: (1) the discovery that the rate of hydrogen uptake 
could be enhanced by coating a material like $\mathrm{Nb}$, which has a large hydrogen storage capacity, with a catalytic material for the hydrogen surface reaction; and (2) the discovery that the hydrogen storage capacity of metals could be increased by going from bulk material to a thin film. Pick et al. (1979) showed that high hydrogen uptake rates into $\mathrm{Nb}$ could be obtained by coating $\mathrm{Nb}$ layers with $\mathrm{Pd}$. An analysis of the kinetics of this process showed that the $\mathrm{Pd}$ did more than just protect the $\mathrm{Nb}$ surface from oxidation. The presence of $\mathrm{Pd}$ greatly improved the uptake rate for hydrogen by reducing the heat of adsorption of hydrogen on the surface which facilitated diffusion into the bulk. On pure $\mathrm{Nb}$, the greater heat of adsorption means that hydrogen is strongly bound to the surface which greatly slows diffusion into the bulk and "clogs" up the surface sites stopping the dissociative chemisorption of hydrogen. Hence, a material could be tailored to have a high heat of solution for hydrogen combined with the lower heat of adsorption for hydrogen on the surface which speeds up diffusion into the bulk.

In addition to this property, it was found by Zabel and Peisel (1979), Feenstra et al. (1983), Moehlecke et al. (1985), Moelle and Fecht (1993) and others that the amount of hydrogen stored in a metal could be changed by making the metal as a thin film, multilayer or powder. Specifically, Moehlecke et al. (1985) showed that the hydrogen storage capacity of $\mathrm{Nb}$ could be increased by incorporating the $\mathrm{Nb}$ in a $\mathrm{Nb}-\mathrm{Pd}$ multilayer with nanometer $\mathrm{Nb}$ layer thickness. This work also showed evidence for the suppression of hydride formation. Both phenomena and the earlier work of Pick (1979) suggested a new approach for making a superior material for hydrogen storage.

\section{Objective}

The purpose of the project is to apply recent fundamental discoveries about hydrogen absorption by multilayered alloy or intermetallic thin film materials composed of late/early transition metal couples to make better hydrogen containing-anodes for Nickel metal/hydrogen (NiMH) batteries and to determine their suitability for battery application. 
The project comprises: (1) the fabrication of multilayered or composite materials, (2) a study of the uptake and discharge of hydrogen from such materials using state-of-the-art probes for materials characterization, (3) the construction of test cells to obtain relevant battery performance data and (4) a preliminary analysis of the economic feasibility of using thin film anodes in selected small scale battery applications. The program ranges from very basic research on the phase diagram of hydrogen in materials to technology assessment of production prototype batteries employing a vacuum coated metal thin film anode. 


\section{Materials and Methods}

\section{Thin Film Fabrication}

Anode materials used in this project were metallic thin films of varying structure and composition ranging in thickness from 0.02 to $0.8 \mu \mathrm{m}$ in thickness grown on glass or metal substrates. The films were made using a commercial multi-target sputtering system developed for prototype materials production (Figure 1). To achieve needed uniformity in the layer deposition and thin film composition, a computerized control system using a personal computer and digital to analog control hardware was developed. Three 3 " and one 2 " sputter gun, mounted vertically through the base plate of the chamber and below a rotating platen located about $6.5^{\prime \prime}$ above the sources were used to make the multilayer films. The 3" guns could be tilted and operated simultaneously to produce binary or ternary alloys by co-deposition. The sputtering system reached a base pressure of $\sim 2-5 x$ $10^{-8}$ Torr and could produce nniobium films with less than 0.4 mole $\%$ impurities. The Argon gas was streamed through the chamber during sputtering with a typical flow rate of 20-25 sccm. giving Ar partial pressures of 8-12 $\mu \mathrm{m}$. A $56 \mathrm{l} / \mathrm{s}$ Balzers turbomolecular drag pump was used during sputtering and initial pump down. A $1500 \mathrm{~V} / \mathrm{s}$ cryopump was used to establish the ultimate base pressure of the system.

The thickness of the films was measured using a Dektak ${ }^{\odot}$ thin film profilometer and rates based on the measured thickness and sputtering time were used as a deposition parameter by the software created for system control. This procedure means that dead reckoning was employed during all materials fabrication. The software also used the empirical rate data to compute sputter gun currents and times for the fabrication of alloys, intermetallic compounds and binary metal mixtures. Subsequent examination of such materials by Auger spectroscopy, x-ray fluorescence and neutron reflectomentry (film thickness and structure) showed that film thickness or composition were typically within a 
few percent of the desired values. The films were grown on room temperature substrates and deposition rates varied from 1 to $16 \AA / s$.

Thin films were deposited on glass (gas or electrochemical testing), rolled $\mathrm{Ni}$ (battery testing) or 304 stainless steel sheets (battery testing). Glass substrates were cleaned using an acid wash $\left(1: 1\right.$ conc. $\left.\mathrm{H}_{2} \mathrm{SO}_{4}: \mathrm{HNO}_{3}\right)$ and a thorough rinse in deionized water. The acid wash changed the surface from being hydrophobic to hydrophilic as noted by the change in the wetting of the glass surfaces. The acid wash not only removes organic contamination but also leaches sodium ions from the glass which improves subsequent film adhesion. Dry $\mathrm{N}_{2}$ gas was employed to dry the glass pieces before insertion into the vacuum system. Metal substrates were cleaned using standard BNL NSLS procedures for materials placed in ultrahigh vacuums. This entailed cleaning with a detergent degreaser and solvents like acetone and ethanol in an ultrasonic bath before being dried using dry $\mathrm{N}_{2}$ gas. After the vacuum system was pumped down to the $10^{-5}$ torr range, the glass substrates were baked in vacuum at temperatures near $70^{\circ} \mathrm{C}$ for $3-5$ hours.

\section{Other Materials and Test Standards}

Electrochemical cells for cyclic voltammetry (cv) and battery test were constructed using $\mathrm{Ni}(\mathrm{OH})_{2}$ anodes supplied by Ovonic Battery $\mathrm{Co}$. We used a sintered $\mathrm{Ni}(\mathrm{OH})_{2}$ tape as a counter electrode in cv experiments and a polypropylene separator and $\mathrm{Ni}(\mathrm{OH})_{2}$ tape as the cathode in a prototype battery. $\mathrm{Hg} / \mathrm{HgO}$ reference electrodes were inserted into our three terminal cv cell to provide a hydrogen reference potential. The test battery was a two terminal device. KOH containing electrolytes were used in all test cells. CV tests and many battery tests employed 1 molar $\mathrm{KOH}$ solution while some battery tests used 6 molar $\mathrm{KOH}$ electrolyte to more closely resemble the commercial product. 


\section{Thin Film Characterization}

The structure and composition of films are characterized by resistivity, superconductivity ( $\mathrm{Nb}$ films), Auger, x-ray scattering, $\mathrm{x}$-ray absorption and neutron reflectivity measurements. Results of such measurements will be discussed in the following sections.

\section{Hydrogen Uptake Studies (gas phase)}

A compact Sieverts system to measure the volumetric uptake of hydrogen into the thin films was constructed. Although complex techniques such as accelerator-based nuclear reaction analysis or neutron reflectivity have been used to determine hydrogen concentrations by various investigators, the simple volumetric technique using a commercial capacitance manometer and four probe resistivity measurement (Figure 2) proved to be extremely effective. The apparatus was designed so that resistivity measurements could be made during the measurement of the uptake of hydrogen. This allowed direct measurements of the resistivity change as a function of the concentration of the hydrogen in the films.

\section{Electrochemical Studies}

Electrochemical studies of hydrogen uptake by our candidate battery components were conducted in closed "flooded" three or two terminal cells using aqueous 1 molar $\mathrm{KOH}$ solutions and a $\mathrm{Hg} / \mathrm{HgO}$ reference electrode, with the $\mathrm{Ni}(\mathrm{OH})_{2}$ counter electrodes fabricated from commercial materials supplied by $\mathrm{OBC}$ and used in their commercial $\mathrm{Ni}$ metal hydride batteries. The cells were purged with $99.998 \%$ pure Ar to exclude air and 
oxygen. The $\mathrm{Ni}(\mathrm{OH})_{2}$ counter electrodes were prepared from sintered $\mathrm{Ni}(\mathrm{OH})_{2}$ and were chosen to minimize oxygen generation. For cv measurements, the cell was driven with a Princeton Applied Research (PAR) model 173 Potentiostat and a PAR model 175 Programmer that was interfaced to a personal computer. A special electrochemical cell (Figure 3) used by the BNL x-ray scattering group was adapted to perform in-situ x-ray measurements of battery materials during (1) cyclic voltammetry and (2) during battery function testing. This permitted one of the first studies of hydrogen phase equibria in NiMH batteries during their operation and provided conclusive identification of hydrogen uptake and discharge in a cv from a composite thin film electrode.

\section{Battery Testing}

Films used for battery measurements were deposited onto $0.1 \mathrm{~mm}$ thick commercial 200 grade $\mathrm{Ni}$ sheet. The deposited films were masked and had an area of 10 $\mathrm{cm}^{2}$. Details of the cell construction are shown in Figure 4. The cell was prismatic, machined from methylmethacrylate (Lucite $($ )). ' The cathode was fabricated from OBC supplied $\mathrm{Ni}(\mathrm{OH})_{2}$ that had been sintered onto a $\mathrm{Ni}$ current collector. The cathode assembly weighed 7.6 gms compared to the active mass of less than $1 \mathrm{mg}$ for the anode and the batteries were anode limited. Electrical leads were fabricated by spot welding annealed $\mathrm{Ni}$ wire to the anode and cathode. The separator was a $125 \mu \mathrm{m}$ thick porous polypropylene sheet and it was impregnated with $\mathrm{KOH}$ electrolyte. The anode, separator and cathode were compressed using a screw assembly. Prior to testing, the battery was purged for about an hour with high purity argon gas and the purge was applied continuously throughout the entire battery test cycle. Test cells were connected to the PAR model Potentiostat operated in the galvanic mode. The Potentiostat was operated under computer control for automated data collection. 
Ovonic Battery Company conducted electrochemical capacity measurements using a computer controlled full cell cycler at their Troy MI laboratory. Each cycler could log results from as many as 24 test pieces simultaneously. OBC used the same $\mathrm{NI}(\mathrm{OH})_{2}$ tape material supplied to BNL for its testing and used a $30 \%$ by weight $\mathrm{KOH}$ solution as the electrolyte. The typical charge applied was $2000 \mathrm{~mA} / \mathrm{gm}$ for $1800 \mathrm{sec}(30 \mathrm{~min}$.). The samples were discharged through a load with a current of 100 or $20 \mathrm{~mA} / \mathrm{gm}$ to a voltage of $0.9 \mathrm{~V}$. 


\section{Results}

As previously noted, the CRADA project had several objectives and the following figures illustrate the research and technology development conducted by the principal investigators at Brookhaven or Ovonic Battery Company. The presentation is organized as follows:

(A) Studies of gaseous hydrogen uptake by nanoscale metal bilayers, multilayers and Pdcapped intermetallic films. This work was undertaken to expand on earlier studies of hydrogen interactions with these materials and improve our scientific understanding. Such work provided confirmation that interfacial clamping does lead to the creation of a novel hydrogen-metal phase that differs in significant ways from metal hydrides. We also used our experimental set-up to study the kinetics of a surface chemical reaction at high pressures more closely approximating those in chemical laboratories or industrial processes. Advanced probes/like XAFS were used to determine the change in electronic structure of $\mathrm{Nb}$ when hydrogen is absorbed. When hydrogen is absorbed, the density of states near the Fermi edge decreases. It was found that this aspect of the electronic structure changes continuously in the new hydrogen-No phase and the superconducting transition temperature $\left(T_{c}\right)$ is depressed continuously in a manner resembling the nonreversible depression of $\mathrm{T}_{\mathrm{c}}$ achieved by inducing disorder in $\mathrm{Nb}$.

(B) Potentiostatic and galvanostatic techniques were applied to study the behavior of the metal films in aqueous environments resembling those of commercially available NiMH batteries. Synchrotron-based $x$-ray techniques were used to analyze hydrogen absorption by the films and provided connections between the bulk hydrogen phases and cyclic voltammograms or the battery discharge curves. The x-ray data provided crucial links between gas phase and electrochemical experiments. The aqueous environment differs 
from the gas phase in that water, hydroxyl and oxygen are present and materials can oxidize (passivate) or corrode and lose the ability to store and discharge hydrogen. This proved to be a critical limitation on the use of simple metallic systems in batteries. We used cv's as a tool to screen materials for battery testing and study the loss of energy and hydrogen storage capacity.

(C) Brookhaven manufactured anode materials were incorporated in test cells at BNL or OBC. Materials for battery testing were thicker than those studied in electrochemical or gaseous experiments. This was done to probe the behavior of films closely resembling those needed for a commercial product. This work showed that simple systems like Pdcapped $\mathrm{Nb}$ multilayers were poor choices for a thin film NiMH battery because they lacked the energy storage or stability of commercial sintered metal hydrides used by OBC in existing products. $\mathrm{OBC}$ found that our multilayered anodes could be activated in the aqueous environment to produce a "metastable" material with energy storage characteristics exceeding commercial materials by in some cases a factor of four. Analysis of such a film showed that the layered structure was disrupted and a complex metal oxide with high concentrations of potassium and calcium was produced. The results obtained from systems like $\mathrm{Pd} / \mathrm{Nb}, \mathrm{Pd} / \mathrm{Ti}, \mathrm{Pd} / \mathrm{V}, \mathrm{Pd} / \mathrm{Mg}$ and $\mathrm{Pd} / \mathrm{Zr}$ prompted a change in the program to a focus on alloy systems and intermetallic compounds either resembling those used to make the hydrides (e.g. $\mathrm{AB}_{2}$ or $\mathrm{AB}_{5}$ compounds) or metallic materials reported to have good hydrogen storage and corrosion resistance characteristics (e.g. $\mathrm{Zr}_{7} \mathrm{Ni}_{10}$ ).

\section{A. Gas Phase Studies (Basic Research)}

Figure 5 shows a plot of the normalized resisitivity variation during hydrogen uptake by a $200 \AA$ thick Pd capped $\mathrm{Nb}$ film as a function of temperature. The change in slope of the resistance curve is attributed to a change in hydrogen-hydrogen correlation's 
for hydrogen in the $\mathrm{Nb}$ matrix and the inflection point maps out the boundary between low and a mixed low/high $\mathrm{H}-\mathrm{Nb}$ phase region. Analysis of the discharge of hydrogen from the film (Figures 6 and 7) shows a departure from Sieverts law behavior when the $[\mathrm{H}] / \mathrm{Nb}]$ exceeds 0.4 at $23^{\circ} \mathrm{C}$ and marks the transition from the mixed phase regime to the high concentration phase. The $\mathrm{H}-\mathrm{Nb}$ phase diagram constructed for the $200 \AA \mathrm{Nb}$ film is shown in Figure 8 and is re-sketched on the bulk phase diagram in Figure 9. Figure 9 suggests that the critical point for $\mathrm{H}-\mathrm{Nb}$ has been depressed more than 100 degrees $\mathrm{K}$ for the thin film as compared to bulk $\mathrm{Nb}$. The physical basis for the modification of the $\mathrm{H}-\mathrm{Nb}$ phases in thin film $\mathrm{Nb}$ is the clamping of the film at the interfaces which reduces the expansion of the $\mathrm{Nb}$ lattice in a direction parallel to the substrate. This special characteristic of thin films suppresses the formation of the $\beta$ hydride phase at room temperature and increases the range of the $\alpha$ or $\alpha^{\prime}$ solid solution phase. It is emphasized that this change in the hydrogen uptake behavior of metals when fabricated into thin films is the principal scientific basis for studying the use of metal films as a battery component. It was hoped that materials with good hydrogen storage capacity and fast hydrogen uptake and discharge kinetics could be made by changing the shape or size of the material rather than the composition (as had been done by those who preceded us).

Figure 10 shows an $\mathrm{X}$-ray diffraction results for a Pd-capped $800 \AA$ thick $\mathrm{Nb}$ film charged with hydrogen $([\mathrm{H}] /[\mathrm{Nb}]=0.7)$ and changes in the $\mathrm{Nb}[110]$ Bragg peak as hydrogen is discharged by reacting with oxygen in air. Initially, the $\mathrm{Nb}[110]$ peak is located near $28.5^{\circ}\left(\mathrm{q}_{\mathrm{z}}=2.57 \AA^{-1}\right)$. This position is characteristic of the high concentration $\mathrm{Nb}-\mathrm{H}$ phase. As hydrogen is removed from the bulk, the peak shifts to large $2 \theta\left(\mathrm{q}_{\mathrm{z}}\right)$ values, then splits into two peaks characteristic of a two phase system. The lower $2 \theta\left(q_{z}\right)$ value peak resulting from the high concentration $\mathrm{H}-\mathrm{Nb}$ phase while the higher $2 \theta\left(\mathrm{q}_{z}\right)$ value peak resulting from the low concentration phase. This pattern is also seen in data from a $600 \AA$ thick film (Figure 1 1a) that was analyzed using a 4 circle Huber goniometer at the $\mathrm{X}-22$ beam line at the NSLS. However, examination of equivalent $\mathrm{Nb}[110]$ planes 
oriented parallel to the substrate disclosed that the such planes do not expand when the material was charged with hydrogen (Figure 11b). This is a particularly elegant demonstration that the film is clamped to the substrate and that the material is placed under great strain when filled with hydrogen. Figure $11 \mathrm{a}$ and $\mathrm{b}$ show different values for the positions of the $\mathrm{Nb}[110]$ and $\mathrm{Pd}[111]$ Bragg peaks. This is attributed to (1) instrumental error and the presence of residual stresses in the film resulting from the thin film growth process.

Neutron reflectometry was done at the Missouri University Research Reactor (MURR) and used to determine the concentration of hydrogen and change in the thickness of the films when hydrogen was absorbed into a $100 \AA$ thick $\mathrm{Nb}$ layer sandwiched between two Pd films (Figure 12). The technique is complementary to the Sieverts and $\mathrm{x}$-ray techniques briefly discussed above and confirmed that the films were of sufficient quality to do the neutron technique (i.e. the interfaces were sufficiently sharp and smooth). The change in contrast when $\mathrm{H}$ went into the $\mathrm{Nb}$ indicated that the $[\mathrm{H}] /[\mathrm{Nb}]$ was 0.59 which agreed with Sieverts and $\mathrm{x}$-ray results. The change in the thickness of the $\mathrm{Nb}$ layer and its contrast to neutrons when hydrogen or deuterium is absorbed is shown in Figure 13.

Other $\mathrm{x}$-ray studies were done to get a better understanding of the nature of hydrogen absorbed in thin $\mathrm{Nb}$ layers less than or equal to $0.1 \mathrm{~nm}$. Hydrogen is a difficult element to probe in metals because it has such a small $x$-ray scattering cross-section and other tools such as optical spectroscopy or nuclear magnetic or electron spin resonance are impossible because the metals absorb electromagnetic radiation. Electrons can scatter from hydrogen and $\mathrm{x}$-ray absorption fine structure is related to the interference of outgoing and scattered photoelectrons when x-rays are absorbed. Lengler (1994) used changes in EXAFS to locate hydrogen in metal hydrides by observing the changes in the intensity of $\mathrm{r}$-space features. EXAFS was used in this project to study $\mathrm{H}-\mathrm{H}$ correlation's by looking at the change in the nearest-neighbor $(n-n) r$-space feature as a function of hydrogen concentration. Figure 14 shows $k^{3}$-weighted $\chi$ data for a $\mathrm{Nb}$ foil (bulk 
standard), a $200 \AA \mathrm{Nb}$ layer in a $10 \mathrm{x} \mathrm{Pd} / \mathrm{Nb}$ multilayer and the same multilayer changed with hydrogen to an $[\mathrm{H}] /[\mathrm{Nb}]$ of 0.3 . The EXAFS signal decreases and the $\chi$ spacing changes indicative of the expansion of the $\mathrm{Nb}$ lattice. When the data is Fourier transformed to provide the r-space function (Figure 15), the changes in the intensity of the first $n-n$ peak in going from the $\mathrm{Nb}$ foil, to the multilayer and to the multilayer charged with hydrogen are obvious. The r-space function loses intensity when hydrogen is absorbed. Figure 16 shows how the intensity of the n-n peak changes with hydrogen absorption. At $[\mathrm{H}] /[\mathrm{Nb}]$ less than 0.2 , the intensity of the peak (now taken to be an order parameter) decreases linearly with hydrogen concentration. This is what could be expected for an uncorrelated $\mathrm{H}-\mathrm{Nb}$ phase like the $\alpha$-phase. For $[\mathrm{H}] /[\mathrm{Nb}]$ more than 0.2 , the system shows a non-linear dependence and an increase in the order parameter. The $\mathrm{H}-\mathrm{Nb}$ phase with hydrogen concentration exceeding 0.2 is correlated and believed to be like the $\alpha^{\prime}$-phase. The conventional wisdom argues that this phase could also be like the bulk $\beta$ hydride phase but the preponderance of our data argues against this conclusion.

The variation in superconducting parameters is another convincing reason for concluding that the high concentration phase in the thinnest samples studied is not a hydride. Figure 17 shows that $T_{c}$ changes in a reversible continuous way with hydrogen uptake. In studies of the suppression of superconductivity by hydriding bulk $\mathrm{Nb}$, two transition temperatures indicative of two $\mathrm{H}-\mathrm{Nb}$ or $\mathrm{H}-\mathrm{Nb}$ and $\mathrm{Nb}$ phases were seen. In the thin film case, there is only one transition temperature indicative of a single phase that has a varying hydrogen concentration.

Theoretical band structure calculations and XANES were employed to study electronic basis for the modification of the superconducting Tc. Ab-initio FLAPW calculations of the partial density-of-states (DOS) (Figure 18) show that the total densityof-states $(n(E))$ decreases when hydrogen is inserted in to a $\mathrm{Nb}$ lattice expanded as indicated by experiment to accommodate the hydrogen. It is well known (Bardeen (1957)) that $T_{c}$ depends on the $n(E)$ and should become smaller when $n(E)$ is reduced. 
XANES (Figures 19 and 20) for the $\mathrm{Nb} \mathrm{K}$ and $\mathrm{L}_{2}$ edges probe the unoccupied s-p and $d$ states and show decreases in $n(E)$ near the Fermi edge that are in excellent agreement with theory. 


\section{B. Electrochemical Studies (Basic and Applied Research)}

Standard electrochemical techniques were used to study the behavior of thin film materials in an environment resembling that of commercial $\mathrm{NiMH}$ batteries. The experiments showed that such an environment placed additional technical requirements on the materials and required changes in our original battery concept. The aqueous environment changes the surface chemistry and although hydrogen is still stored in the material, other factors such as oxidation and corrosion became a significant problem that needed be overcome before a working battery using simple metal film anodes can be produced.

Powerful synchrotron-based x-ray scattering was used to make in-situ measurements of the structure and hydrogen phases in the metal film anodes during cyclic voltammetry and battery discharge experiments. Figures 21 and 22 show a cyclic voltammogram (cv) and $x$-ray diffraction data, for the hydrogen charging of an $800 \AA$ thick $\mathrm{Pd}$ film, taken at various numbered points on Figure 21 during the $\mathrm{cv}$. Features in the $\mathrm{cv}$ and $\mathrm{x}$-ray data related to the uptake and discharge of hydrogen from the H-Pd phases $\left(\alpha\right.$ and $\left.\alpha^{\prime}\right)$ are closely correlated. Figures 23-26 show the same data obtained for a Pd-capped $800 \AA$ thick Nb film and a Pd-capped $3 \times \mathrm{Pd} / \mathrm{Nb}$ multilayer with $800 \AA$ thick $\mathrm{Nb}$ and $200 \AA$ thick Pd layers. The $\mathrm{x}$-ray data shows the sequential charging of the $\mathrm{Nb}$ and $\mathrm{Pd}$ layers, the sequential discharging of the $\mathrm{Pd}$ and $\mathrm{Nb}$ and the effect of clamping at the interfaces. It is interesting that the $\mathrm{x}$-ray data obtained during cv's matches that obtained during gas phase hydrogen experiments. It should also be noted that buried $\mathrm{Nb}$ or Pd layers charge with hydrogen at the same electric potentials and that hydrogen concentrations in the layers follow the same trends (Figure 27) with cell potential as hydrogen concentrations follow pressure in gas phase experiments. There is about $1 / 2$ volt difference in the chemical potential of hydrogen in $\mathrm{Nb}$ when compared to palladium.

Figures 28-30 show in-situ x-ray results for hydrogen in working NiMH cells using 
$\mathrm{Pd}$ or $\mathrm{Pd} / \mathrm{Nb}$ multilayer anodes. For a palladium film, we see a rapid drop in the cell voltage when the high concentration $\alpha^{\prime} \mathrm{H}-\mathrm{Pd}$ phase is exhausted. This marks the full discharge, of such a battery. When the same experiment is performed for the $\mathrm{Pd} / \mathrm{Nb}$ multilayer, significant amounts of hydrogen are still in the $\mathrm{Nb}$ layer when the electrical potential begins to decrease rapidly. The hydrogen in the $\mathrm{Nb}$ layer had goes into a two phase region. Clearly, the relationship between hydrogen in $\mathrm{Pd}$ and $\mathrm{Nb}$ and battery voltage is different for a $\mathrm{Nb}$-containing multilayer than a pure $\mathrm{Pd}$ film.

Cyclic voltammetry provided the evidence that corrosion and oxidation (passivation) are significant problems for pure metal anodes. Figures 31 and 32 show cv's for $\mathrm{Pd} / \mathrm{Nb}$ bilayers and multilayers $(800 \AA \mathrm{Nb} / 200 \AA \mathrm{Pd})$. Peaks $\mathrm{B}$ and $\mathrm{E}$, previously identified with hydrogen charging and discharging, decrease in magnitude with increasing cycle number. This shows that the hydrogen storage capacity is lost during each re-dox cycle. The rate of lose varied from film to film and a feature at positive potential attributed to niobium oxidation was sometimes observed.

Given the evidence that $\mathrm{Nb}$ was being oxidized, we tried a variety of capping layers in an attempt to increase the protection afforded the buried $\mathrm{Nb}$. We tried thicker $\mathrm{Pd}, \mathrm{Pd} / \mathrm{Ag}, \mathrm{Ni}$ and $\mathrm{Pd} / \mathrm{Ni}$ capping layers but found that none provided the desired protection. Figures 33-35 show cv's for $\mathrm{Pd}, \mathrm{Ni}$ and $\mathrm{Ni} / \mathrm{Pd}$ capped $\mathrm{Nb}$ multilayers. Interesting changes in the hydrogen charging potentials for $\mathrm{Nb}$ were seen when $\mathrm{Ni}$ replaces $\mathrm{Pd}$. The $\mathrm{Ni} / \mathrm{Pd}$ capped $\mathrm{Pd} / \mathrm{Nb}$ multilayer shows $\mathrm{cv}$ features that are a summation of those from $\mathrm{Ni}$ and $\mathrm{Pd}$ capped $\mathrm{Nb}$. Repeated cycling of the anode shows a progressive evolution to a $\mathrm{CV}$ resembling the Pd-capped multilayer. This indicates that $\mathrm{Ni}$ capping layers are subject to etching in the alkaline $\mathrm{KOH}$ electrolyte and $\mathrm{Ni}$ is dissolved into the electrolyte.

Another approach to suppression of oxidation and corrosion of battery anodes and cathodes is the addition of other metals to the electrode. For example, the addition of $\mathrm{Ni}$ to $\mathrm{Ti}$ improves oxidation resistance and increases battery life. State-of-the-art metal 
hydride materials contain as many as a dozen such additives to improve a range of physical or chemical properties of battery materials. Making thin films with such complex compositions would require complex sources and targets that might prove to be very uneconomic. When it became apparent that no elemental multilayer had the resistance to oxidation or corrosion necessary for battery application, the program changed focus to binary and a ternary metal systems. Ni was added to $\mathrm{Nb}, \mathrm{Ti}$ and $\mathrm{Zr}$. Vanadium and FeTi systems often advanced for use in gaseous hydrogen storage systems, proved to be soluble in the $\mathrm{KOH}$ electrolyte. The effect of adding $\mathrm{Ni}$ to $\mathrm{Nb}$ is shown in Figure 36 . It was found that $\mathrm{Ni}$ additions to $\mathrm{Nb}$ decreased the initial hydrogen loading but improved the stability of the anode. The best performance for $\mathrm{Ni}-\mathrm{Nb}$ occurred for $\mathrm{Ni}$ concentrations between $10-30 \%$. This corresponded to the formation of a highly disordered $\mathrm{Ni}-\mathrm{Nb}$ phase that co-existed with a $\mathrm{Nb}$-rich or $\mathrm{Nb}$ second phase. $\mathrm{Ni}$-rich $\mathrm{Ni}-\mathrm{Nb}$ films had poor hydrogen storage capacities. Hydrogen is not soluble in pure $\mathrm{Ni}$ and the hydrogen storing $\mathrm{Ni}-\mathrm{Nb}$ phase may have been discontinuous in $\mathrm{Ni}-$ rich $\mathrm{Ni}-\mathrm{Nb}$ films leading to hydrogen percolation problems.

The behavior of bimetallic anodes varied from sample to sample for reasons that are not entirely obvious. Figure 37 shows results for three anodes with a composition of $\mathrm{Ni}_{0.2} \mathrm{Nb}_{0.8}$. One sample showed a high relatively stable hydrogen capacity during cycling, another showed low capacity which was quickly lost and the third increased capacity in a discontinuous manner and eventually exceeded the capacity of the first sample. Ni-Ti films were tested (Figure 38) but the results were not promising and the work was stopped.

The last bimetallic system studied at Brookhaven was the $\mathrm{Zr}-\mathrm{Ni}$ system. $\mathrm{Zr}$ is a highly reactive metal and used in non-evaporable getter pumps in vacuum technology. Wakao et al. (1984) and McCormack et al. (1996) found that $\mathrm{Ni}-\mathrm{Zr}$ and $\mathrm{Ni}-\mathrm{M}-\mathrm{Zr}(\mathrm{M}=\mathrm{Ti}$ and $\mathrm{Cr}$ ) alloys have particularly good hydrogen storage characteristics and resistance to corrosion. They identified the desired $\mathrm{Ni}-\mathrm{Zr}$ phase as an intermetallic compound having a 
composition of $\mathrm{Zr}_{7} \mathrm{Ni}_{10}\left(\mathrm{Zr}_{0.41} \mathrm{Ni}_{0.59}\right)$. We made $800 \AA$ thick films of this composition and other $\mathrm{Ni}-\mathrm{Zr}$ films and found that $\mathrm{Ni}-\mathrm{Zr}$ films with compositions near that of $\mathrm{Zr}_{7} \mathrm{Ni}_{10}$ gave excellent results (Figure 39). The cv's proved to be stable and the anodic and cathodic charges were almost equal (Figure 40) after several cycles. When such films were inserted in a prismatic cell for battery function test results approaching those of state-of-the-art metal hydrides were obtained.

\section{Battery Testing (Applied Research)}

Tests of battery function using Brookhaven grown thin films materials were conducted at both BNL and OBC and the results will now be discussed:

\section{Brookhaven Results:}

Figure 41 shows raw and processed data obtained for a $10 \mathrm{~cm}^{2} 0.24 \mu \mathrm{m} \mathrm{Zr}_{0.4} \mathrm{Ni}_{0.6}$ film capped with $400 \AA$ of Pd. The film was cycled 50 times and charged with a $4.71 \mathrm{~mA}$ current to an $\mathrm{H} / \mathrm{M}$ of 0.7 . The charging time was $360 \mathrm{sec}$.. The film was discharged through a load at a current of $-0.924 \mathrm{~mA}$ to a voltage of $0.8 \mathrm{~V}$. Figure 41 shows the voltage, charge to discharge (in coulombs), charging efficiency, charging and discharging current and energy efficiency. The results for this $\mathrm{Zr}_{0.4} \mathrm{Ni}_{0.6}$ sample were excellent with charging efficiency exceeding $90 \%$ and energy efficiency exceeding $70 \%$ after 50 cycles. The capacity of this anode exceeded $270 \mathrm{mAhr} / \mathrm{gm}$ for a $\mathrm{H} / \mathrm{M}$ ratio of 0.7 making it comparable to commercial metal hydride battery materials. This anode was not a fluke, Figure 42 summarizes results obtained for $24 \mathrm{Zr}-\mathrm{Ni}$ anodes and at least a quarter of the test pieces showed comparable performance.

The performance of other materials studied at Brookhaven are summarized graphically in Figures 43-47. They show that $2400 \AA \mathrm{Pd}$ capped Nb films had a peak 
capacity of $65 \mathrm{mAhr} / \mathrm{g}$ at an $\mathrm{H} / \mathrm{M}$ ratio of 0.7 but relatively low (less than $50 \%$ ) charge and energy efficiencies (Figure 43). The addition of 40 atomic \% Ni increased the capacity to as much as $150 \mathrm{mAhr} / \mathrm{gm}$ and increased charge and energy efficiency for H/M ratios less than 0.5 (Figure 44). Similar results were obtained for $\mathrm{Ni}_{0.4} \mathrm{Ti}_{0.6}$ (Figure 45). The best results for $\mathrm{Ni}-\mathrm{Nb}$ and $\mathrm{Ni}-\mathrm{Ti}$ (Figures 46,47 ) were seen for $\mathrm{Ni}$ concentrations between 20 and $40 \%$. Ni-Nb and $\mathrm{Ni}-\mathrm{Ti}$ samples with the above concentrations were found to be highly disordered.

\section{OBC Testing Results:}

Figures 48-50 show results obtained at $\mathrm{OBC}$ for $800 \AA$ thick $\mathrm{Nb}, \mathrm{Nb}_{0.8} \mathrm{Ni}_{0.2}$ and $\mathrm{Nb}_{0.4} \mathrm{Ni}_{0.6}$ films on float glass capped with $200 \AA$ of $\mathrm{Pd}$. Most BNL samples showed electrochemical capacities less than $100 \mathrm{mAhr} / \mathrm{gm}$ but some samples exhibited an activation process which lead to a spike in capacity followed by a significant increase in capacity to as much as $1000 \mathrm{mAhr} / \mathrm{gm}$ and often exceeding $500 \mathrm{mAhr} / \mathrm{gm}$. This result was of great interest to $\mathrm{OBC}$ since the company is seeking to improve the capacity of their existing commercial metal hydride material. OBC's existing materials have electrochemical capacities of $300-350 \mathrm{mAh}$ /gm and the identification of a phase with capacity exceeding $500 \mathrm{mAhr} / \mathrm{gm}$ would be a major advance in an industry that usually sees incremental changes in the performance of battery materials.

$\mathrm{OBC}$ used Auger spectroscopy and x-ray diffraction in an attempt to identify the new phase. Figure 51 shows typical Auger depth profiling results. Electrochemical cycling of the BNL material causes extensive inter diffusion, electromigration, solid state reactions and reactions with electrolyte components like potassium. The layered structure is replaced by a multi-element oxide of $\mathrm{Nb}-\mathrm{Pd}-\mathrm{Ni}$ that has significant amounts of potassium and chlorine. The material may also have hydrogen, hydroxyls or be hydrated. 
Figures 52 shows a plot of discharge capacity (mAhr/gm) vs. discharge current $\left(\mathrm{mA} / \mathrm{gm}_{\mathrm{i}}\right)$ for an activated $\mathrm{BNL}$ anode and the results are excellent. Unfortunately, the material is metastable (Figure 53) and significant capacity is lost after only a few cycles. Future research should include studies of additives that might stabilize this tantalizing phase.

\section{Discussion}

The scientific studies and battery test work show that nanostructured anode materials with modified hydrogen uptake and discharge properties can be made in thin film form. Elemental multilayers have excellent hydrogen storage and kinetics in gas phase environments and might have applications in sensors, fuel cells and other applications using gaseous reactants. The elemental multilayers tested suffer oxidation (passivation) and corrosion in basic aqueous environments similar to those in NIMH commercial batteries. Intermetallic phases that are relatively simple in composition, that resist corrosion and oxidation and have properties approaching if not exceeding commercial materials were found. Thin films with a composition $\mathrm{Zr}_{0.4} \mathrm{Ni}_{0.6}\left(\mathrm{Zr}_{7} \mathrm{Ni}_{10}\right)$ make excellent anodes and could be a component of a thin film NiMH battery provided appropriate separators, proton conducting electrolytes and cathodes can be developed.

Figures 54 and 55 show conceptual multilayered thin film batteries that might be developed using the anode technology developed during this CRADA. The films could be deposited on thin tapes and rolled up for installation in a canister (Hong (1996)) (Figure 56) familiar to any battery user. The films could also be deposited on a substrate as a part of a solid state thin film battery (Figure 57) (Ovshinsky (1996)) resembling a rechargeable thin film Li battery recently developed at Oak Ridge National Laboratory (Bates (1996)). Key to the further development of this technology is whether thin film NiMH (Ni-metal 
hydrogen) batteries can be made economically using current thin film deposition technology.

Economic feasibility was judged by comparing the BNL thin film anode against sintered metal hydride tapes already in production by $\mathrm{OBC}$. The BNL anode material has to have markedly better hydrogen sorptive properties in at least one or more areas and compare well with existing metal hydride battery materials to justify the high cost of production. Our CRADA partner provided data showing a base line cost of $\sim \$ 2.00$ per battery for a conceptual NiMH AA cell based on a jelly roll design with a $1.5 \mathrm{Ahr}$ storage capacity. Using this criterion, a $200 \mathrm{~cm}^{2} 10 \mu \mathrm{m}$ thick film of our material would be needed to make such a battery. This requires that the anode element cost significantly less than $\$ 1.00$ and a survey of state-of-the-art electron beam and plasma spray coaters indicates that this cost target may be within reach for a plant designed to produce 30000 AA cells per day.

Figures 58-60 provide details of an economic analysis of electron beam evaporation and plasma spraying as potential methods of making our anode material on a thin tape. Figures 61-62 show conceptual production lines for making anode tapes. It was found for the case of electron beam deposition that an anode for a AA sized battery could be made for about $\$ 0.99$ which is close to the $\$ 0.60$ cost that $\mathrm{OBC}$ charges for a similar component made using metal hydrides and thick film techniques. Given the stage of development of our material and technology, this finding is encouraging.

\section{Significant accomplishments}

1. The phase diagram of hydrogen was measured in thin $\mathrm{Nb}$ layers as a function of the thickness of the film. These experiments show that the critical point in the bulk phase is lowered and the hydrogen at room temperature never forms a hydride phase. Instead 
we find that there is co-existence of a "gas" like phase where there are no correlation's and a "liquid " phase where there are correlation's between the hydrogen atoms. The coexistence is established by direct $\mathrm{x}$-ray diffraction measurements, and also by resistivity measurements which together with volumetric measurements, show behavior confirming the correlated behavior and coexistence of two phases.

2. These bilayer systems have been used to monitor the reaction of hydrogen and oxygen on the Pd surface at high pressures. Once calibrated the resistance of the film can be used to determine the amount of hydrogen in the film. When oxygen is added to a $\mathrm{Pd} / \mathrm{Nb}$ bilayer loaded with hydrogen, the rate at which hydrogen leaves the layer can be used to monitor the rate of reaction with oxygen on the surface. This technique might be useful for hydrogen or oxygen sensors.

3. The distribution of hydrogen in multilayer films has been determined by $x$-ray diffraction measurements. The measurements show that there is a uniform chemical potential throughout multilayer systems, which implies that the hydrogen diffuses rapidly through the multilayer. For example in the $\mathrm{Nb} / \mathrm{Pd}$ bilayer system all the $\mathrm{Nb}$ layers fill with hydrogen before $X$-ray measurements indicate that the $P d$ layers are filing with hydrogen. This has been confirmed in both gas phase and aqueous measurements.

4. In-situ measurements have been made of multilayer films used as an anode under actual battery discharge conditions. These measurements indicate that complex phenomena occur on the surface during discharging and not all hydrogen goes to the cathode.

5. Studies of bimetallic systems undertaken in the final months of the CRADA revealed that $\mathrm{Zr}_{7} \mathrm{Ni}_{10}$ thin films could be made with performance in battery tests that were 
close to the best metal hydride materials on the commercial market and rapid charging and discharging kinetics. Such material may be an effective anode for a thin film or all solid state NiMH battery.

\section{Significant problems}

Oxidation (passivation) and corrosion of $\mathrm{Nb}$ and other metals thwarted attempts to make high performance NIMH batteries using pure metal multilayers. Another problem was the finding that elemental multilayered films are unstable in electrolytes during repeated charging and discharging with associated hydrogen-induced lattice expansions. In other words, artificially layered elemental metal films are metastable systems far from equilibrium and susceptible to physical and chemical processes that reduce their energy storage capacity. However, some intermetallic compound films provided adequate energy storage and efficiency and could be used in a thin film NiMH battery. Hence, the goal of making thin films for hydrogen storage in NiMH batteries using appropriate intermetallic systems is still viable.

\section{Industry and laboratory benefits realized}

The Department of Energy supports a number of programs that might benefit from this research. These programs include projects in the National Laboratories concerned with battery technology, hydrogen energy, corrosion and thin film sensors for hydrogen. Similar projects are supported at several universities under the DOE's extra mural grant program. DOE has an interest in improved battery technology and the successful development of a non-hydride metal/hydrogen battery replacement for the $\mathrm{Ni}-\mathrm{Cd}$ cell in common use would serve the goal of providing an environmentally superior replacement. 
The program addressed several technical needs identified in Notice 96-05" Research for Improving Vehicular Transportation and Reducing Energy Consumption and Pollution from Manufacturing Processes". DOE's interest in NiMH battery technology is also demonstrated by recent agreements signed by the Secretary of Energy and the Russian Ministry of Atomic Energy which will èstablish a joint US-Russian venture with our CRADA partner ECD to make such batteries in Russia for sale in Europe and Asia. Our CRADA partner also received a $\$ 8,000,000$ grant from the DOE through its USABC (US. Advanced Battery Consortium) to pursue cost reduction for its proposed NiMH automotive battery. $\mathrm{OBC}$ also conducted $\mathrm{x}$-ray studies of its metal hydrides at Brookhaven. This work contributed to OBC's defense of its proprietary technology and successful licensing of its technology to a number of battery manufacturers.

\section{Recommended follow-up work}

The following work would contribute to the development of a prototype thin film Ni-metal hydrogen battery and advance general NiMH battery technology:

1. In-situ $x$-ray techniques were developed to study hydrogen uptake in thin film anodes in working NiMH cells. These techniques are being used at BNL by other groups (Mukerjee (1995) and Thurston (1996)) to study alternative battery systems and could also be used to study the cathodes used in commercial NiMH cells. In fact this type of study between the PI's and OBC was proposed for submission to LTR for a new CRADA with OBC. Unfortunately, LTR guidelines excluded the project as a "continuation" of the existing CRADA.

2. While it is unlikely that thin film anodes will be used in large NiMH batteries, the basic physics and chemistry studied in this project could still be exploited to provide 
improvements to the materials used in such batteries. For example, Moelle and Fecht (1994) have shown that hydrogen uptake can be modified by making metals as nanoscale powders. There is considerable work elsewhere concerning nanostructured materials made by cluster deposition. Our films proved to be fine grained nanoscale materials that resemble such nanostructured materials and beneficial changes in hydrogen sorptive properties might be achieved in bimetallic systems like $\mathrm{Zr}_{7} \mathrm{Ni}_{10}$ assembled as nanophase particle composites.

3. It may be possible to make micron scale layered composite foils using metallurgical techniques resembling those being developed to make high quality superconducting tapes. A useful battery anode might be made by rolling plates of the appropriate bimetallic materials to micron sized dimensions or by thin film growth on textured metal substrates.

4. BNL thin film anodes could be a good component in a solid state proton battery. In fact, researchers at CUNY and ECR Ltd. (Rehovot, Israel) have developed a proton conducting polymer and cathode that could use integrated with the BNL anode to make a solid state hydrogen battery that might be comparable to thin film Li batteries developed at ORNL. 


\section{Bibliography}

J. Bardeen, L. N. Cooper and J. R. Schrieffer, Phys. Rev., 108, 1175 (1957).

J. B. Bates, "Rechargeable Lithium Battery for Use in Applications Requiring Low to High Power Output", U. S. Patent No. 5,569,520 (October 29, 1996).

R. Feenstra, G. J. de Bruin-Hordijk, H.-L. Bakker, R. Greissen and D. G. de Groot, J. Phys. F, 13, L13 (1983).

K. Hong, "Hydrogen Storage Material and Ni Hydride Batteries Using Same", U.S. Patent No. 5,501,917 (Mar. 26, 1996).

B. Lengler, Phys. Rev. Lett., 53, 74 (1994).

M. McCormack, M. E. Badding, B. Vyas, S. M. Zahurak and D. W. Murphy, J. Electrochem. Soc., 143, L31 (1996).

S. Moehlecke, C. F. Majkrzak and M. Strongin, Phys. Rev. B 31, 6804 (1985).

C. Moelle and H. J. Fecht, Nanostructured Materials, 3, 93 (1993).

S. Mukerjee, J. M. McBreen, J. J. Reilly, J. R. Johnson, G. Adzic, K. Petrov, M. P. S. Kumar, W. Zhang and S. Sirininasan, J. Electrochem. Soc., 142, 3429 (1995).

S. R. Ovshinsky, M. A. Fetcenko and J. Ross, Science, 260, 176 (1993).

S. R. Ovshinsky, "Thin Film Solid State Battery Employing an Electrically Insulating Ion Conducting Electrolyte Material", U.S. Patent No. 5,512,387 (April 30, 1996).

M.A. Pick, J. W. Davenport, M. Strongin and G.J. Dienes, Phys. Rev. Lett. 43, 286 (1979).

M. Pourbaix, "Atlas of Electrochemical Equilbria in Aqueous Solutions: Nat"1 Assoc. of Corrosion Engineers Int', Houston, TX, (1974), p 248.

T. R. Thurston, N. M. Jisrawi, S. Mukerjee, X. Q. Yang, J. McBreen, M.L. Daroux and X. K. King, Appl. Phys. Lett., 69, 194 (1996).

S. Wakao, H. Sawa, H. Nakano, S. Chubachi, and M. Abe, J. Less Common Met., 104, 365 (1984).

H. Zabel and H. Peisel, Phys. Rev. Lett., 42, 511 (1979) 


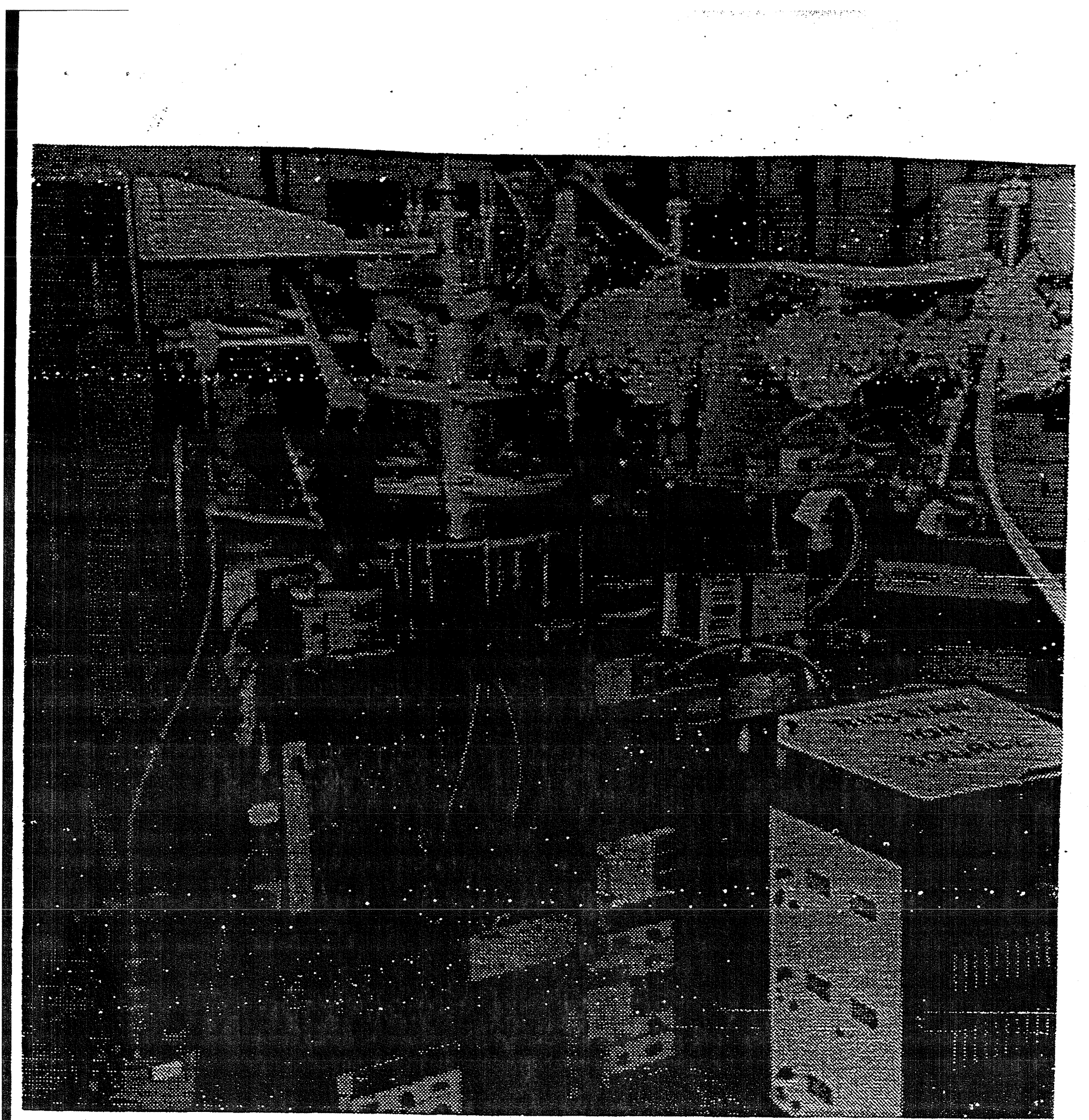

FIGURE I 


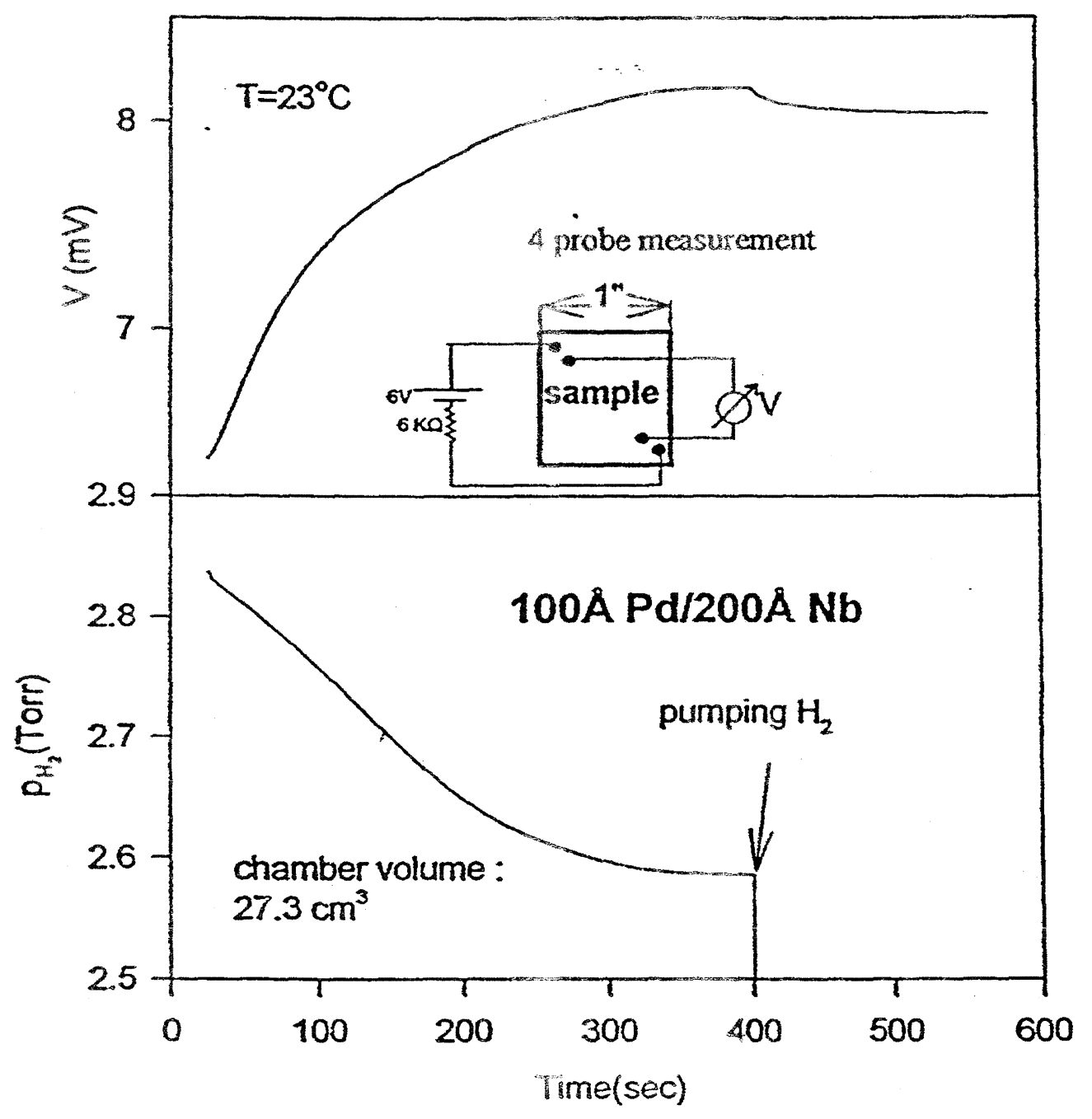

FIGURE 2 


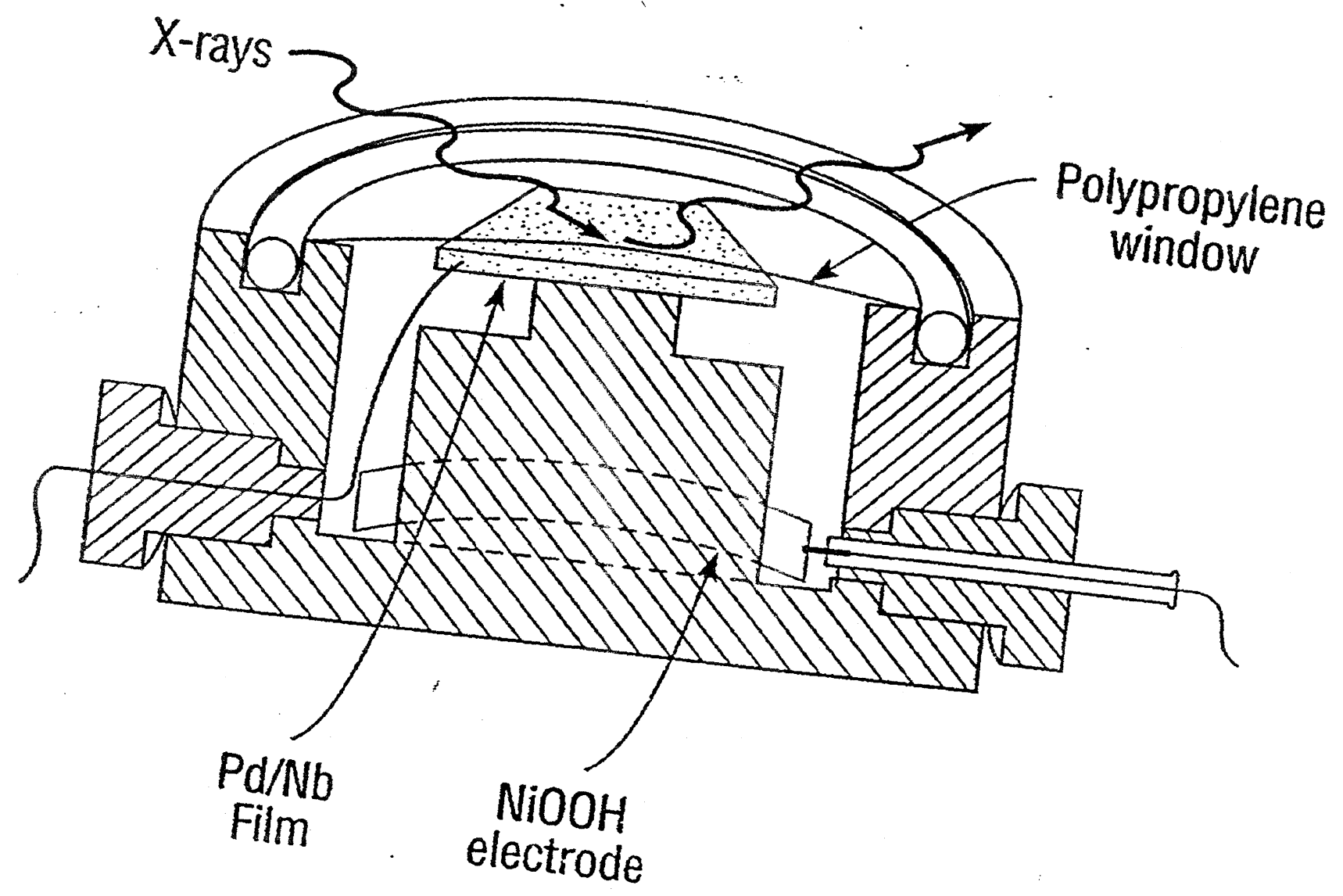

FIGURE 3 


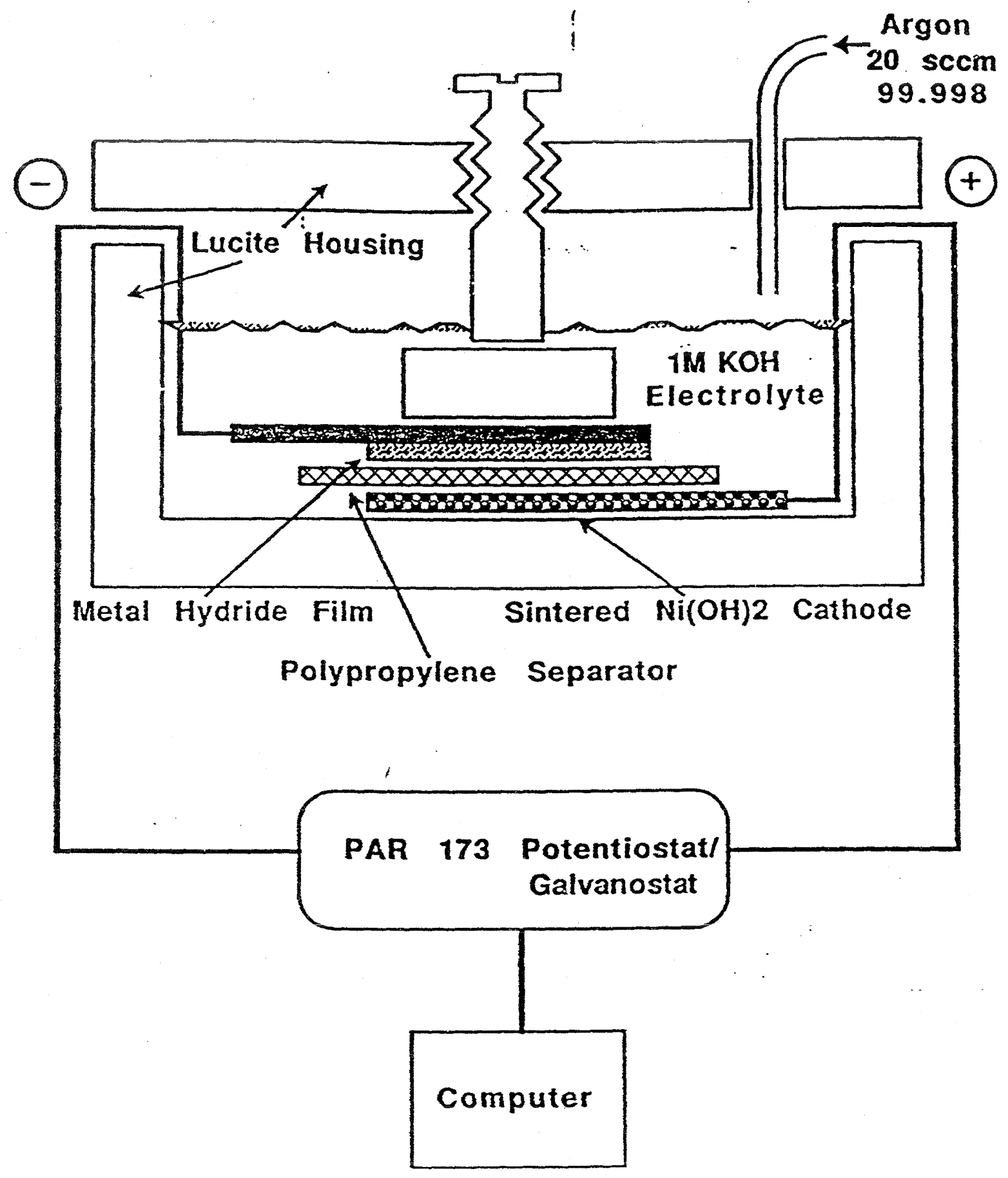

FIGURE 4 


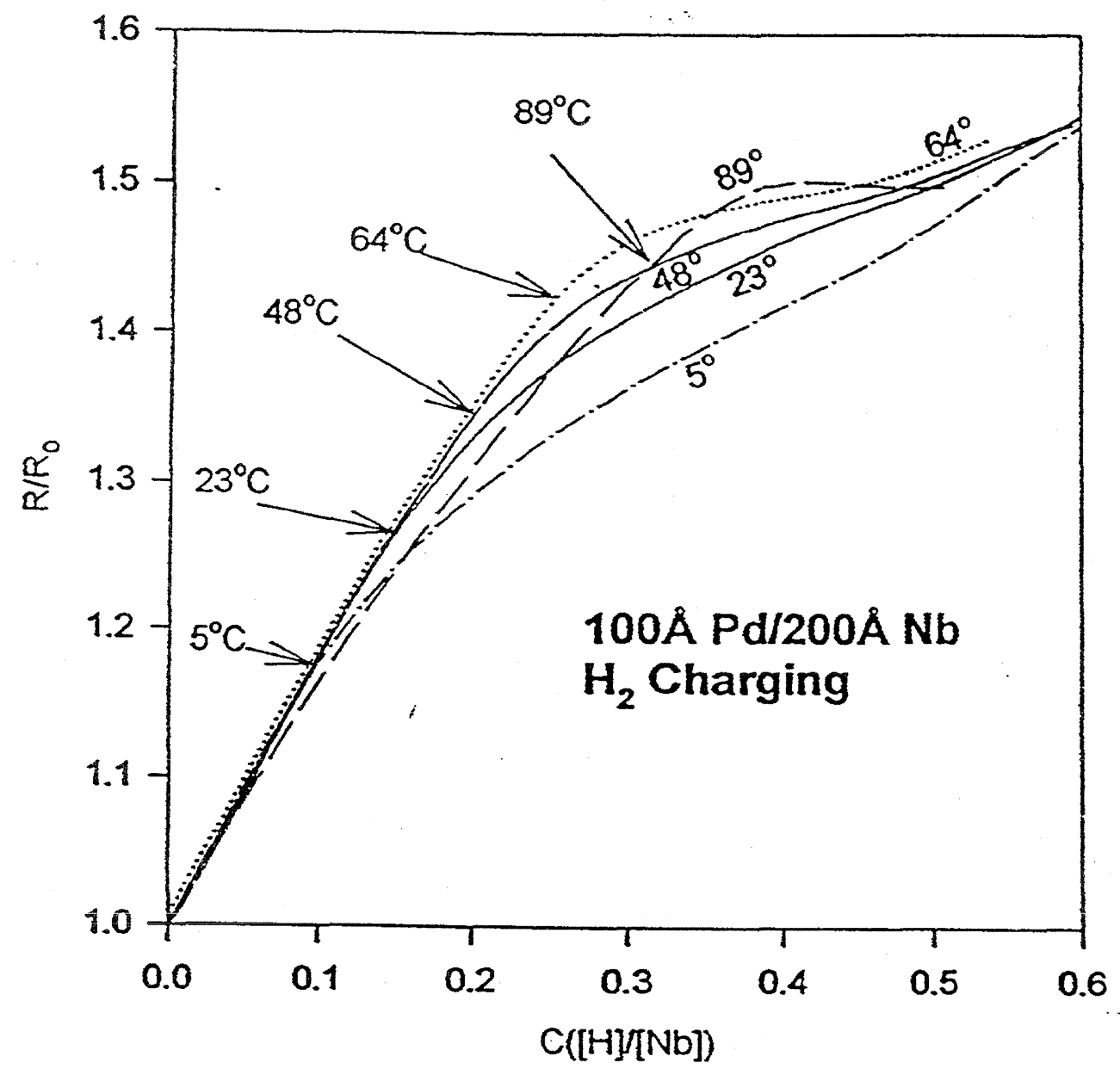

FIGURE 5 


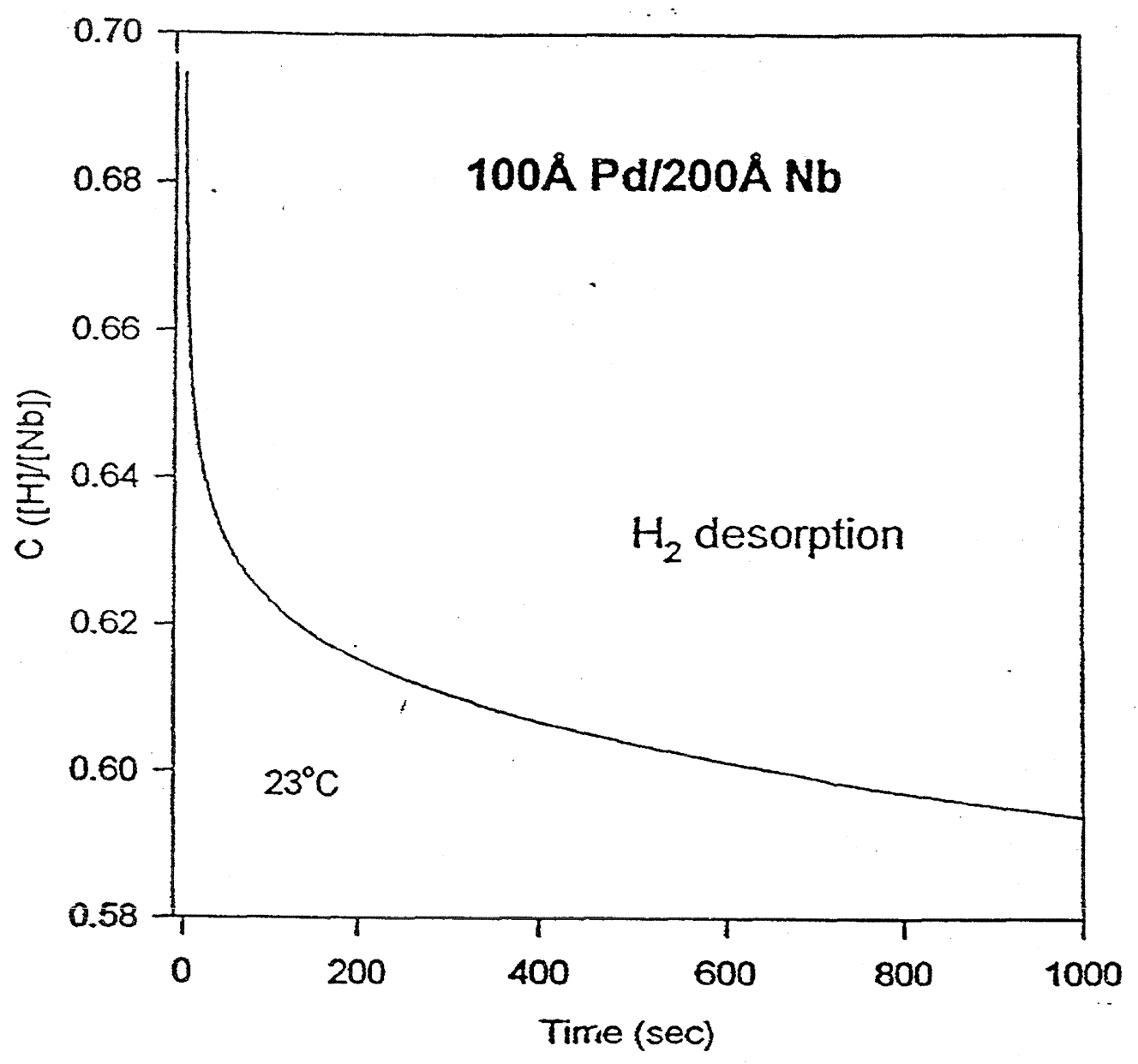

FIGURE 6 


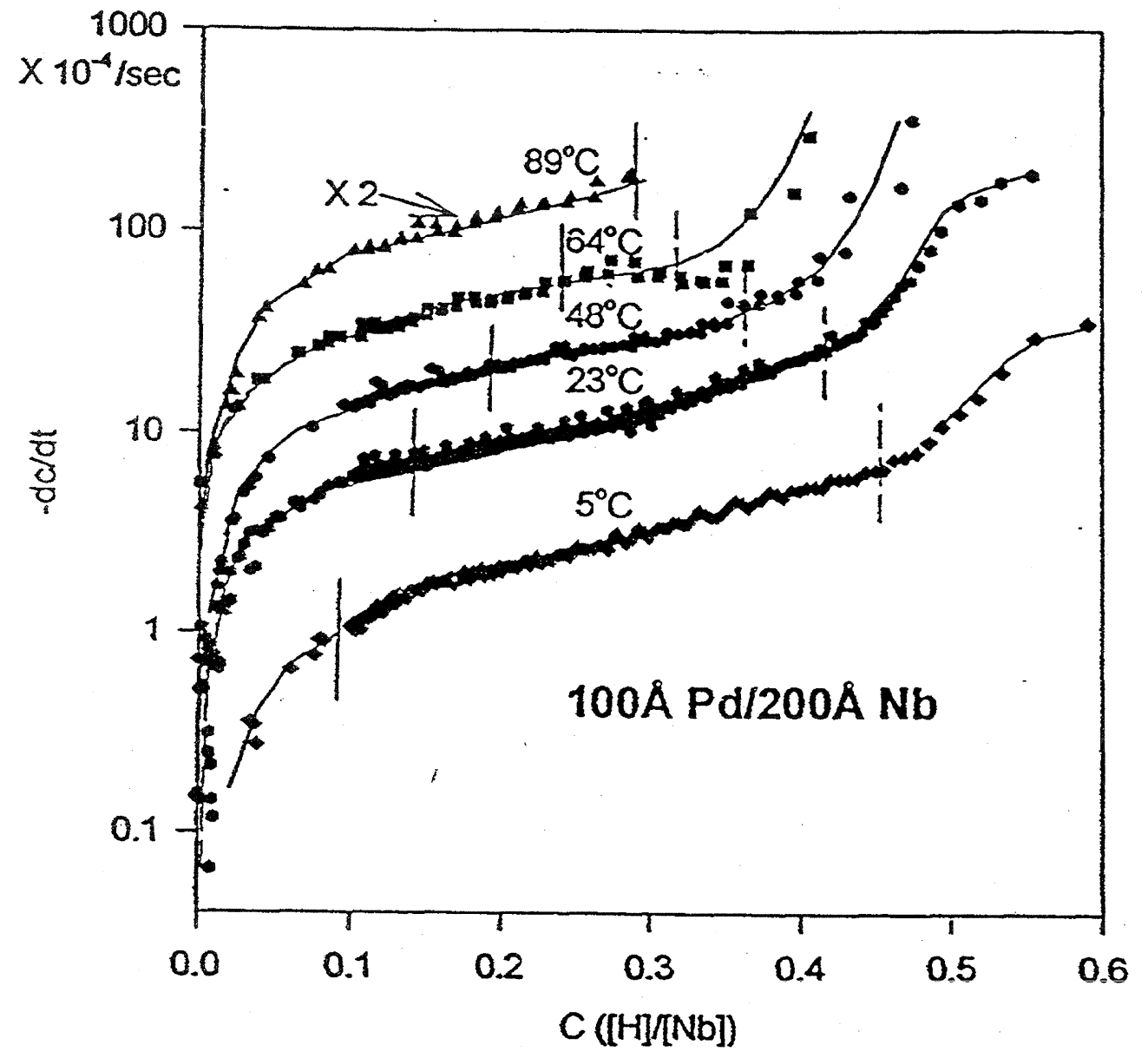

FIGURE 7 


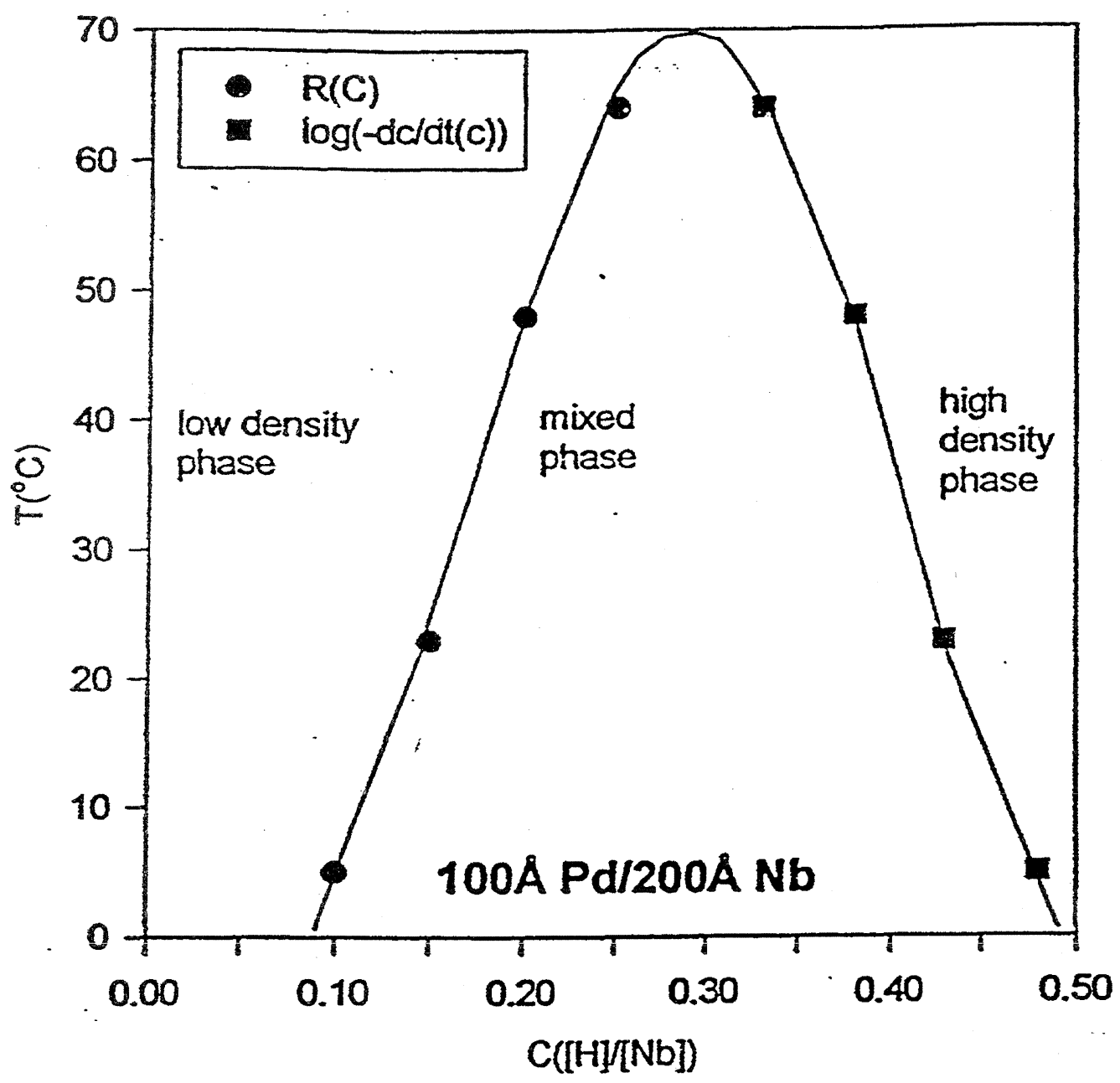

FIGURE 8 


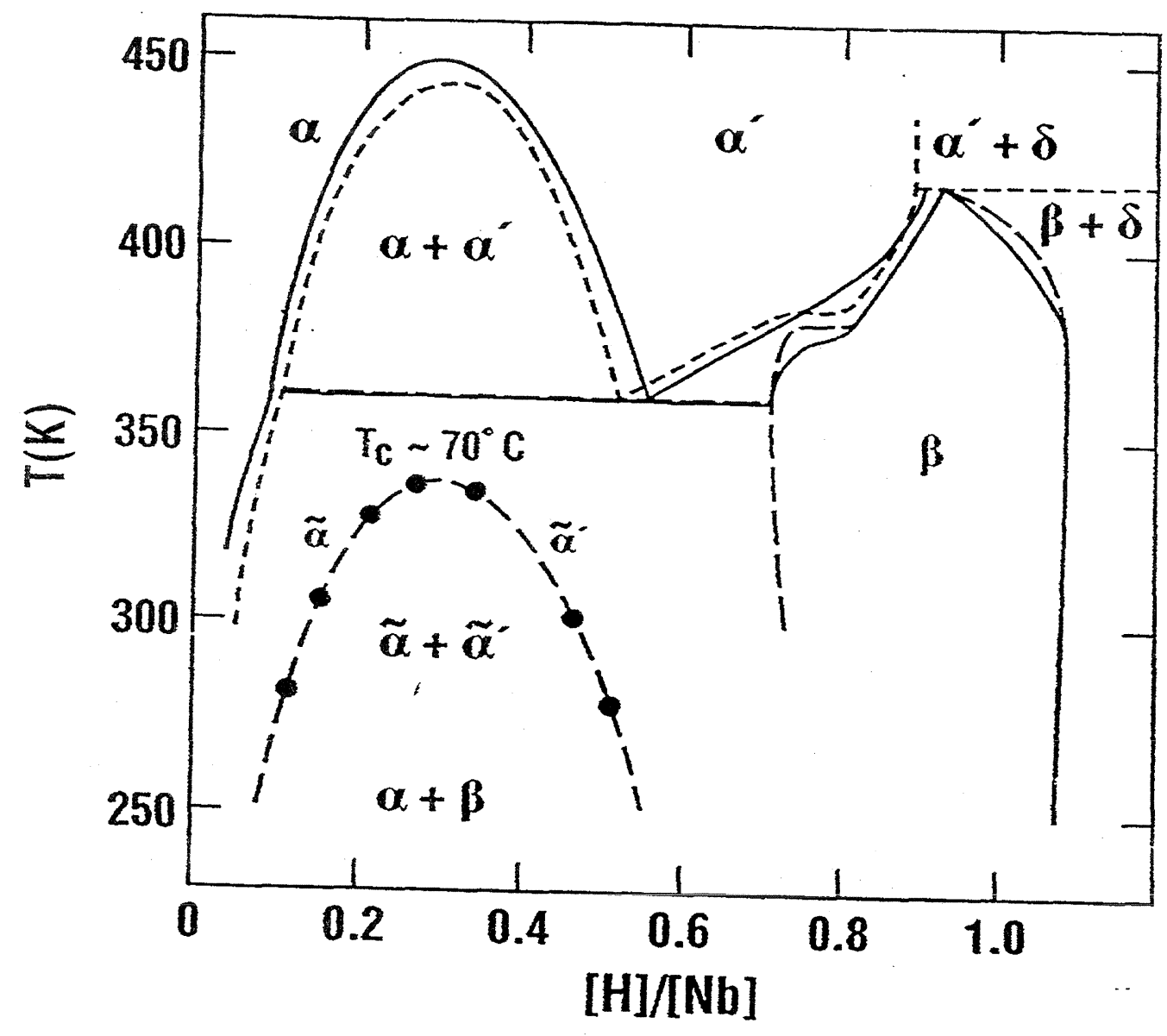

FIGURE 9 


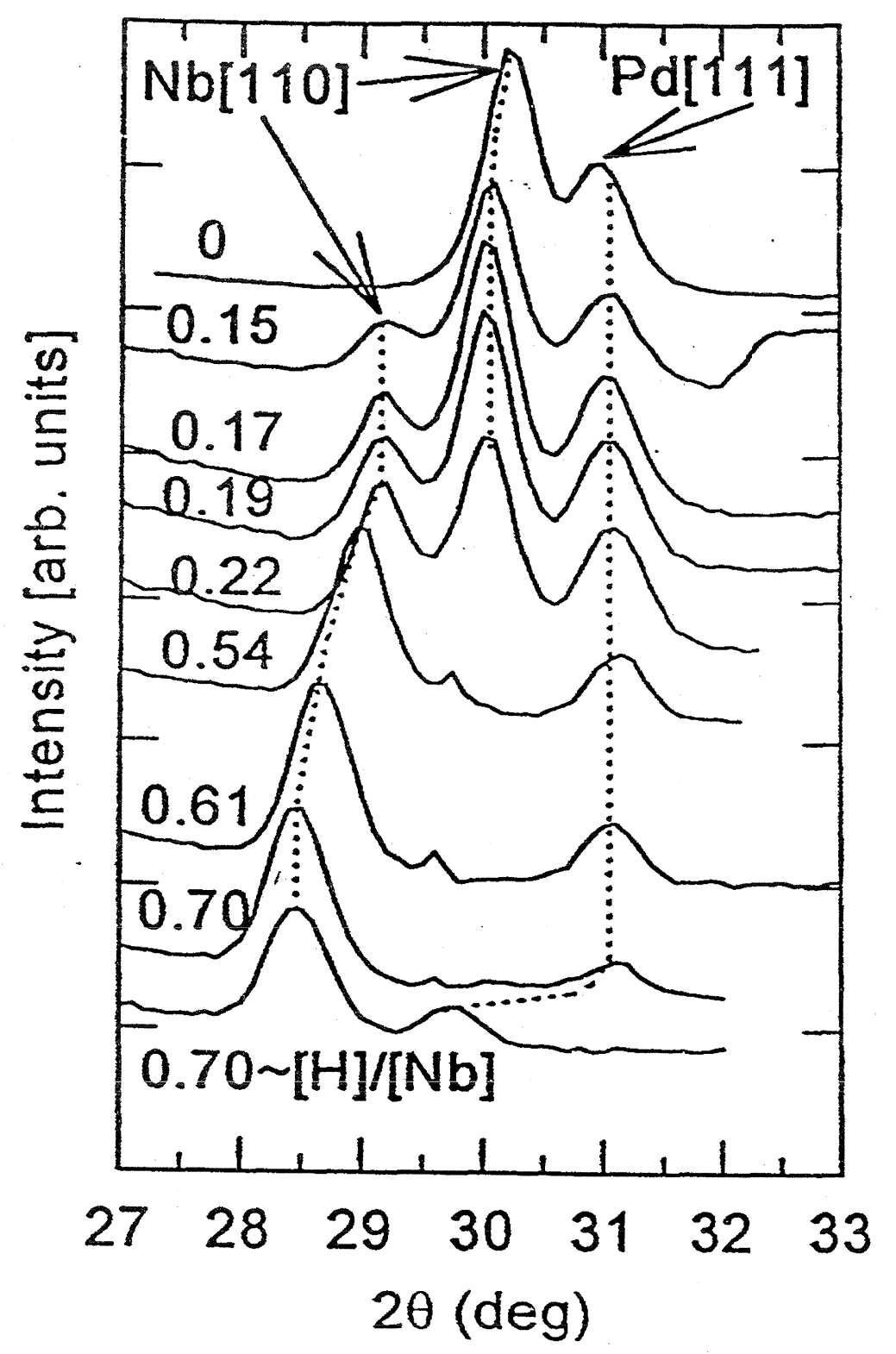

FIGURE 10 

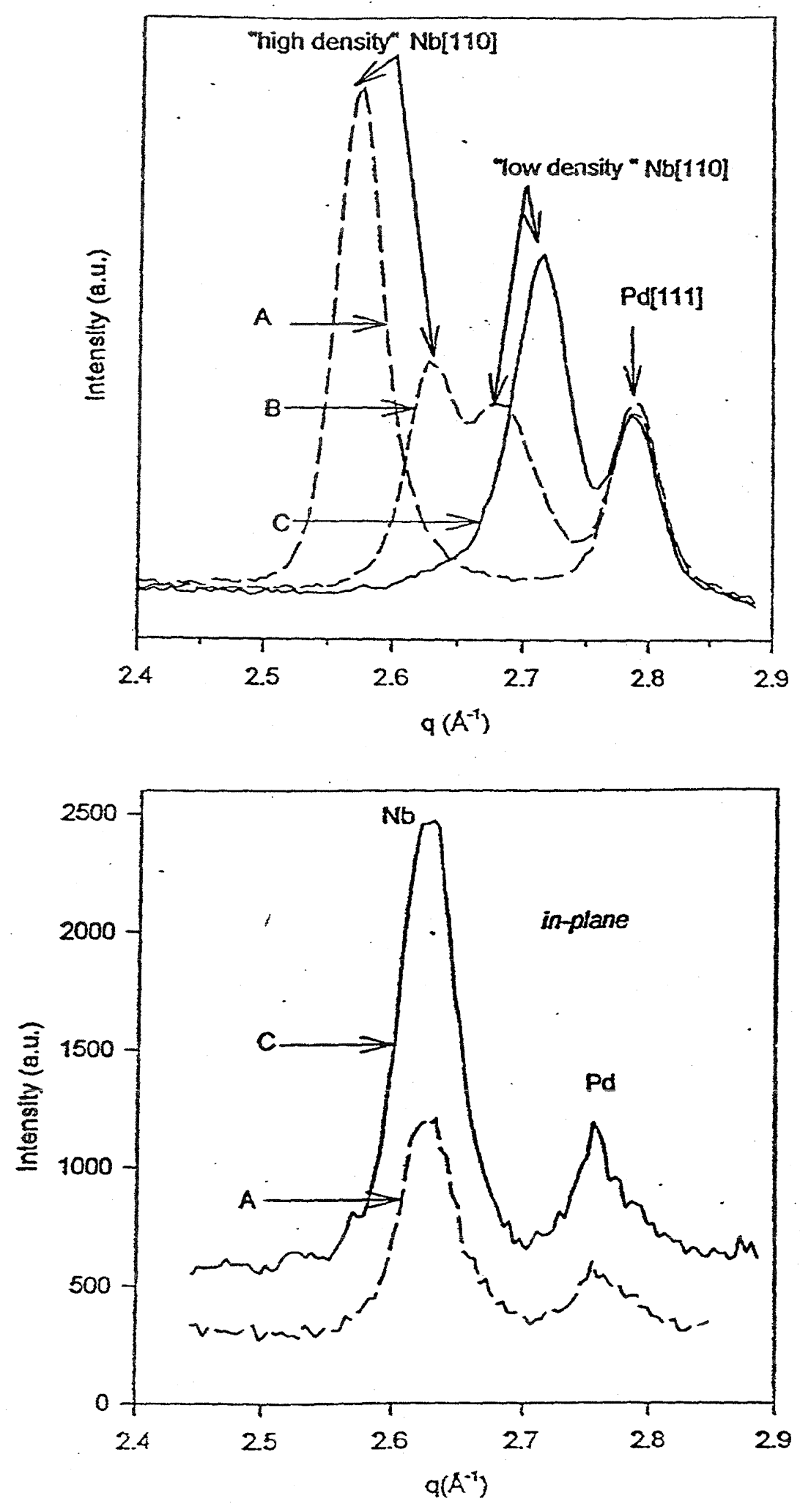

FIGURE II 


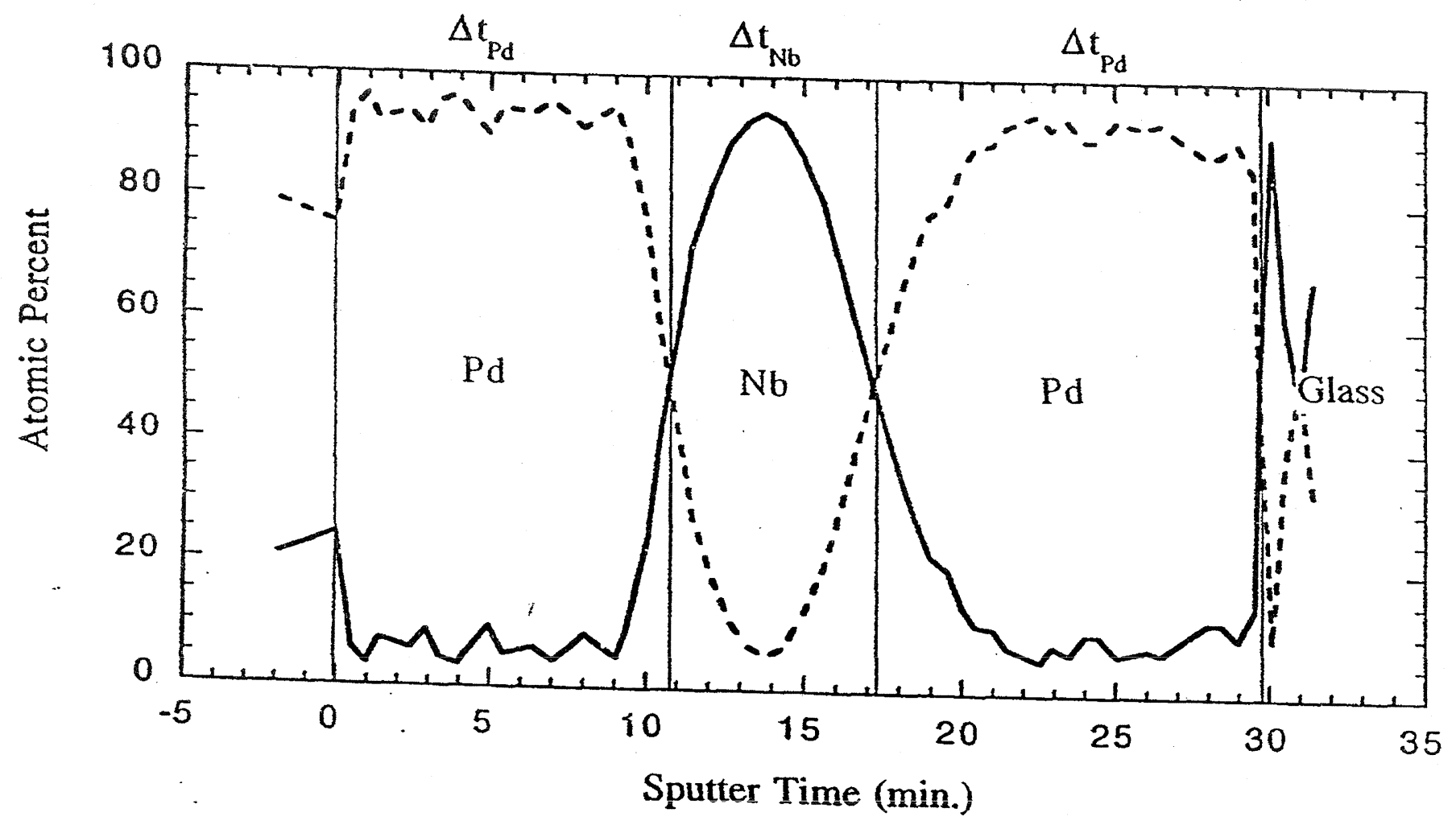

FIGURE 12 


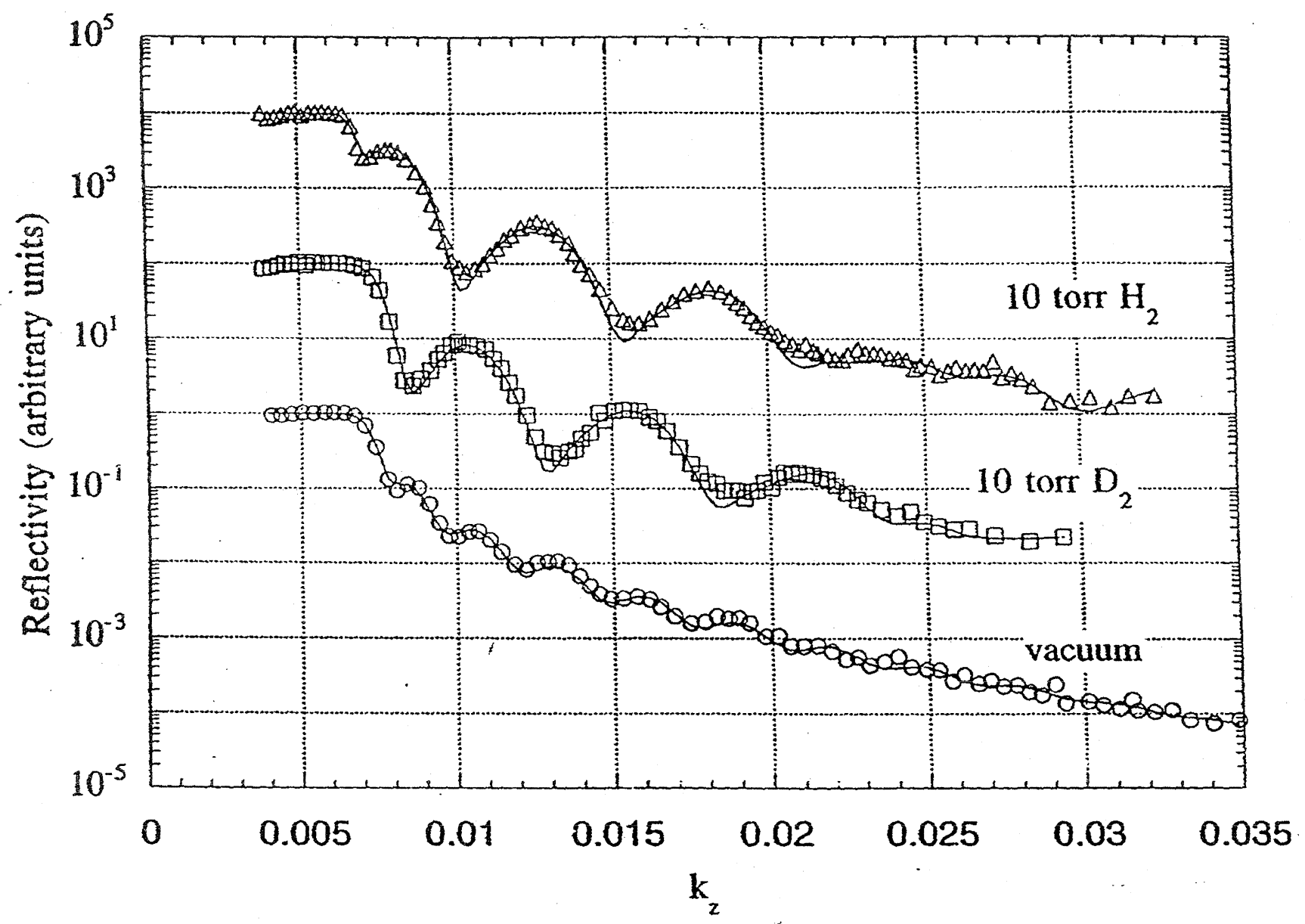

FIGURE 13 


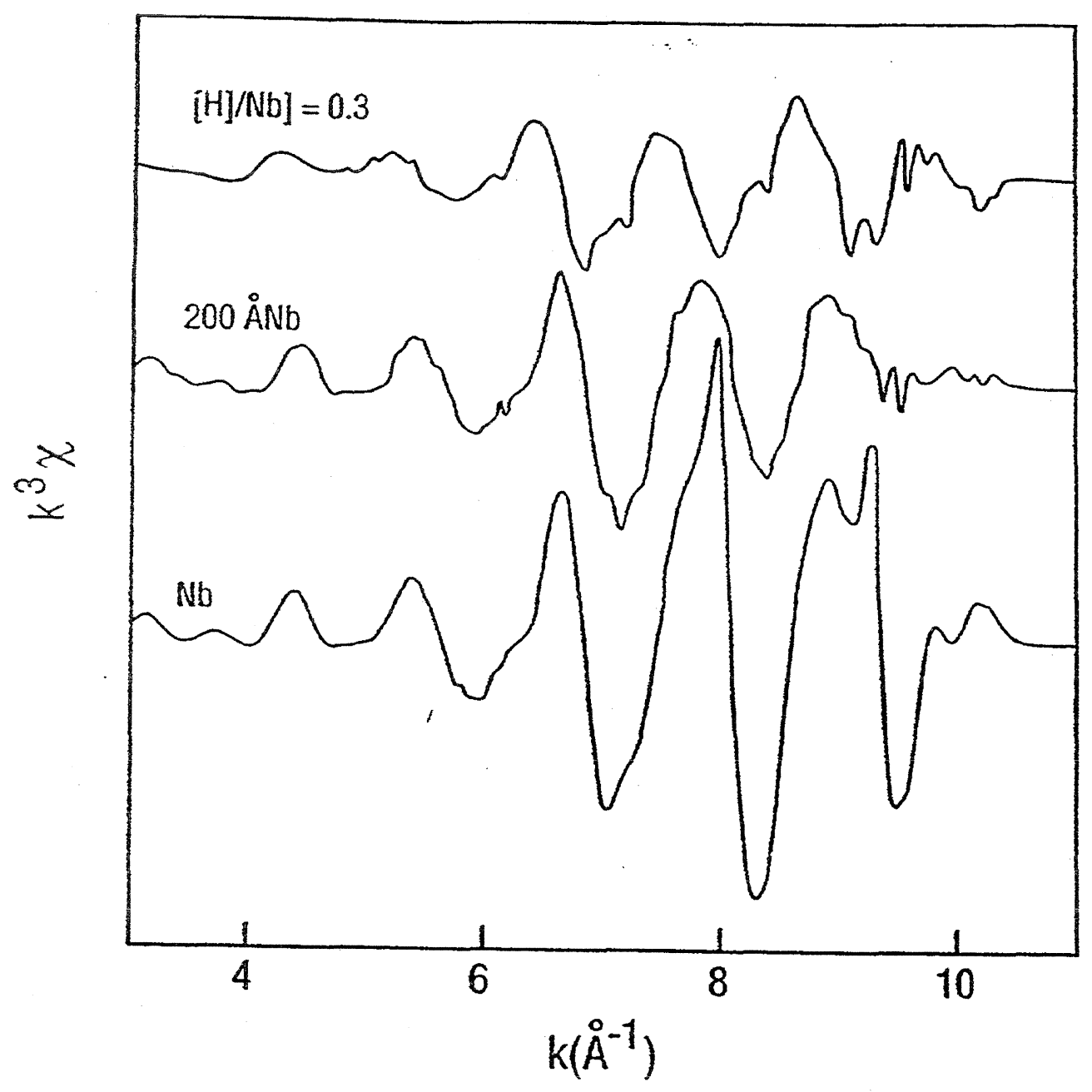

FIGURE 14 


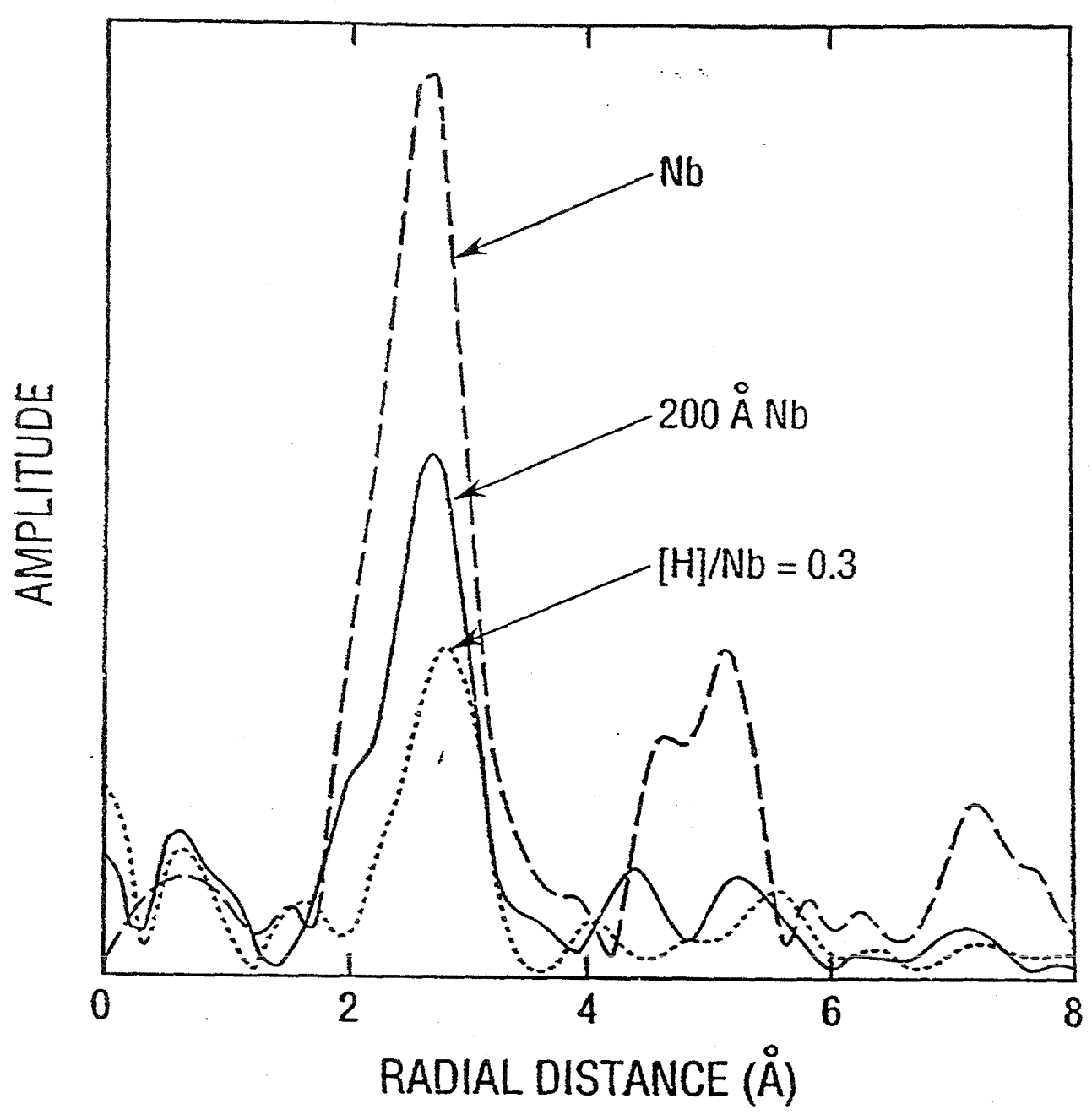

FIGURE 15 


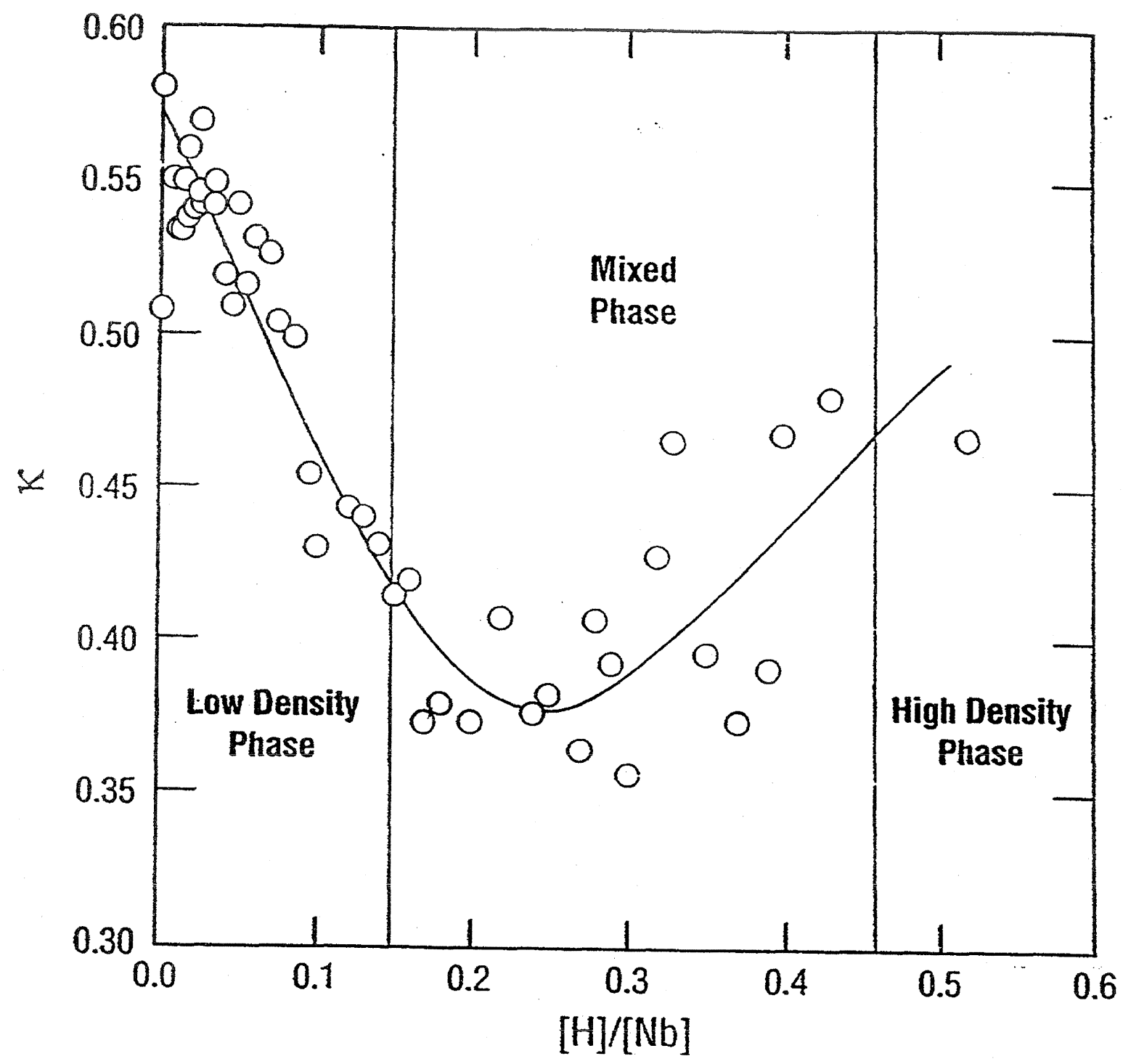

FIGURE 16 


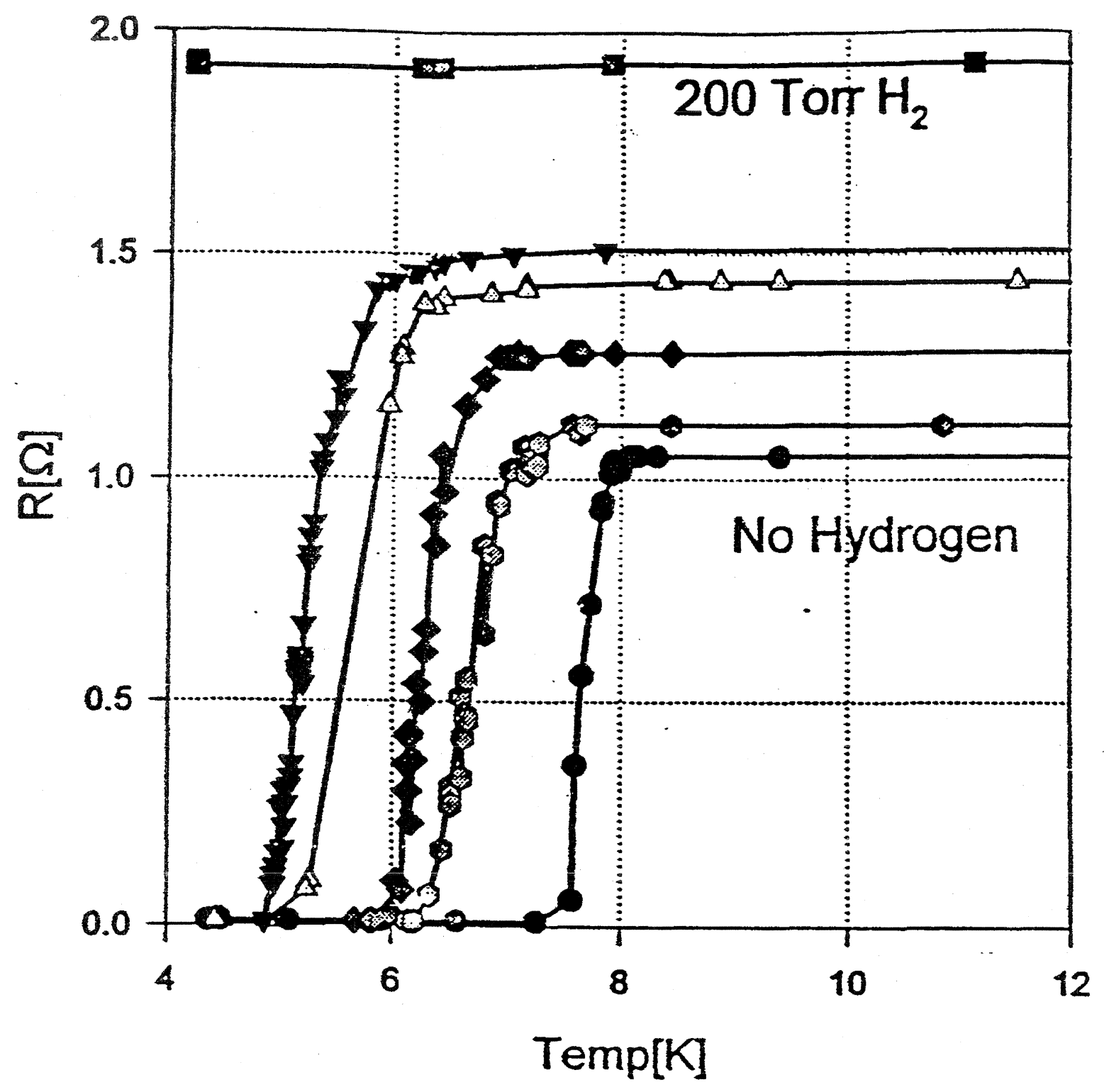

FIGURE 17 


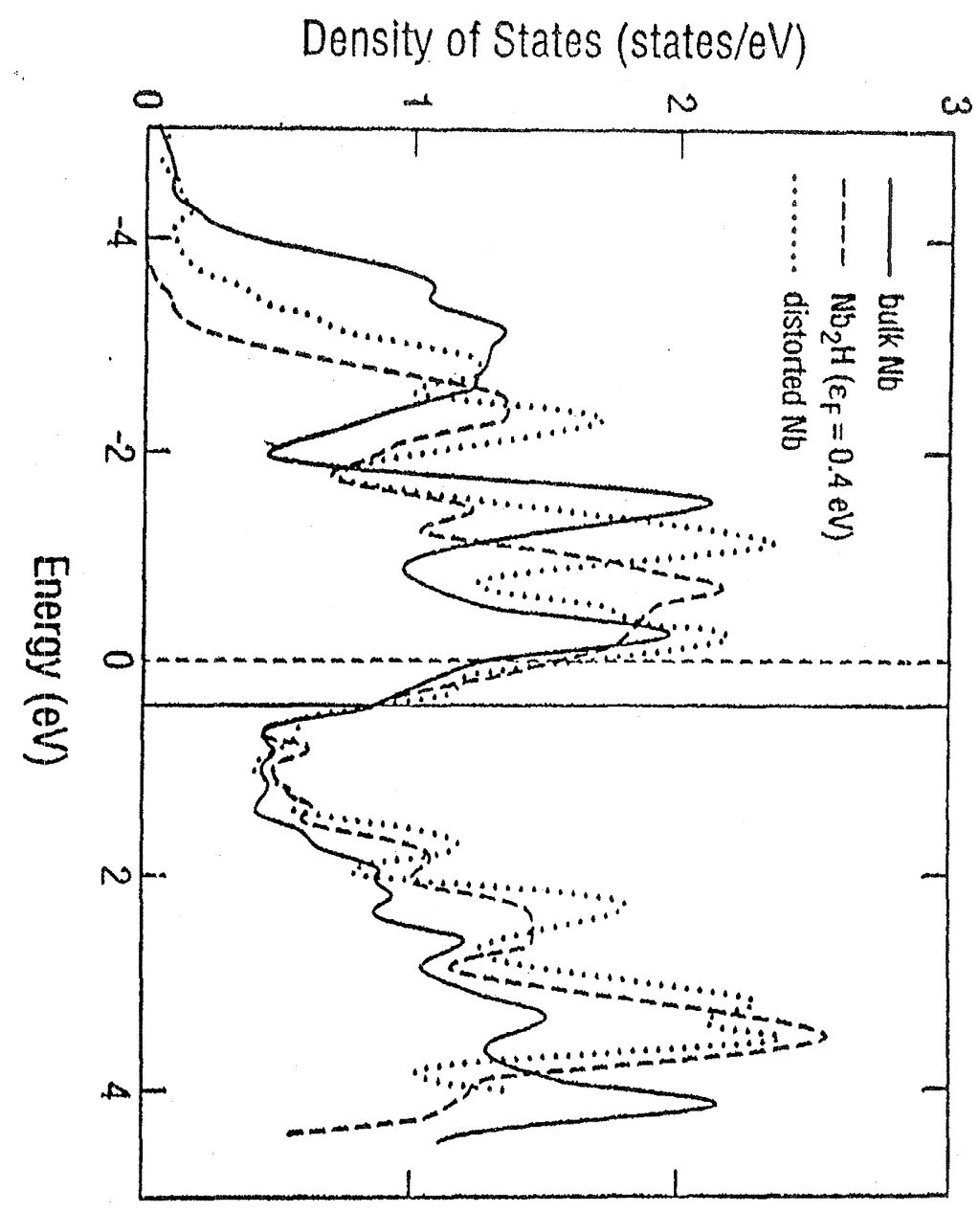




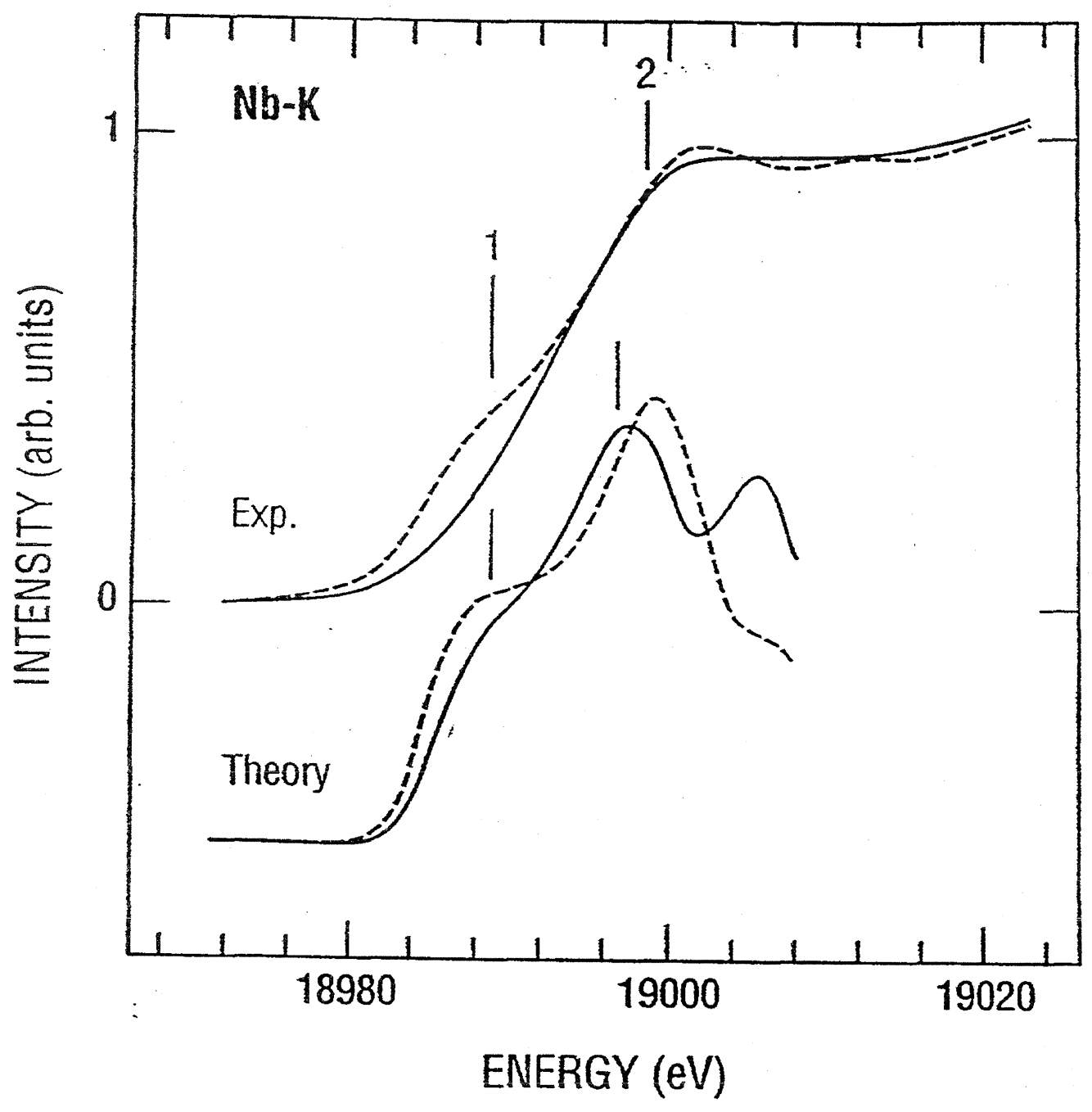

FIGURE 19 


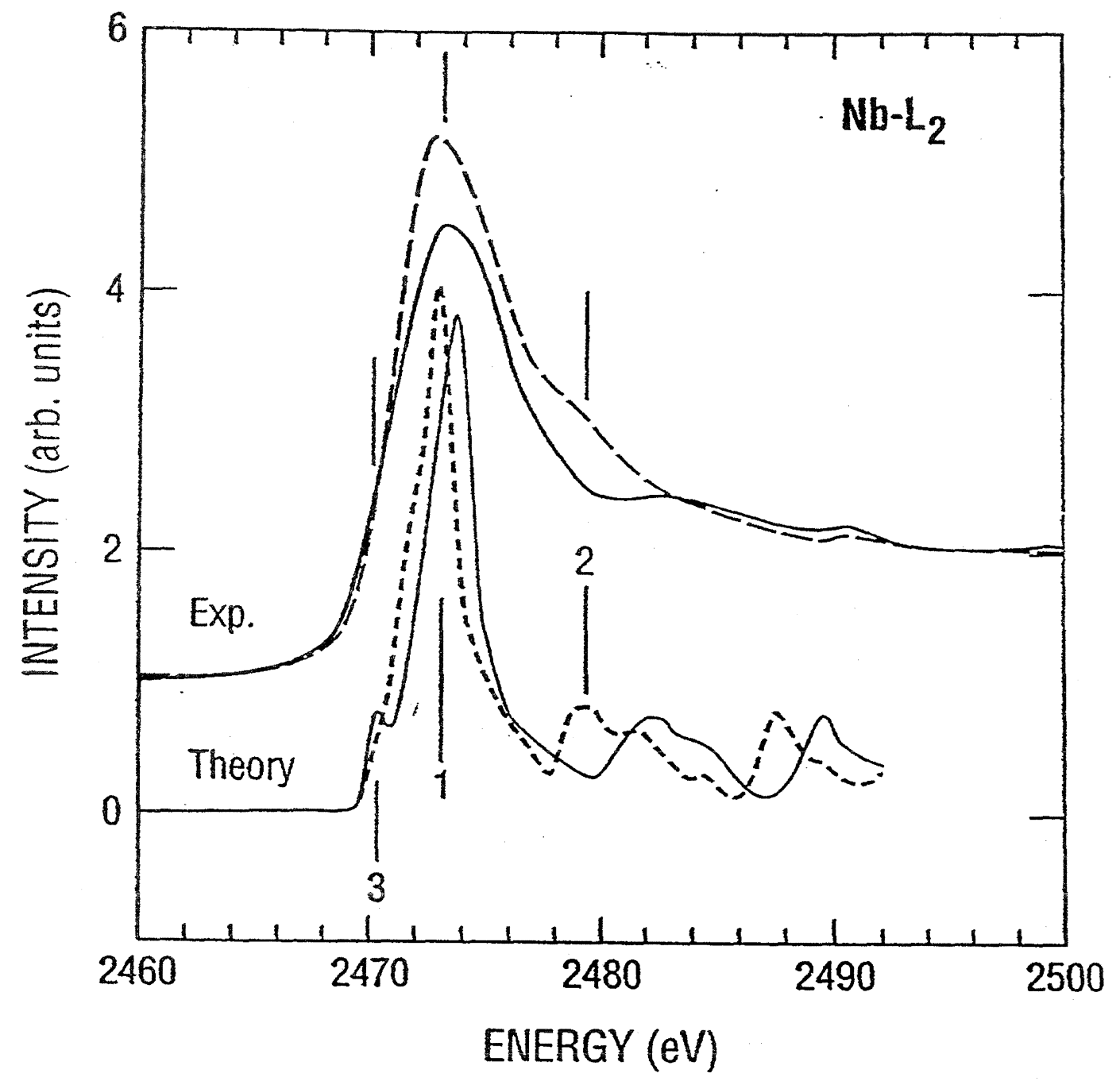

FIGURE 20 


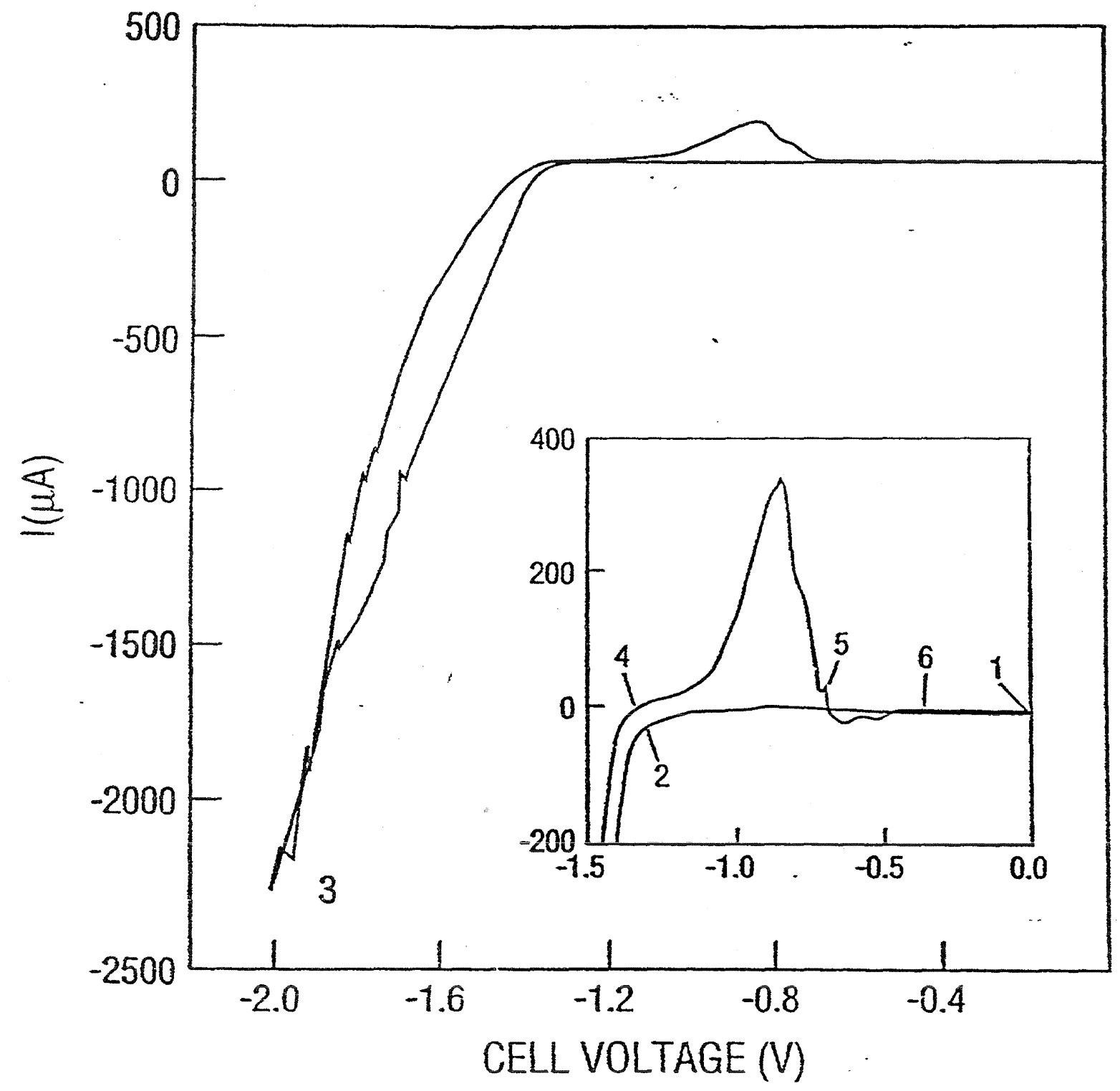

FIGURE 21 


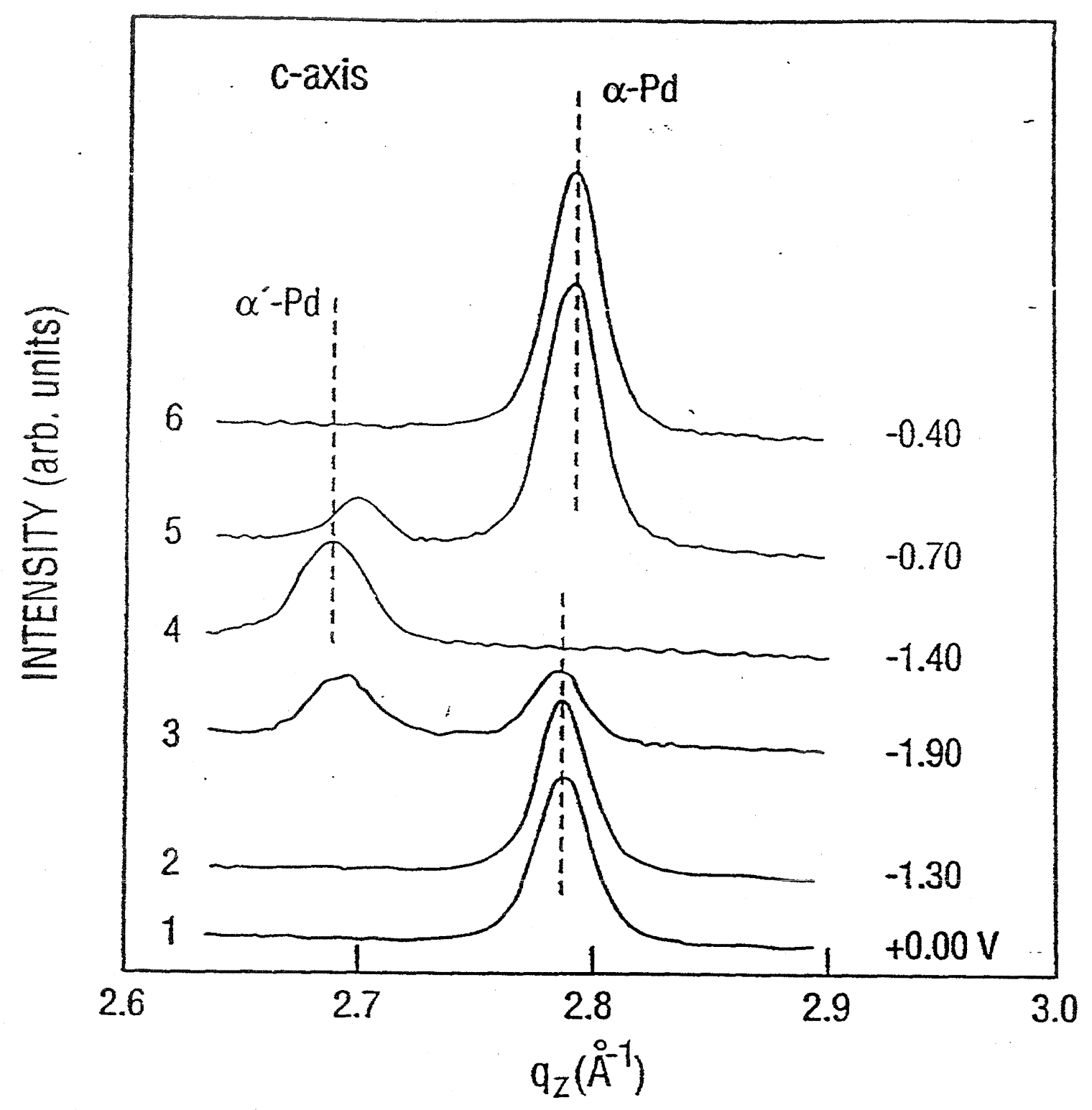

FIGURE 22 


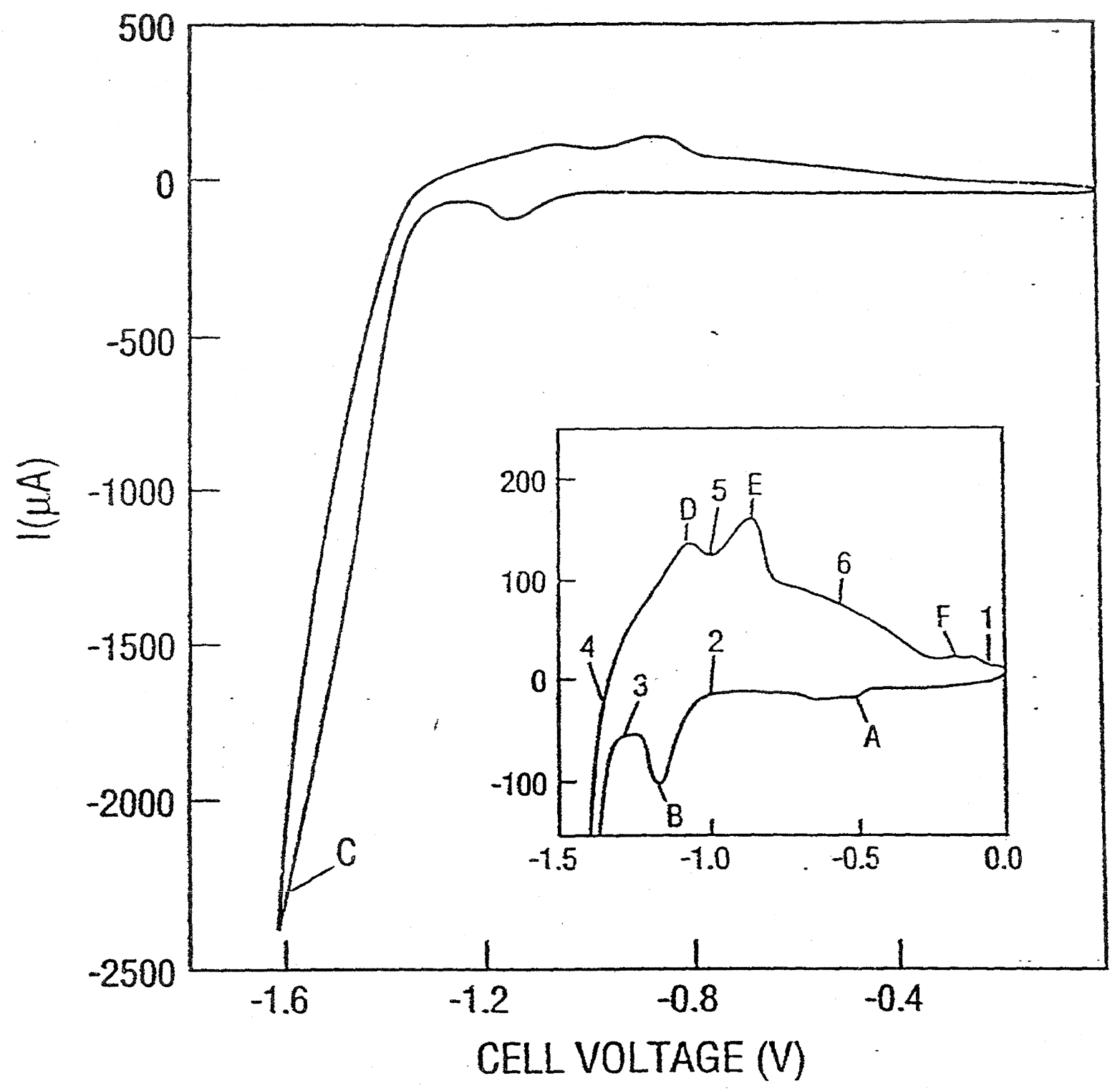

FIGURE 23 

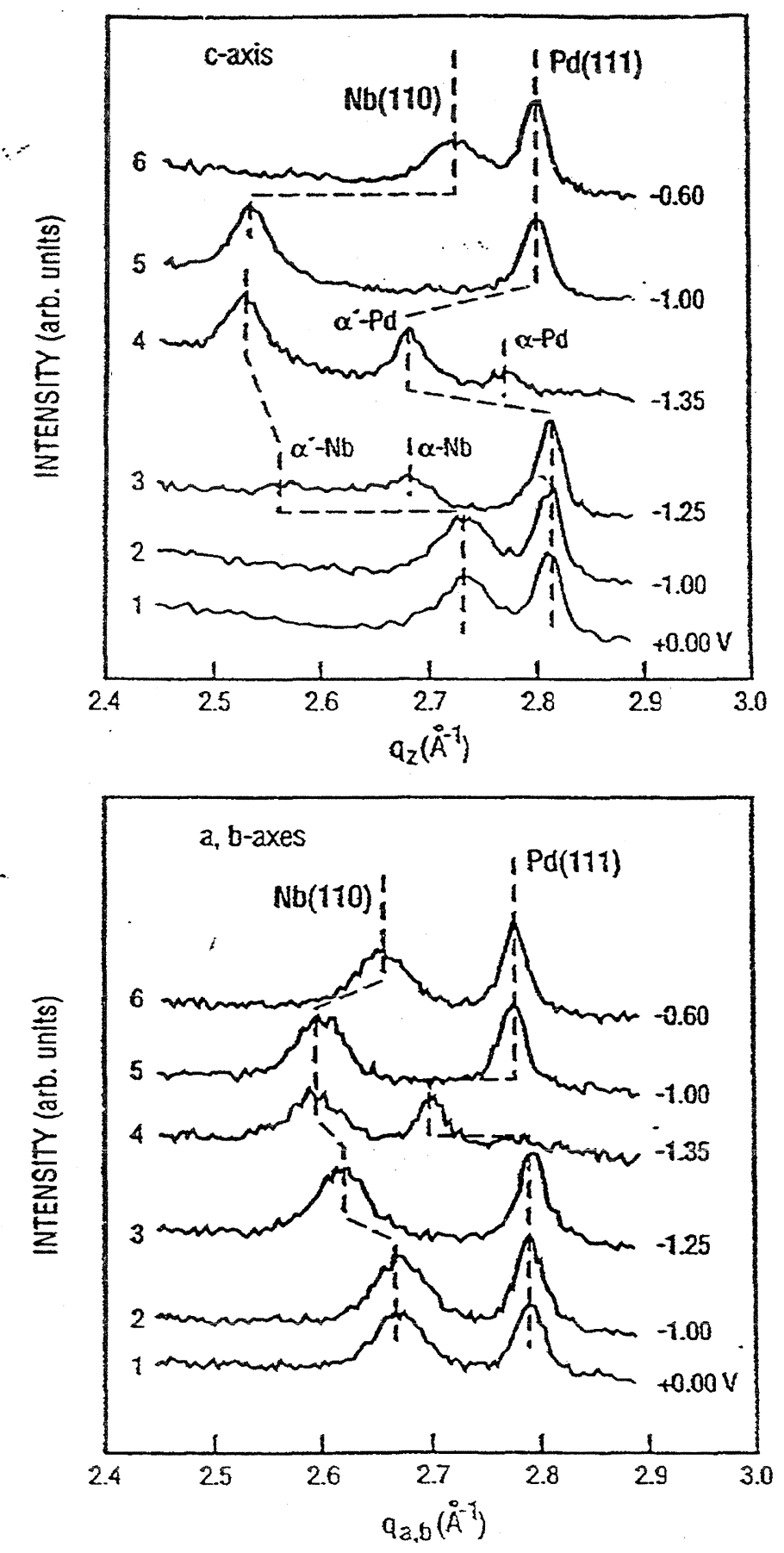

FIGURE 24 


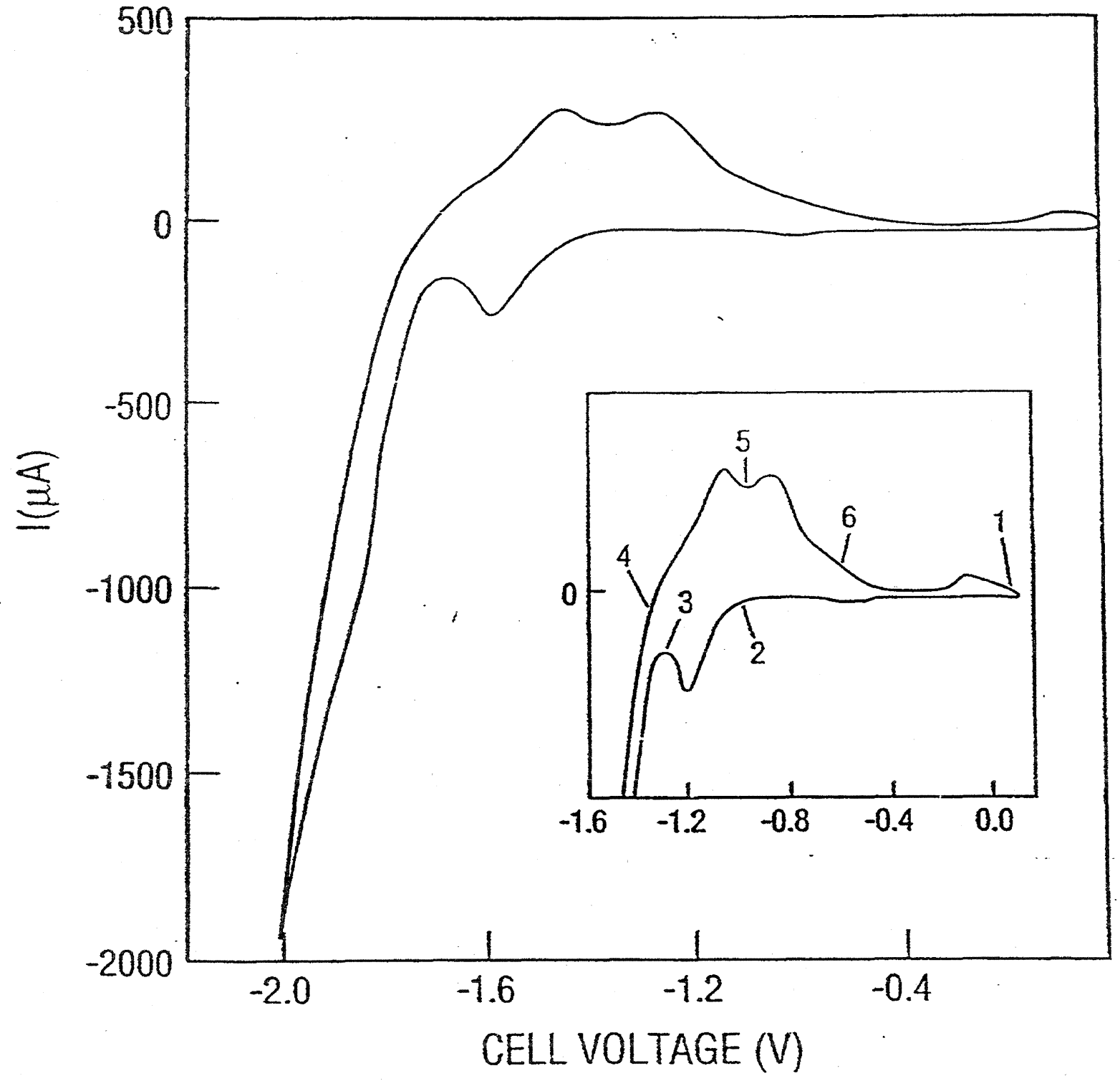

FIGURE 25 


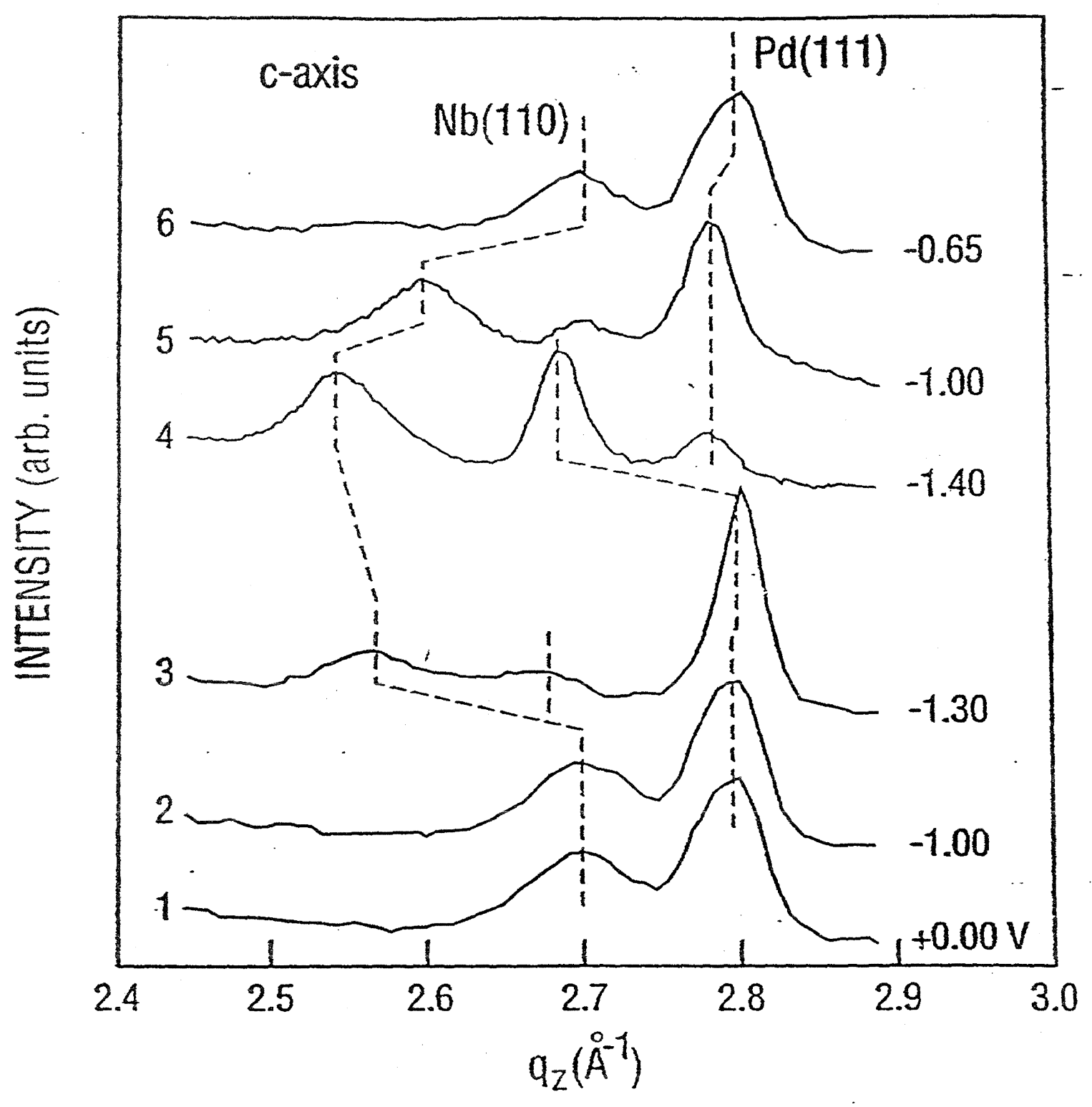

FIGURE 26 


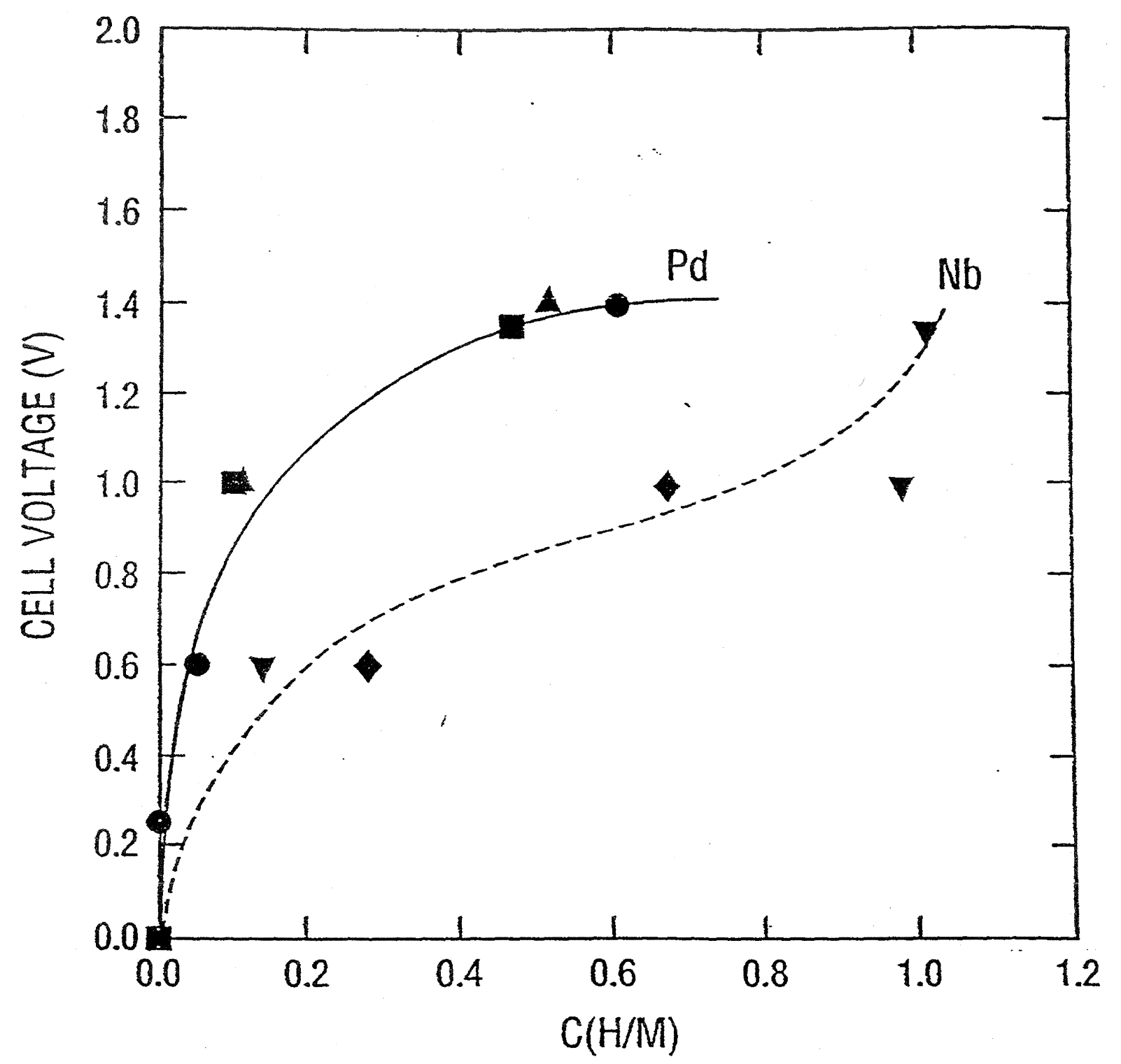

FIGURE 27 

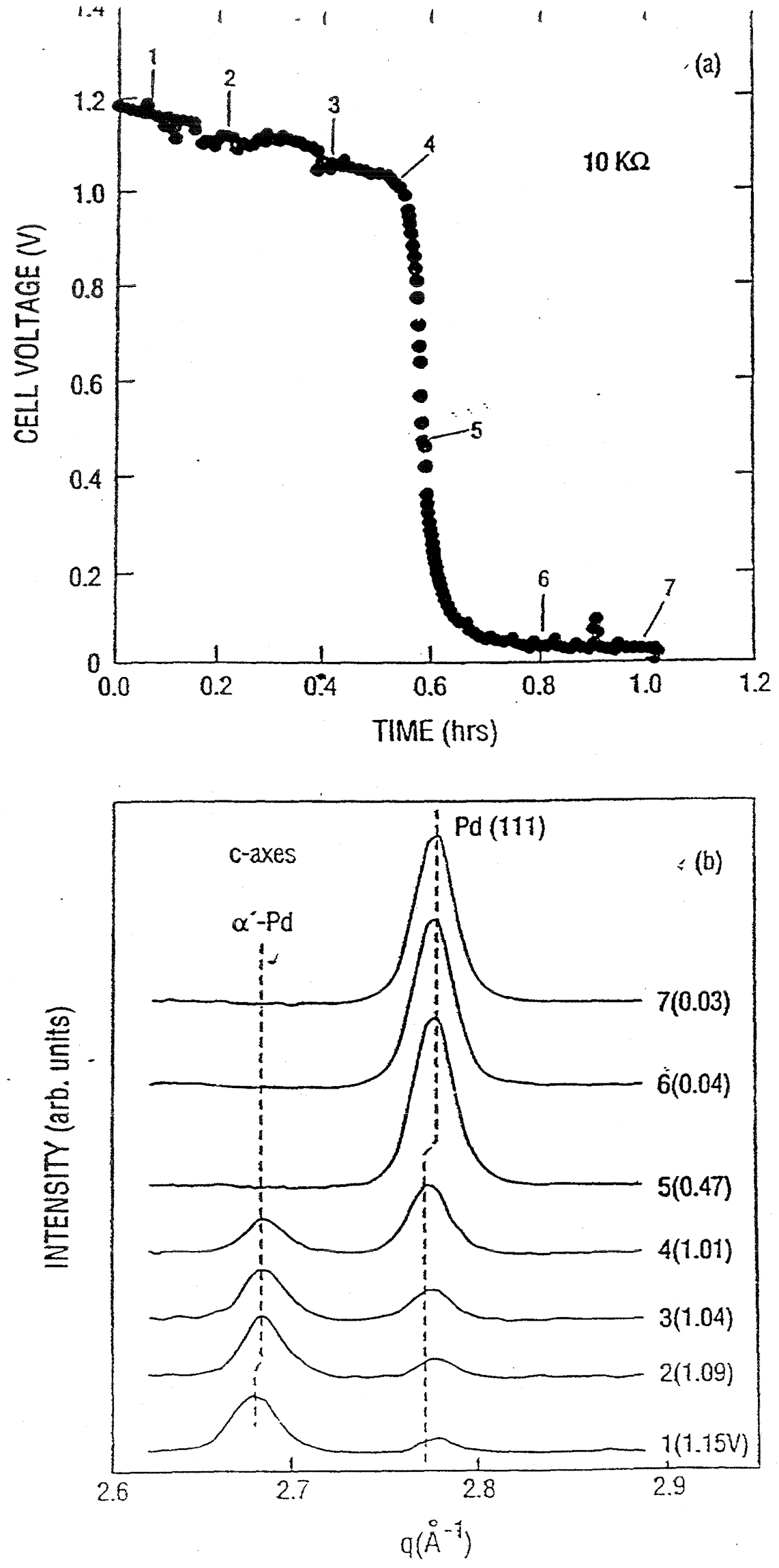

FIGURE 28 


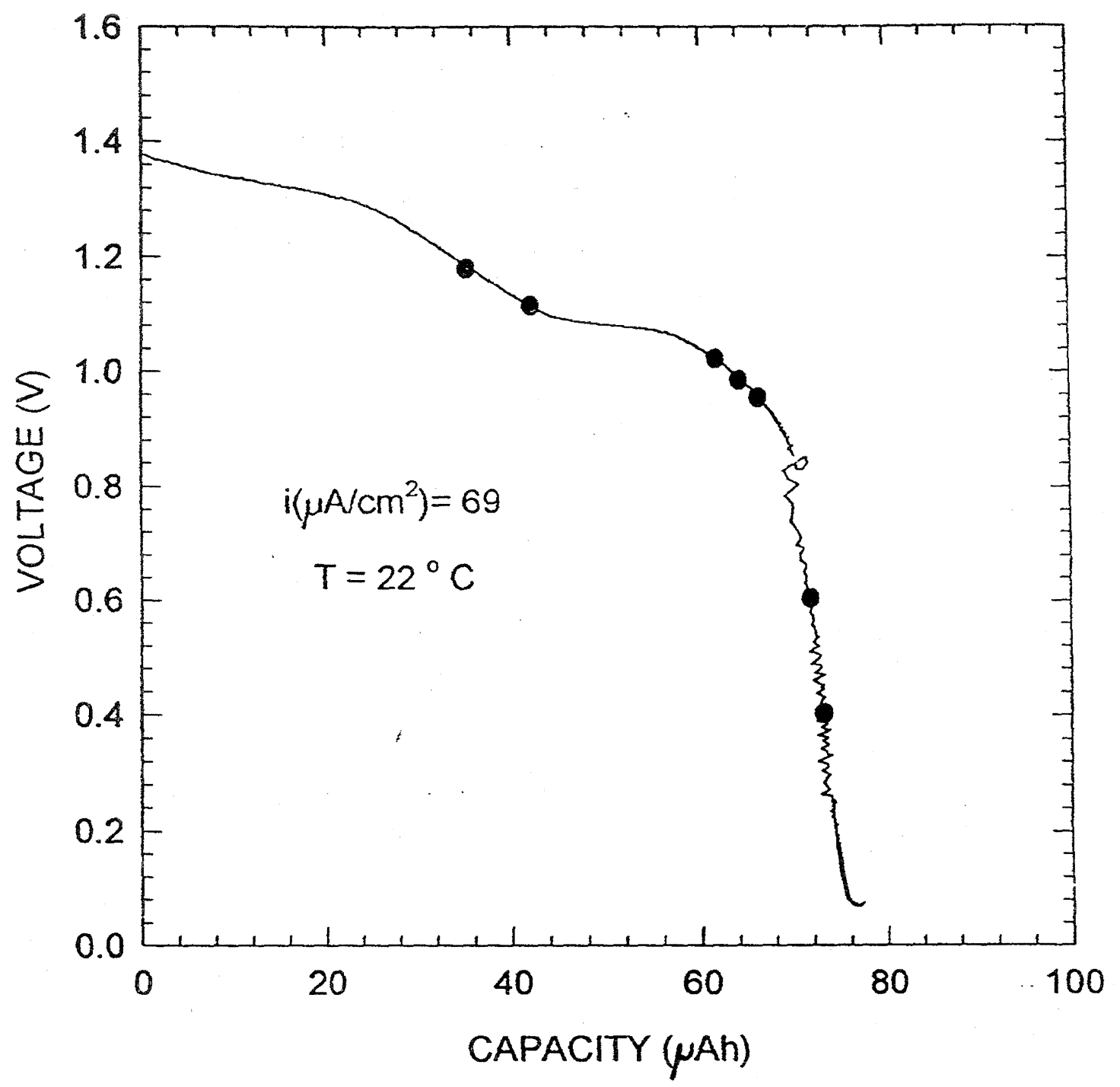

FIGURE 29 

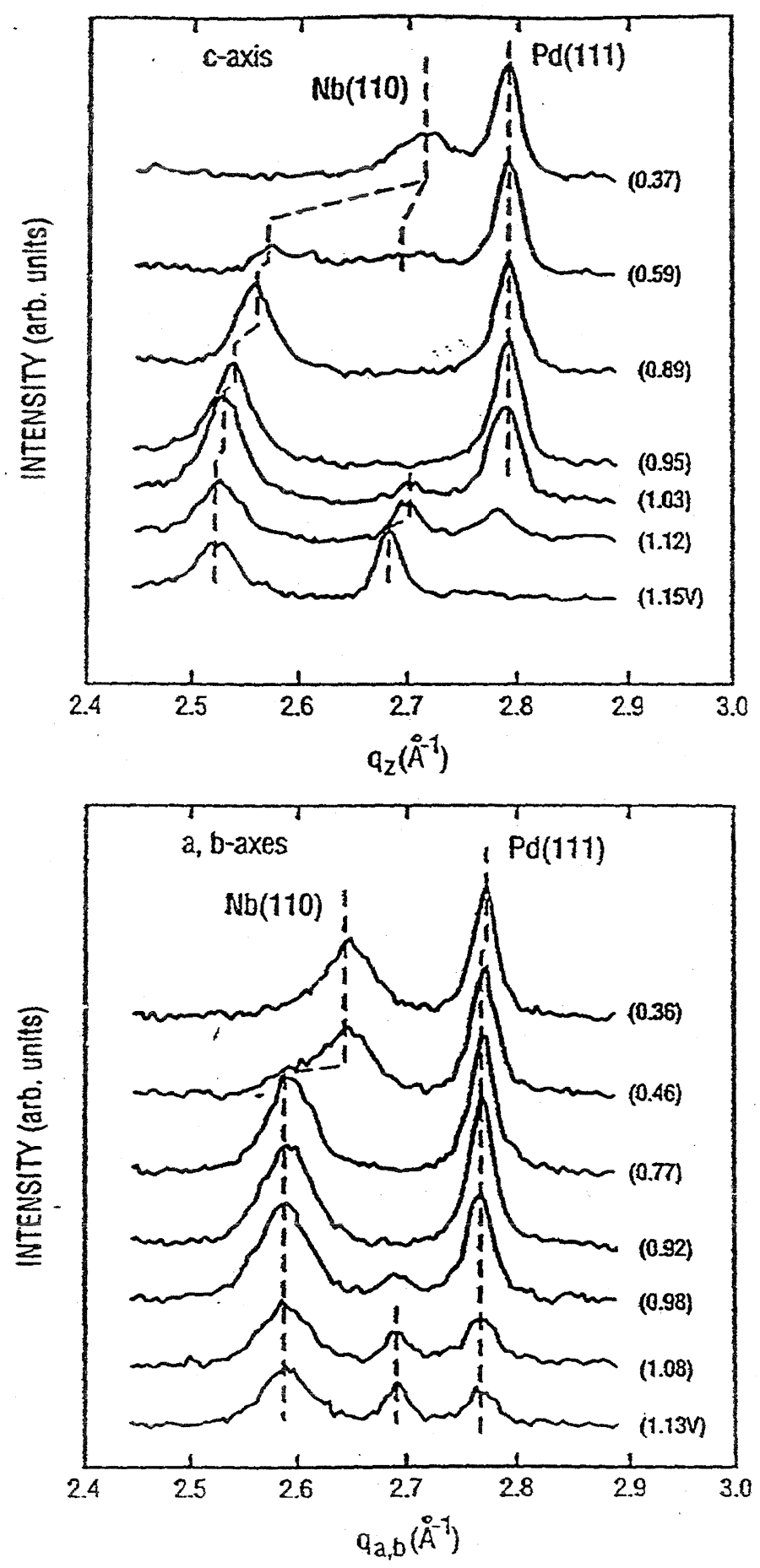

FIGURE 30 


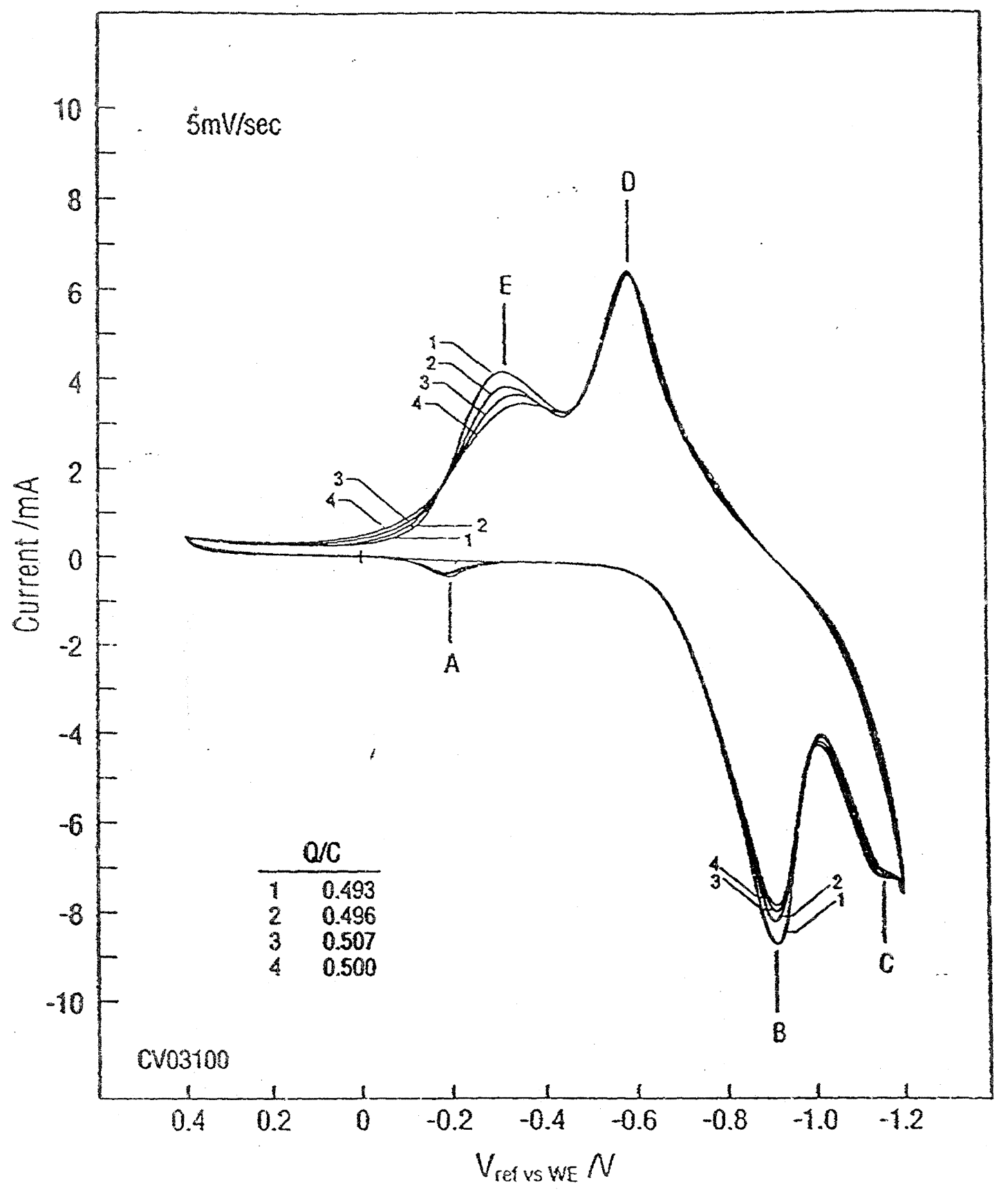

GIGURE 31 



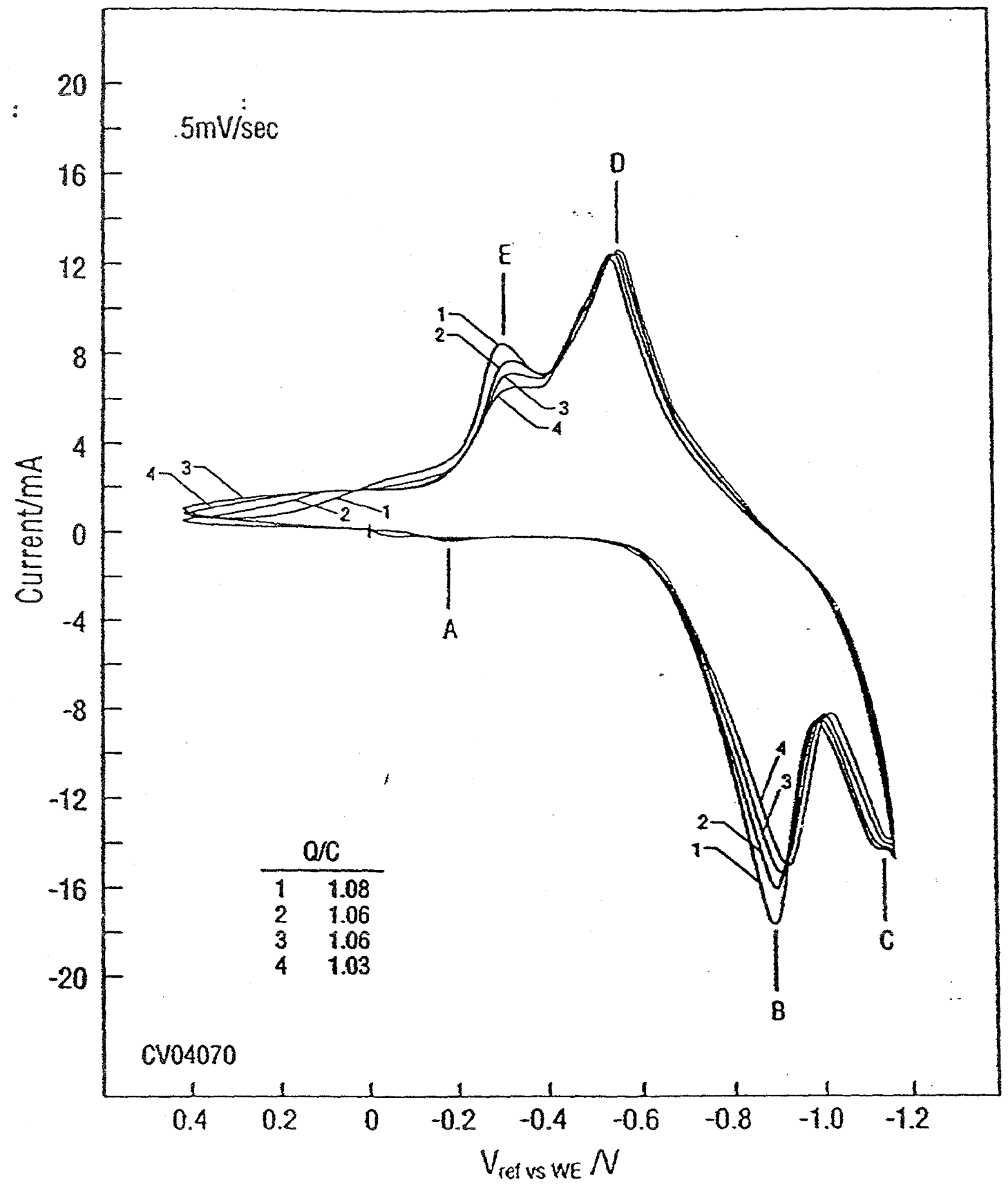

FIGURE 32 


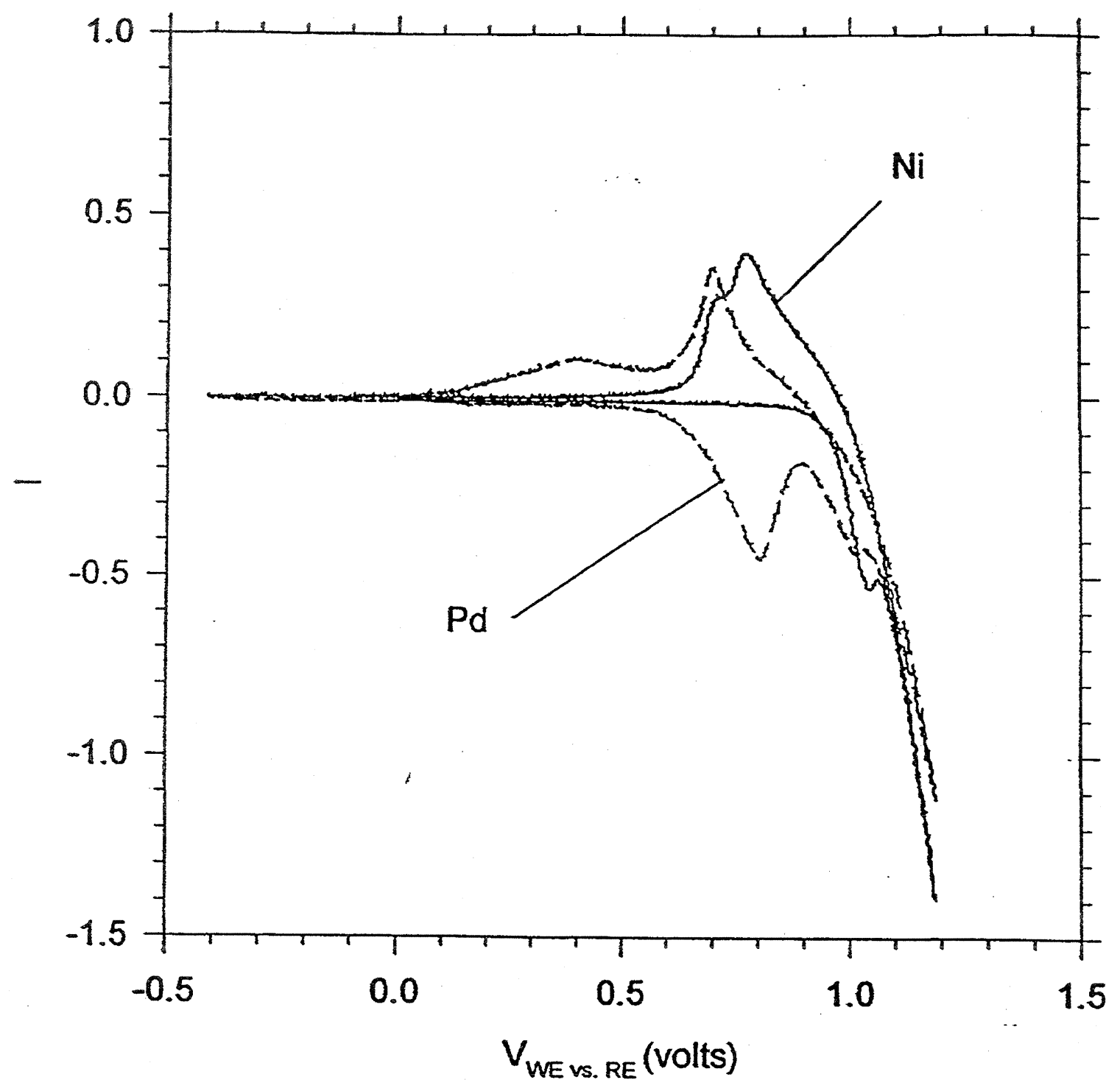

FIGURE 33 


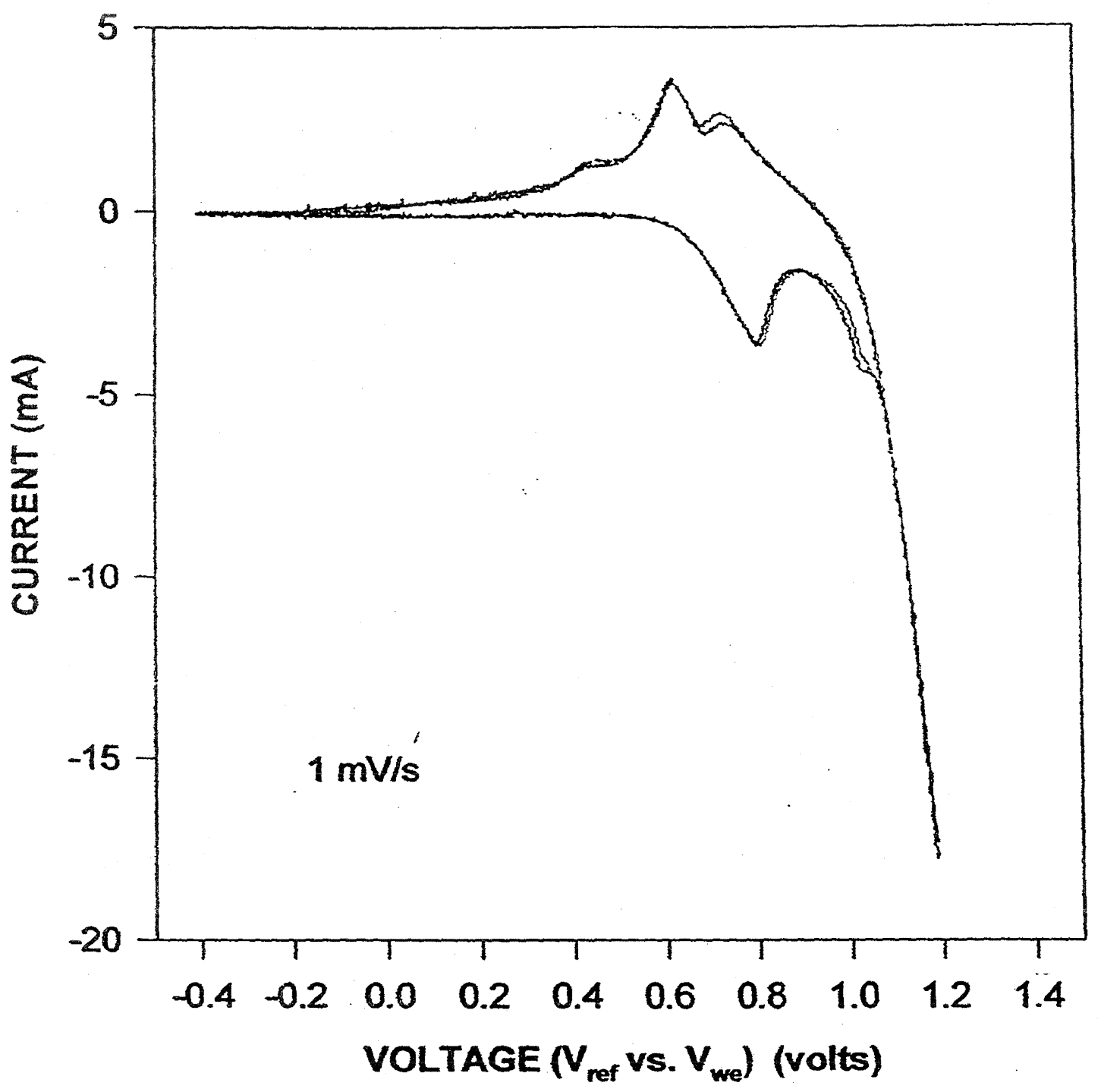

FIGURE 34 


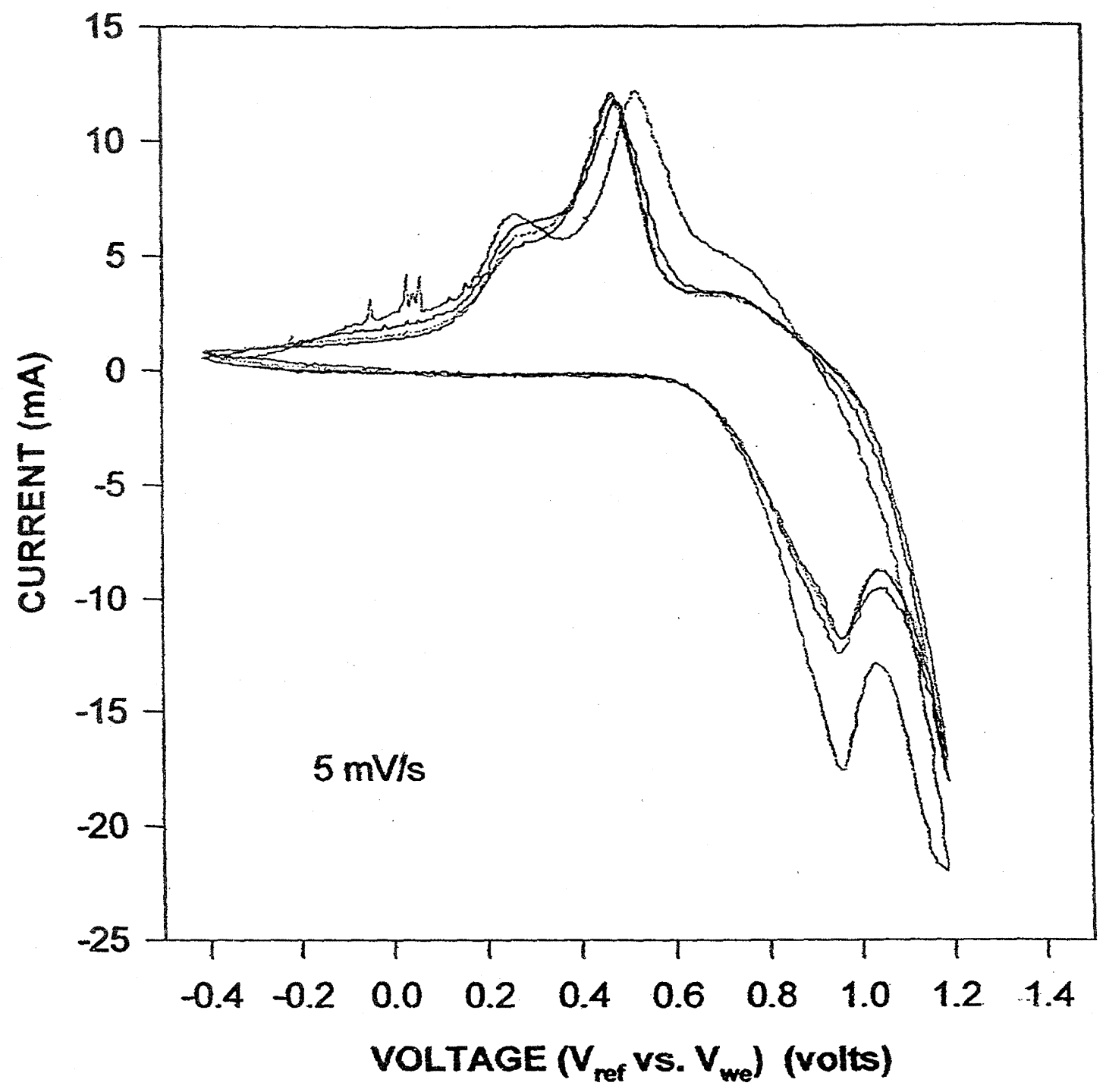

FIGURE 35 


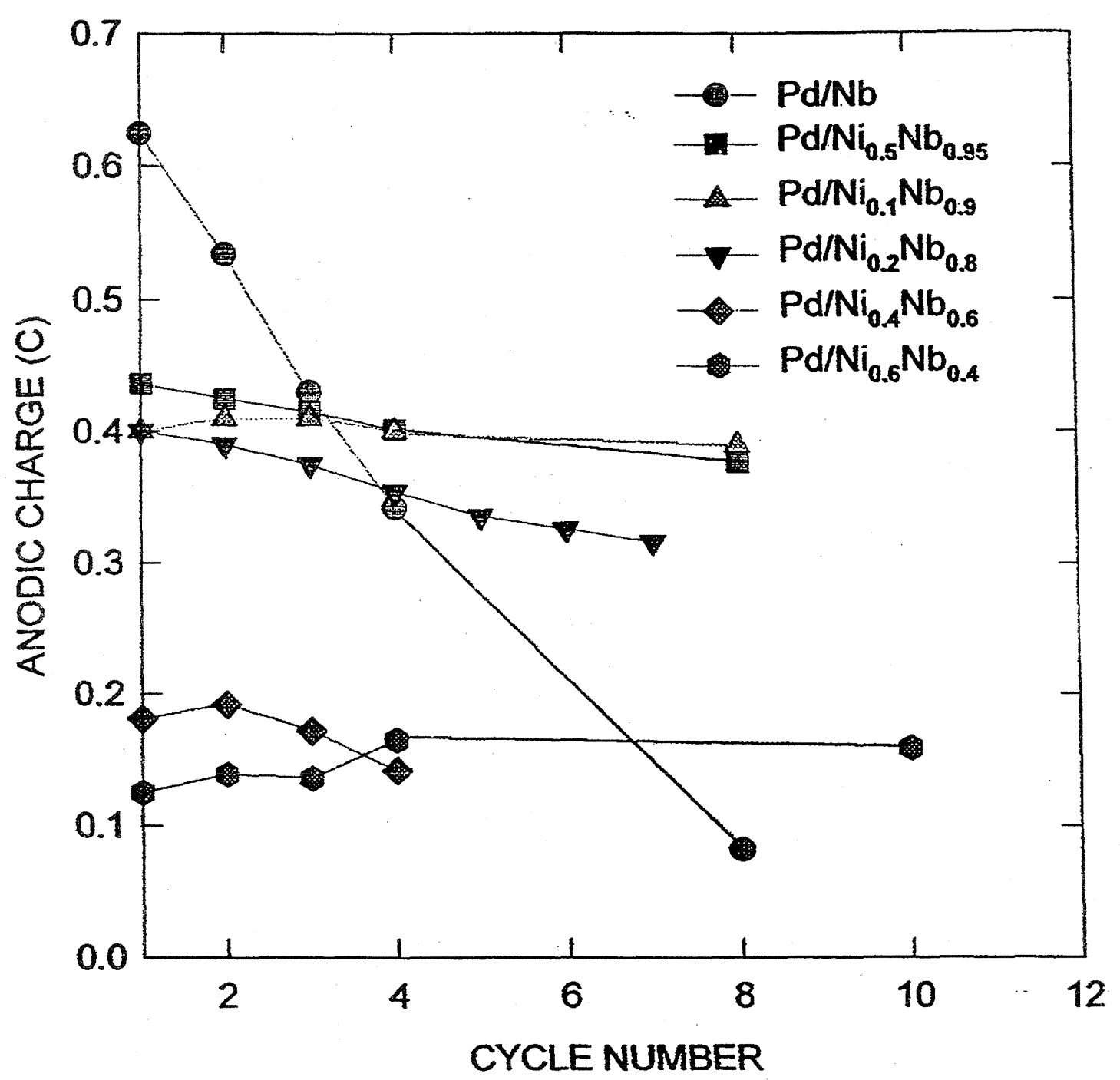

FIGURE 36 


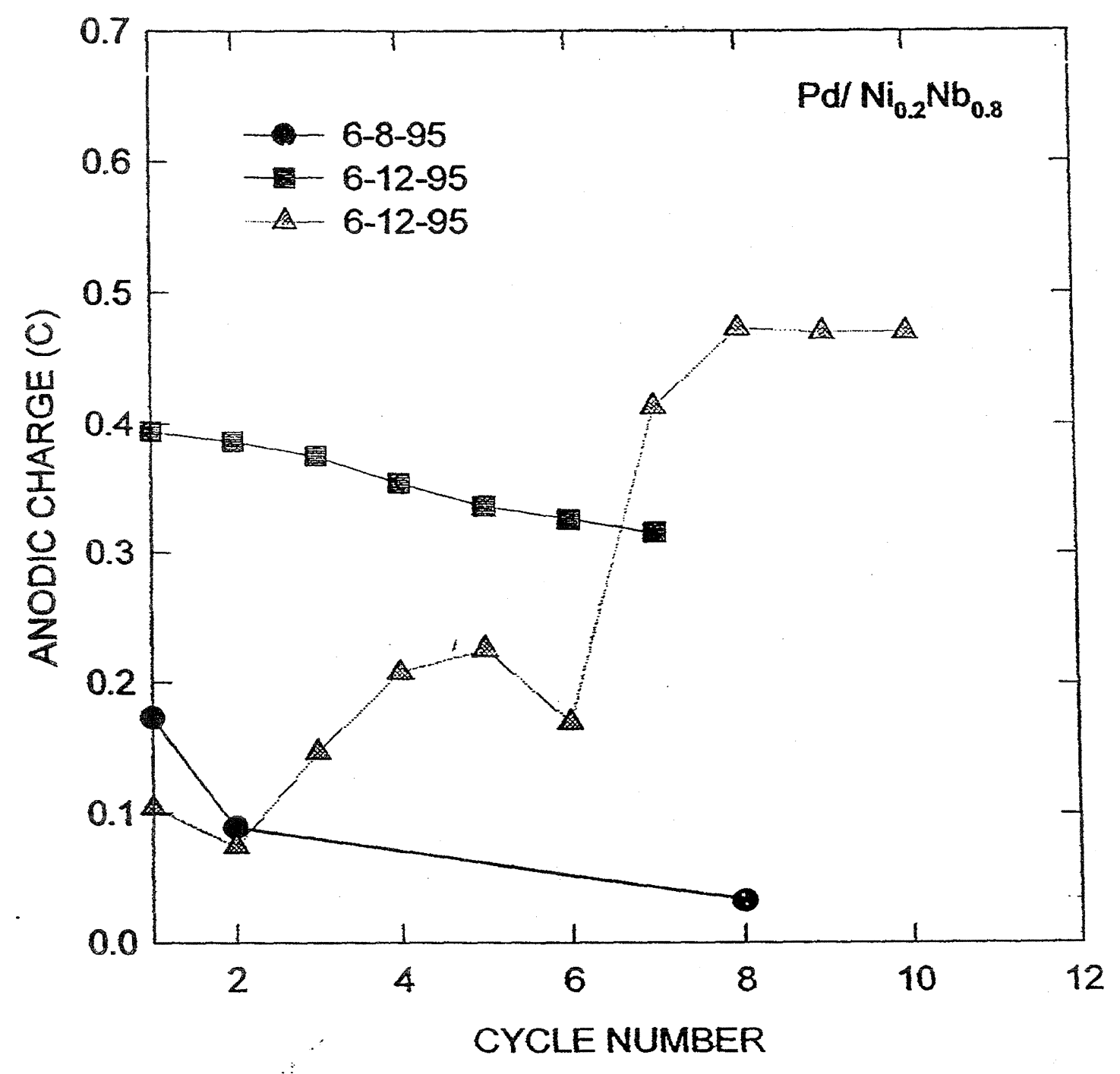

FIGURE 37 


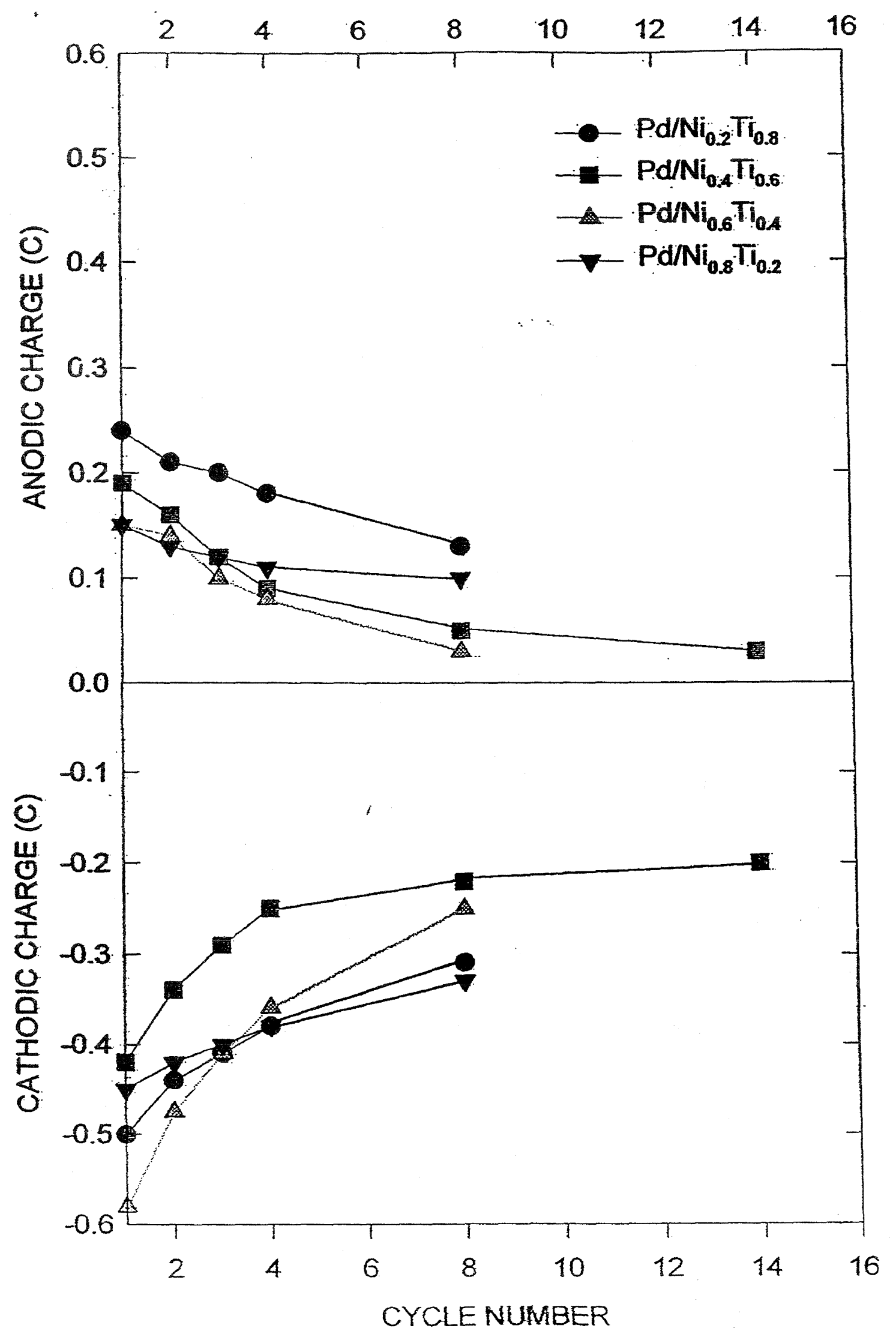

FIGURE 38 


\section{Cyclic Voltammogram for $\mathrm{Pd} / \mathrm{Zr}_{0.4} \mathrm{Ni}_{0.6}$}

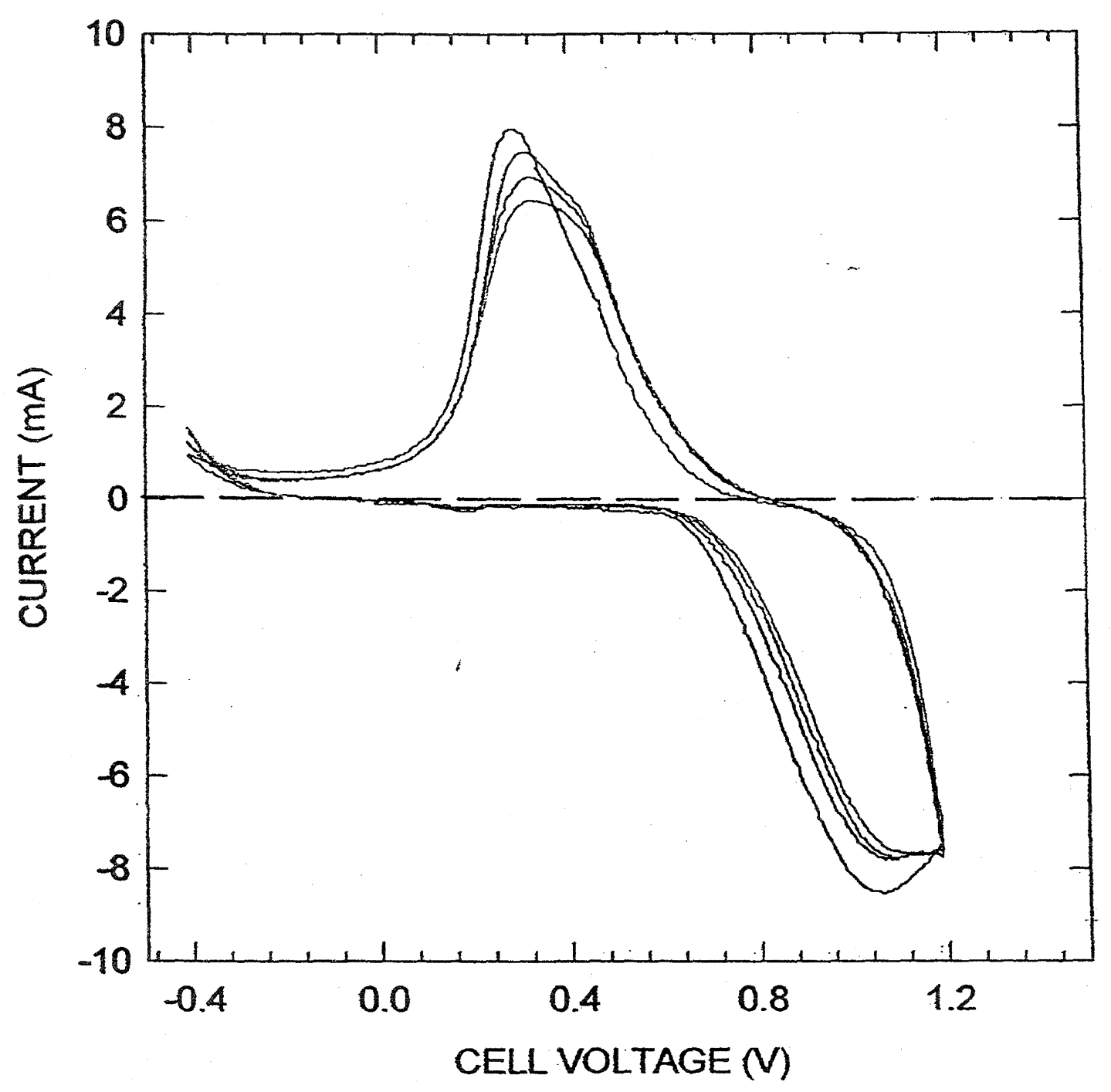

FIGURE 39 


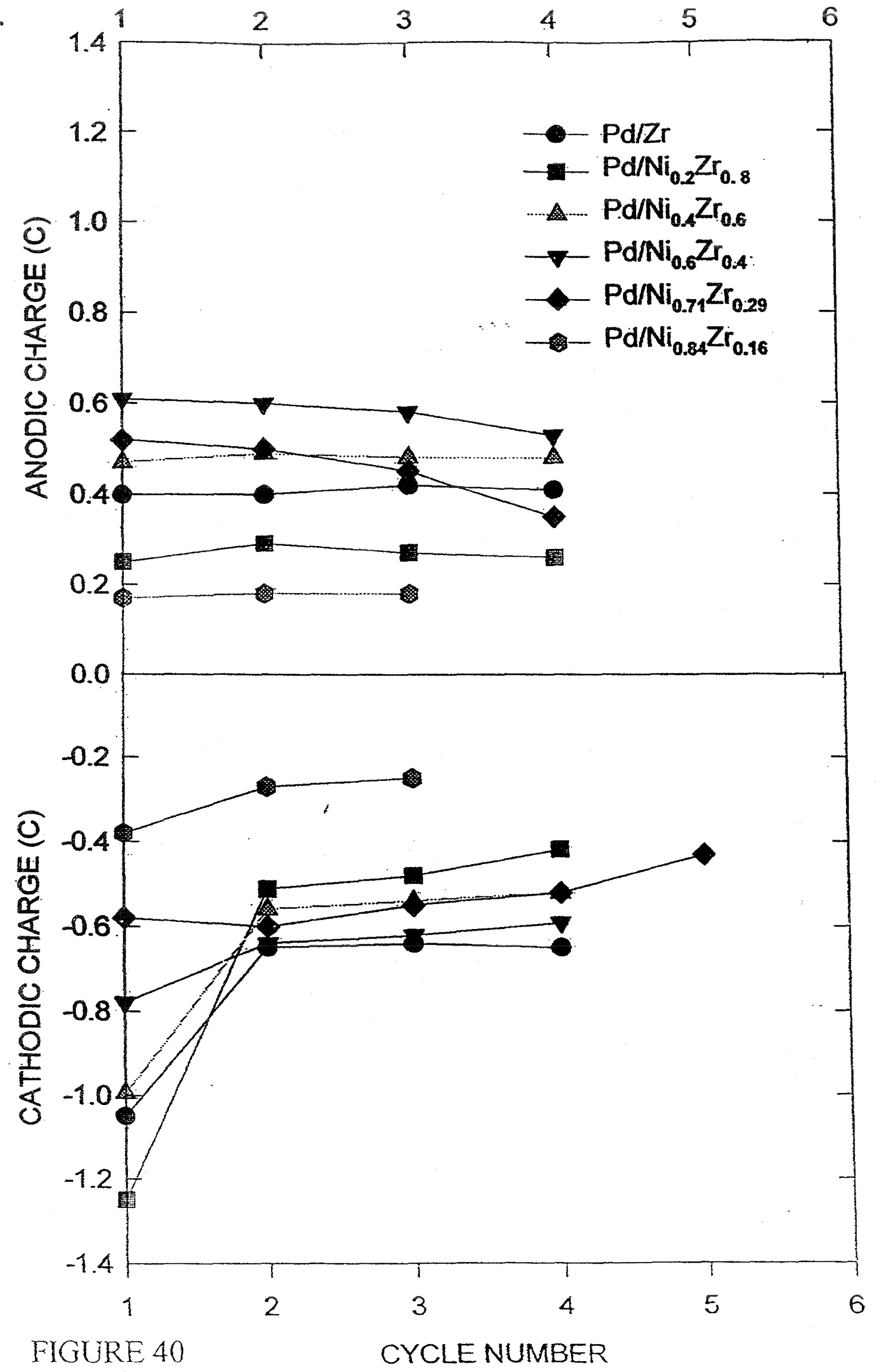


File bc12050 Sample 2-12/5/96-SSRZro.4Nio.6/Pd-2400/400 Area, $10 \mathrm{~cm} 2$ * Cycles 50. Charge 1, $4.71 \mathrm{ma}$ C10. Discharge 1, -0.941 ma C2. HM = 0.7 Charge Tume 360 sec. Pull Down Voltage +0.800 . Cathode ECD 4/4/96.
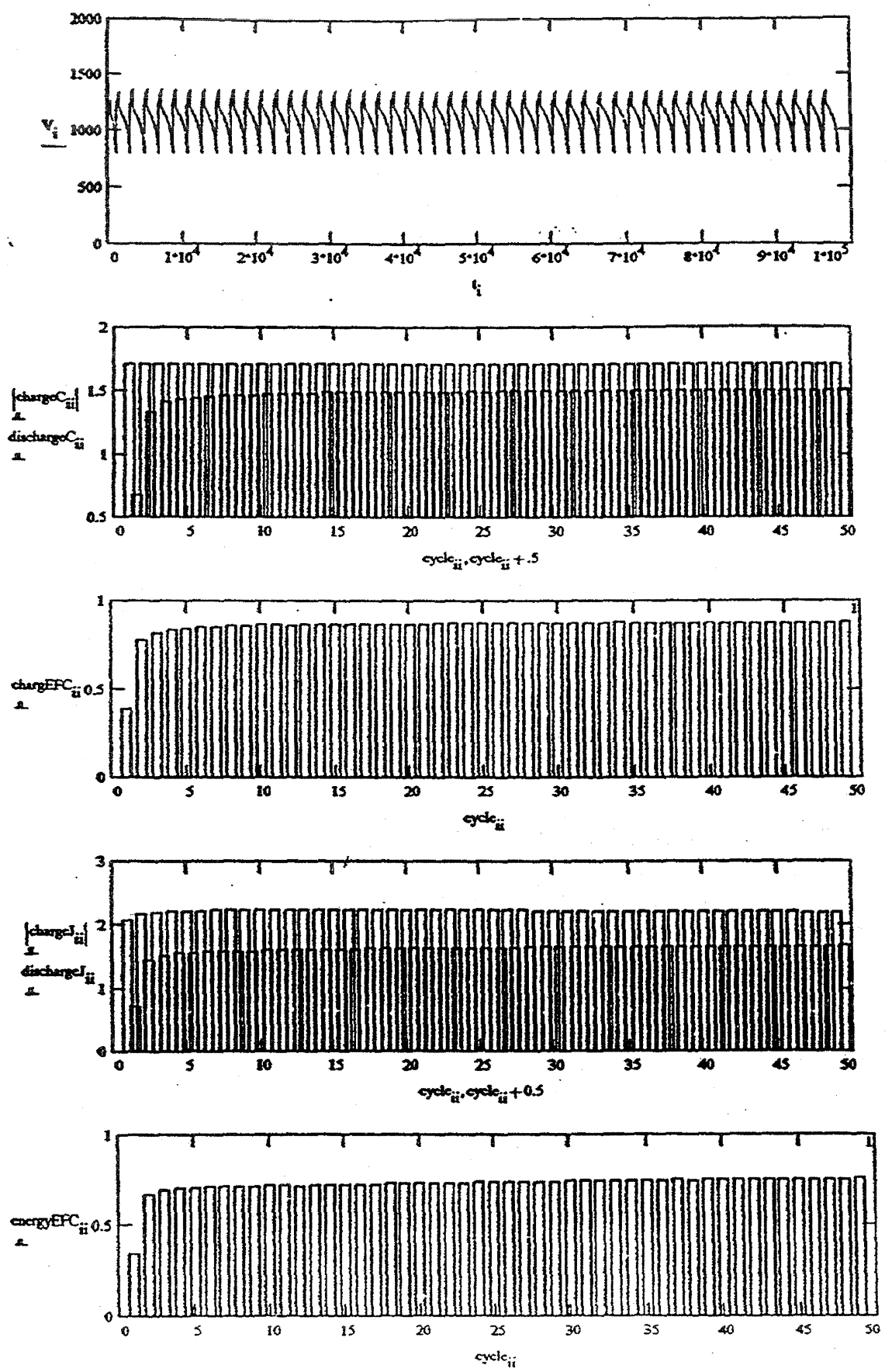

FIGURE 41 


\section{CHARGING EFFICIENCY OF Zr-Ni ANODES}

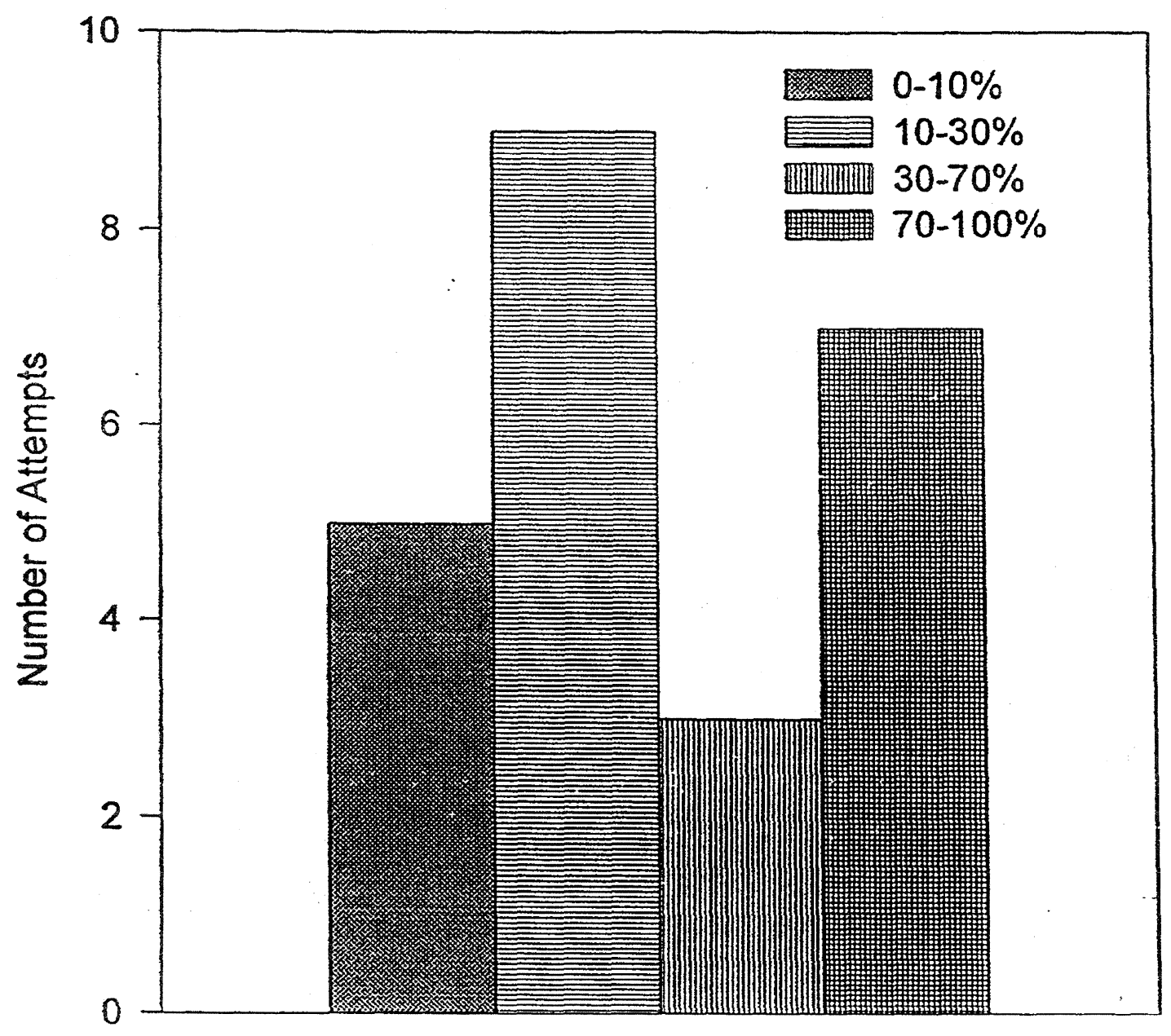

FIGURE 42 


\section{$\mathrm{Ni} / \mathrm{Nb} / \mathrm{Pd} \quad 2400 / 200$}

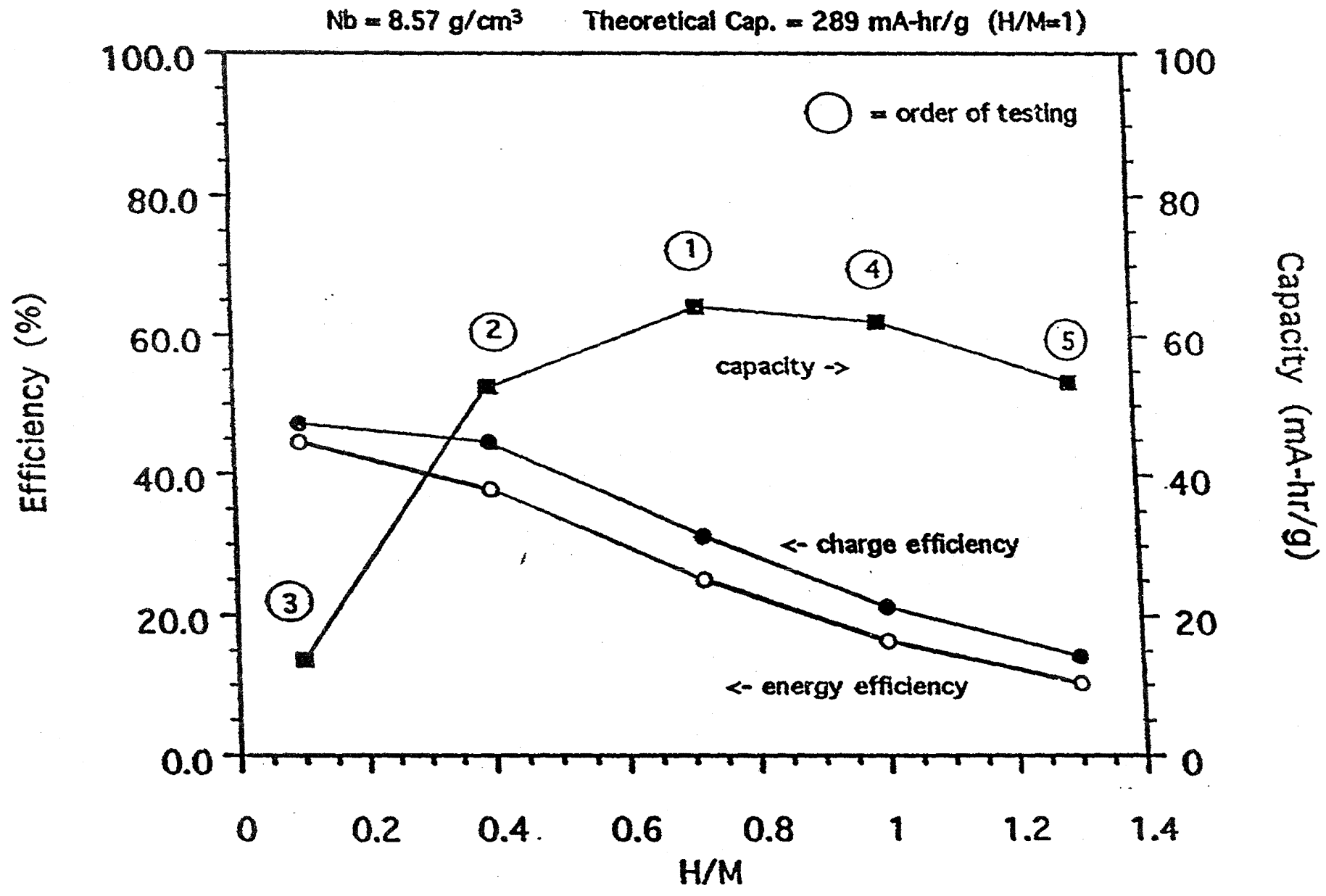

FIGURE 43 
$\mathrm{Ni} / \mathrm{Ni}_{0.4} \mathrm{Nb}_{0.6} / \mathrm{Pd} \quad 3 \times(800 / 100) / 100$

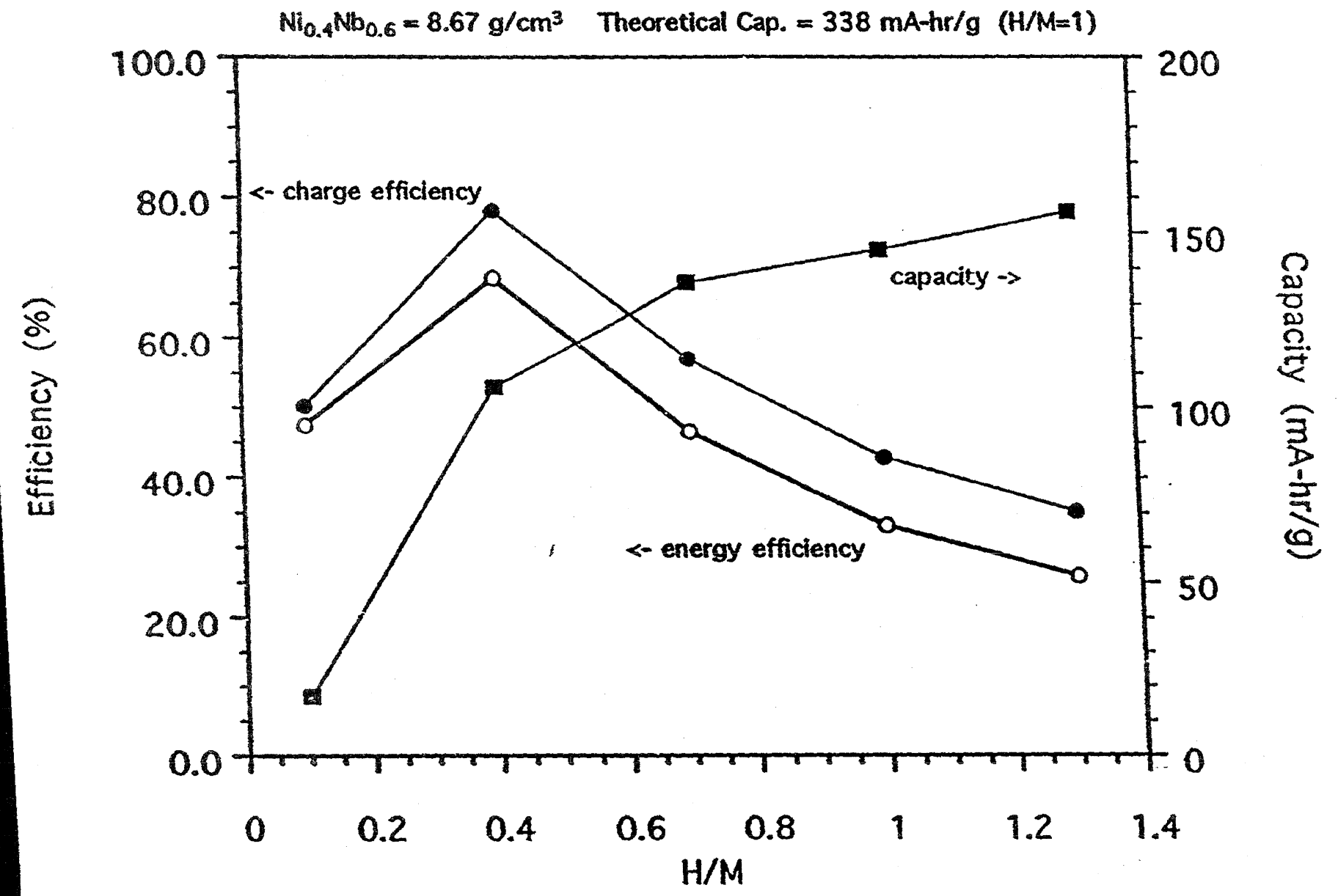




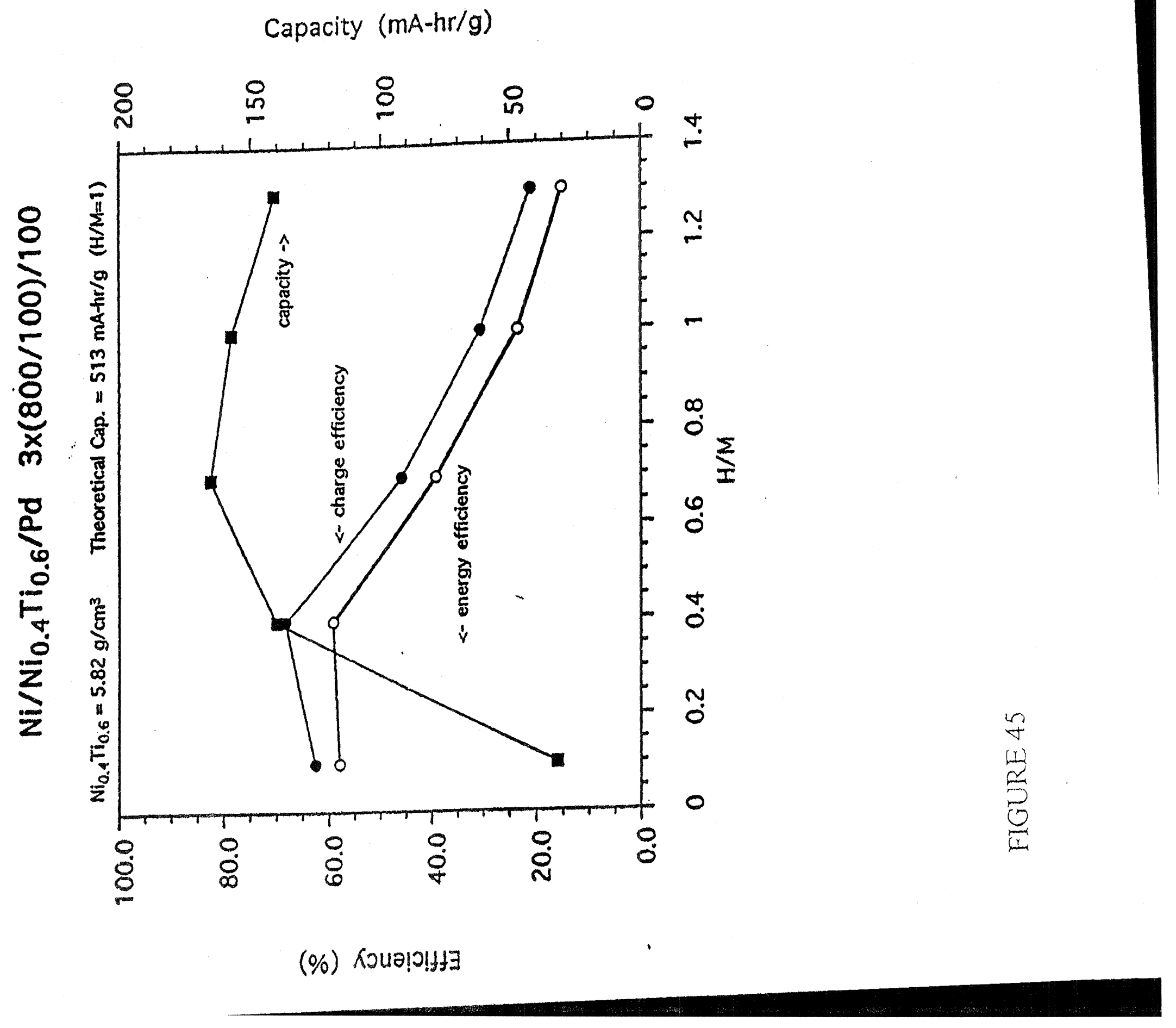




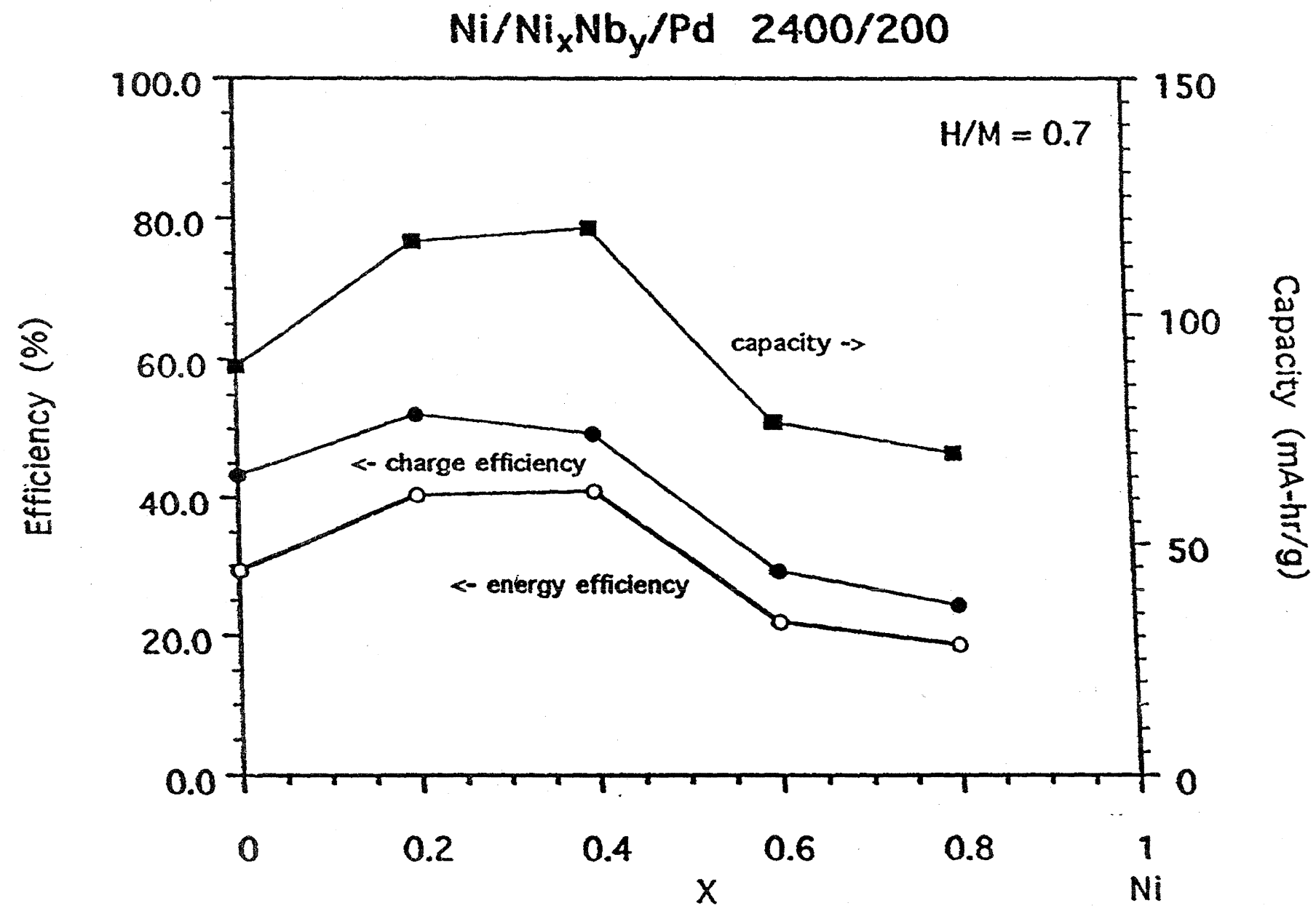

FIGURE 46 


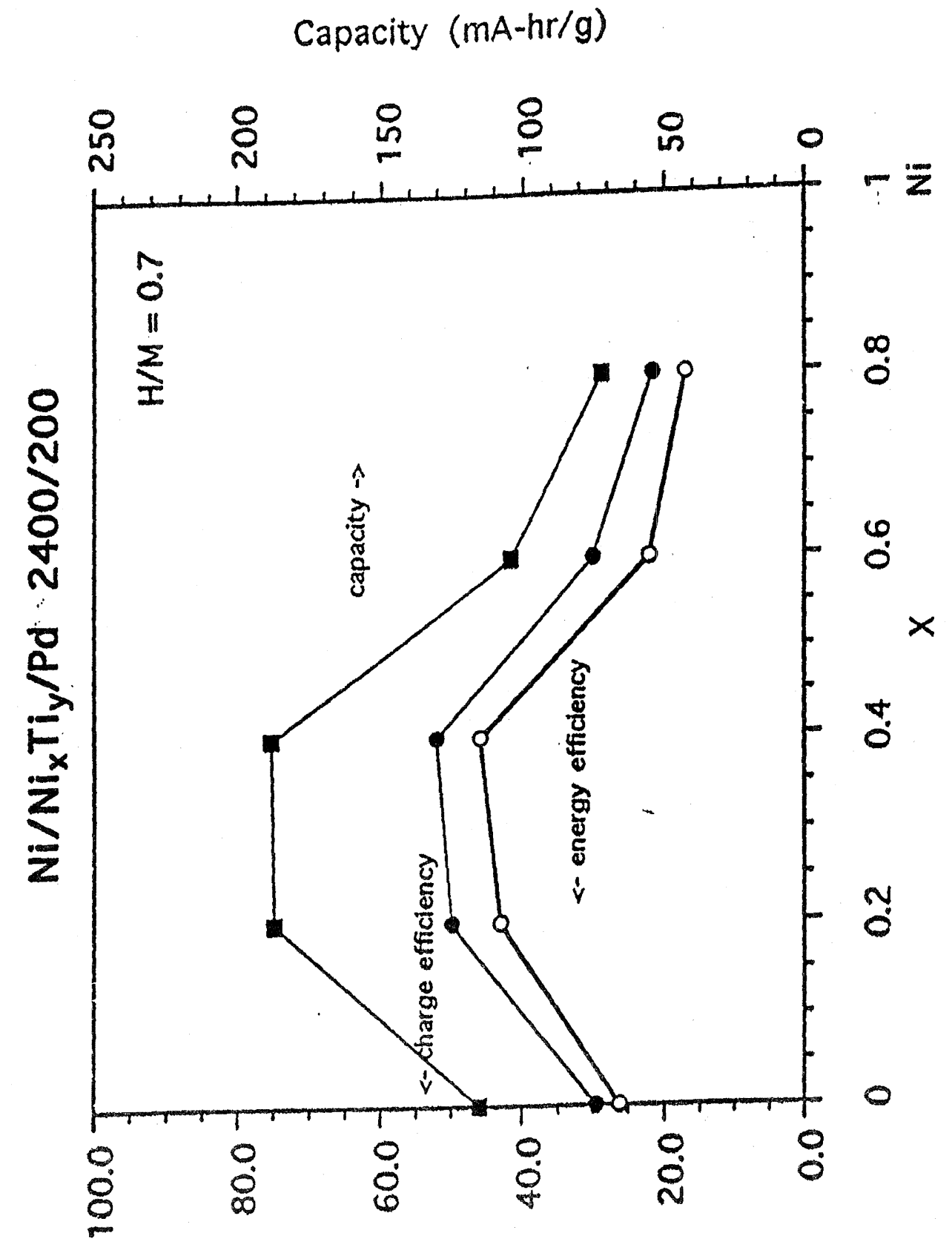

5
4
5
5
0

(\%) Кวนว!ว!กม 


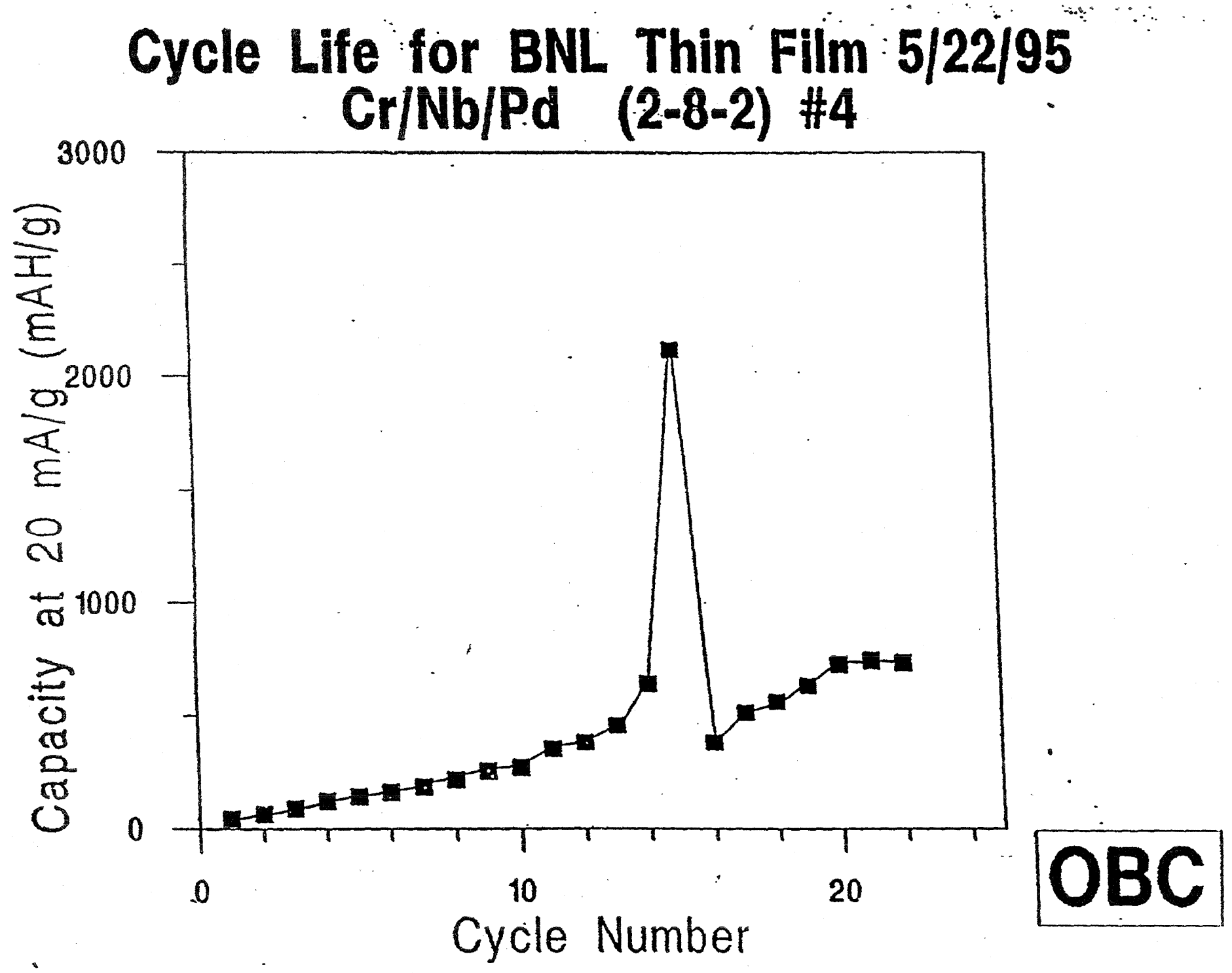

FIGURE 48 


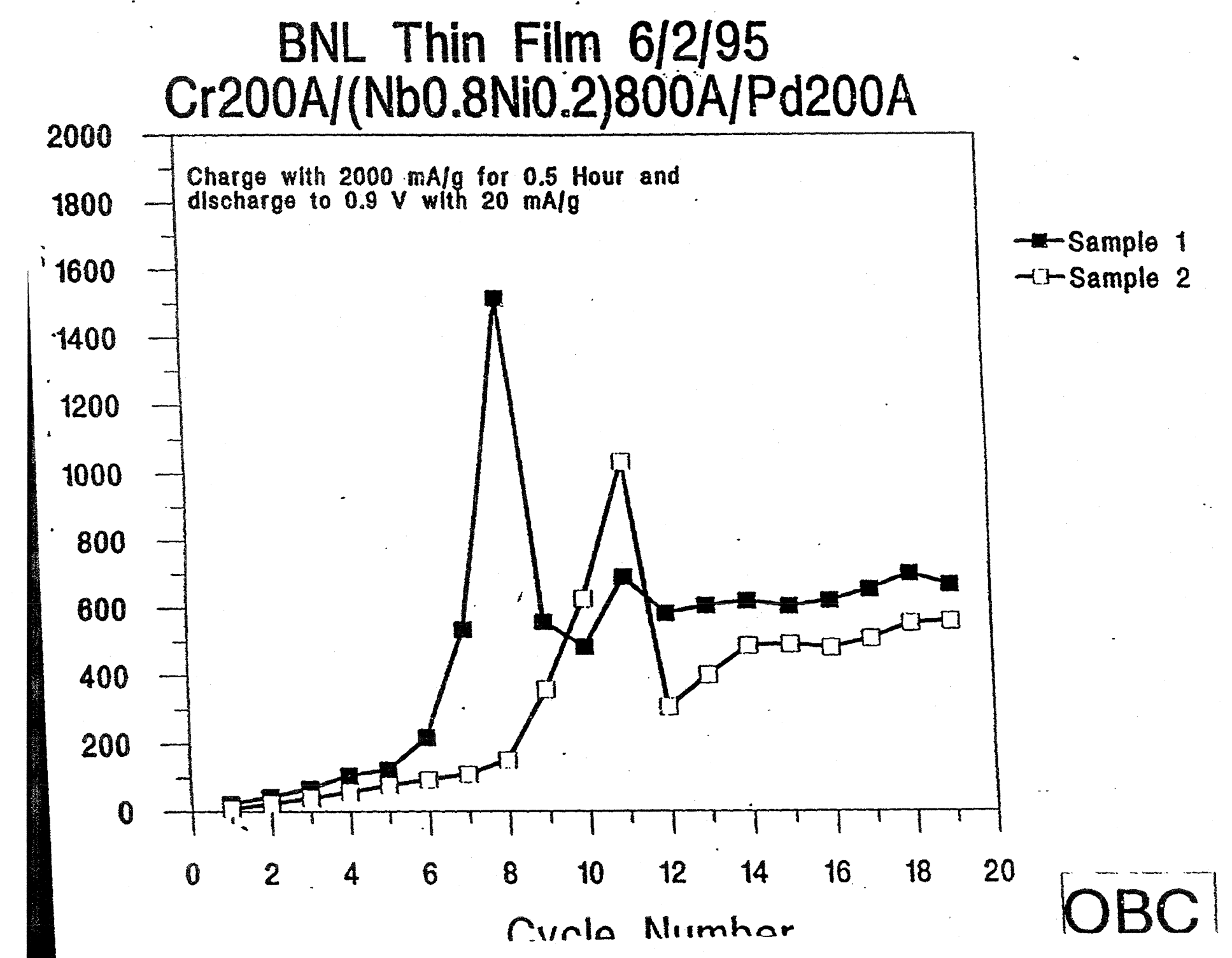

FIGURE 49 


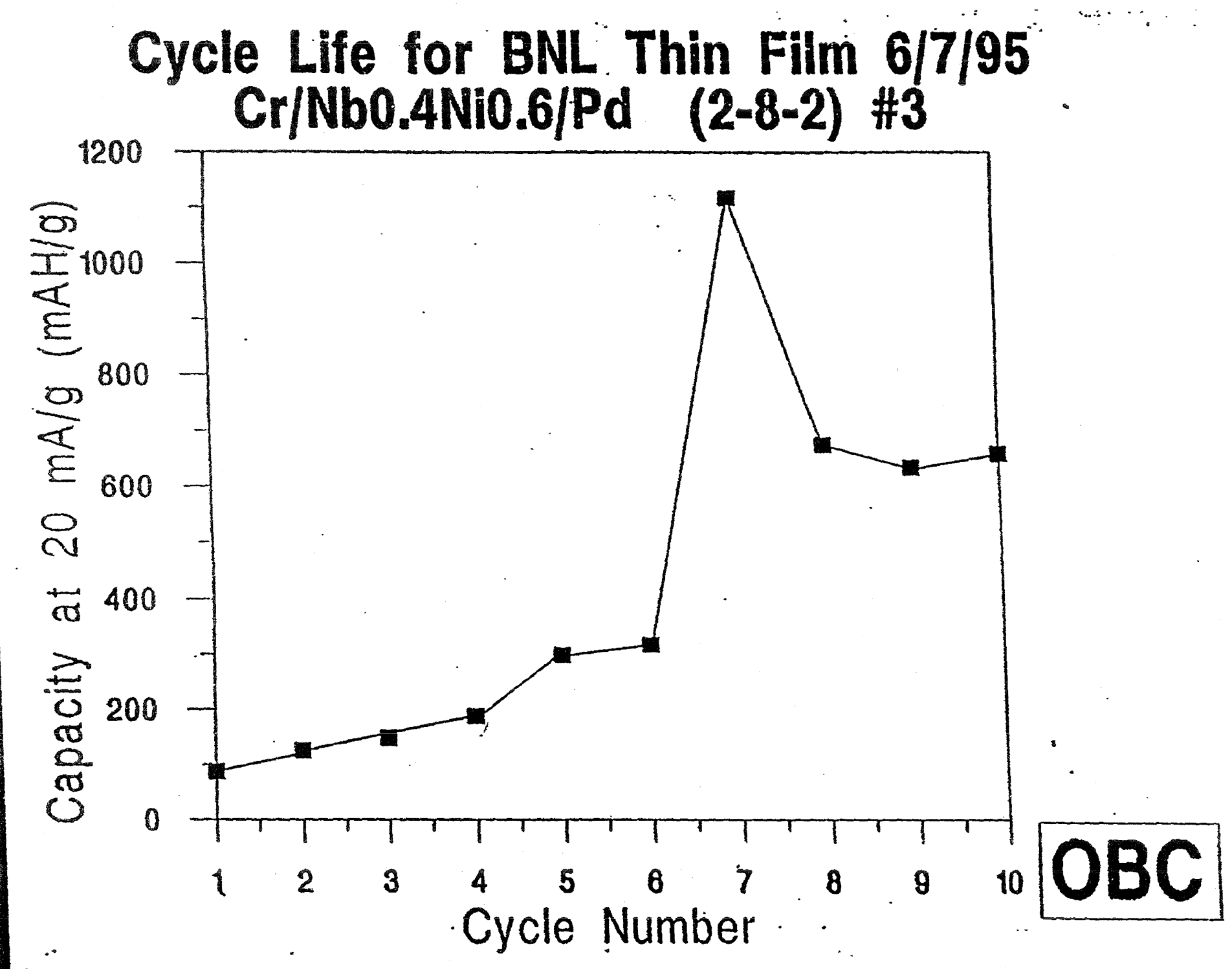

FIGURE 50 

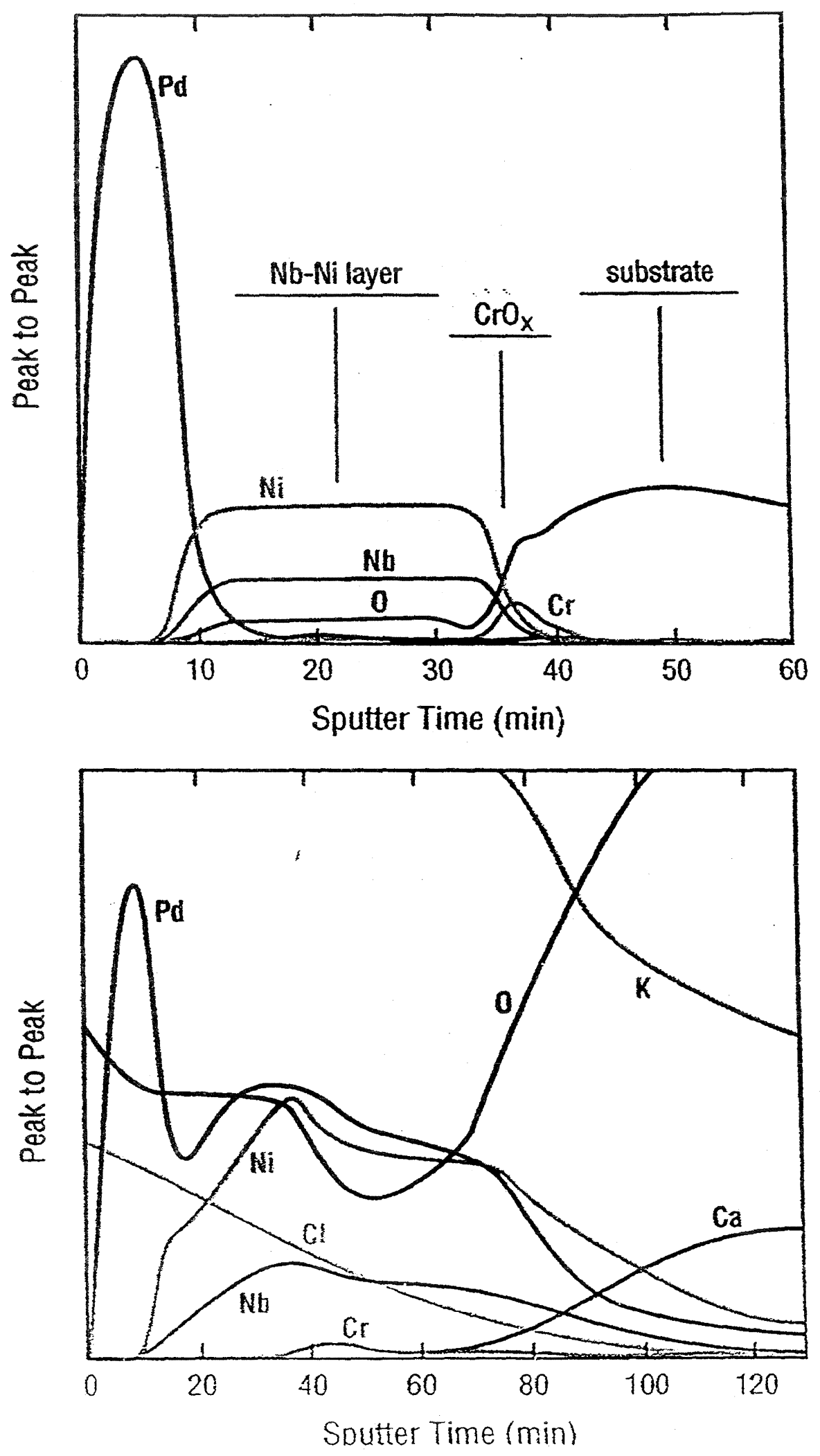

FIGURE 51 


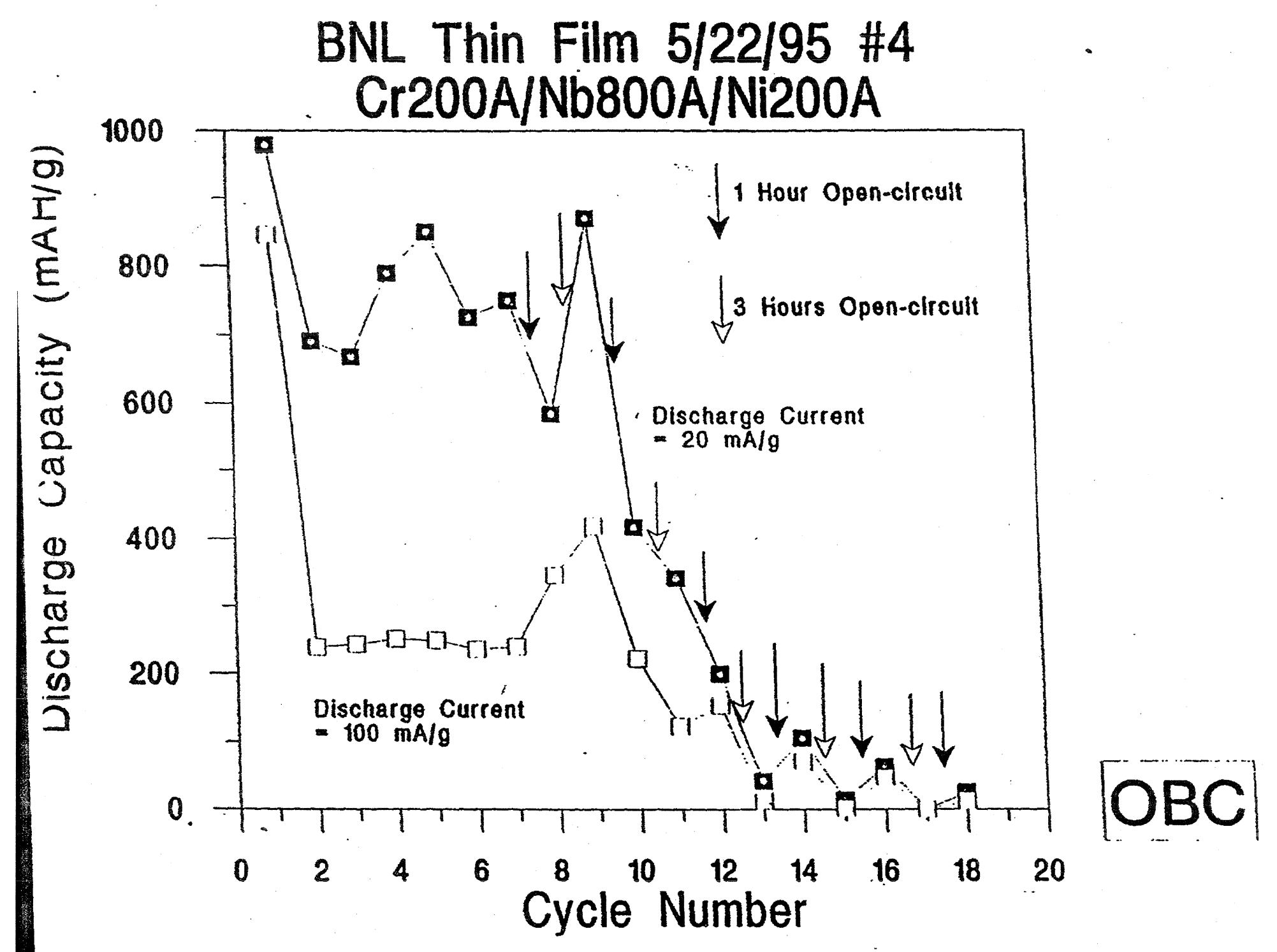

FIGURE 52 


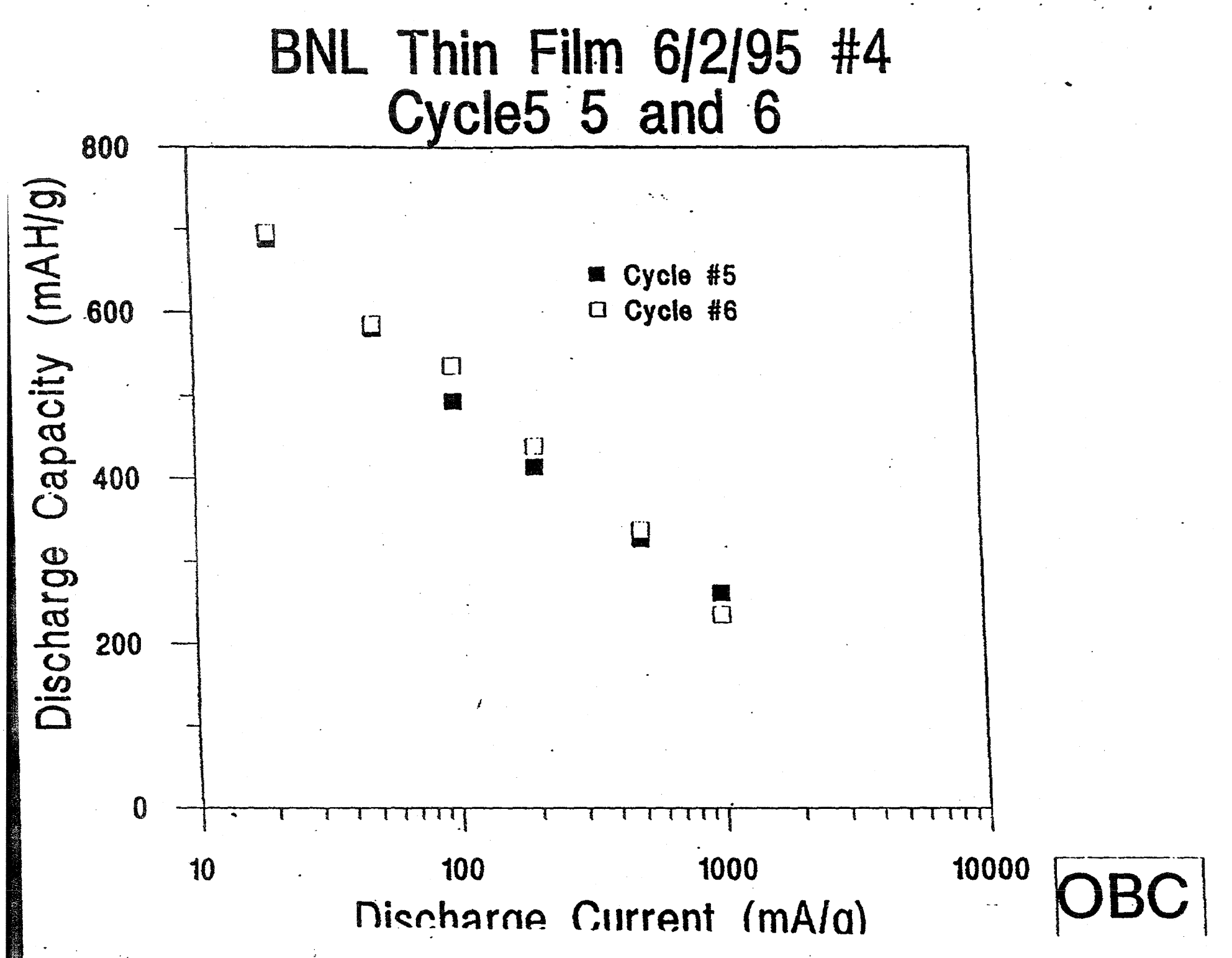

FIGURE 53 


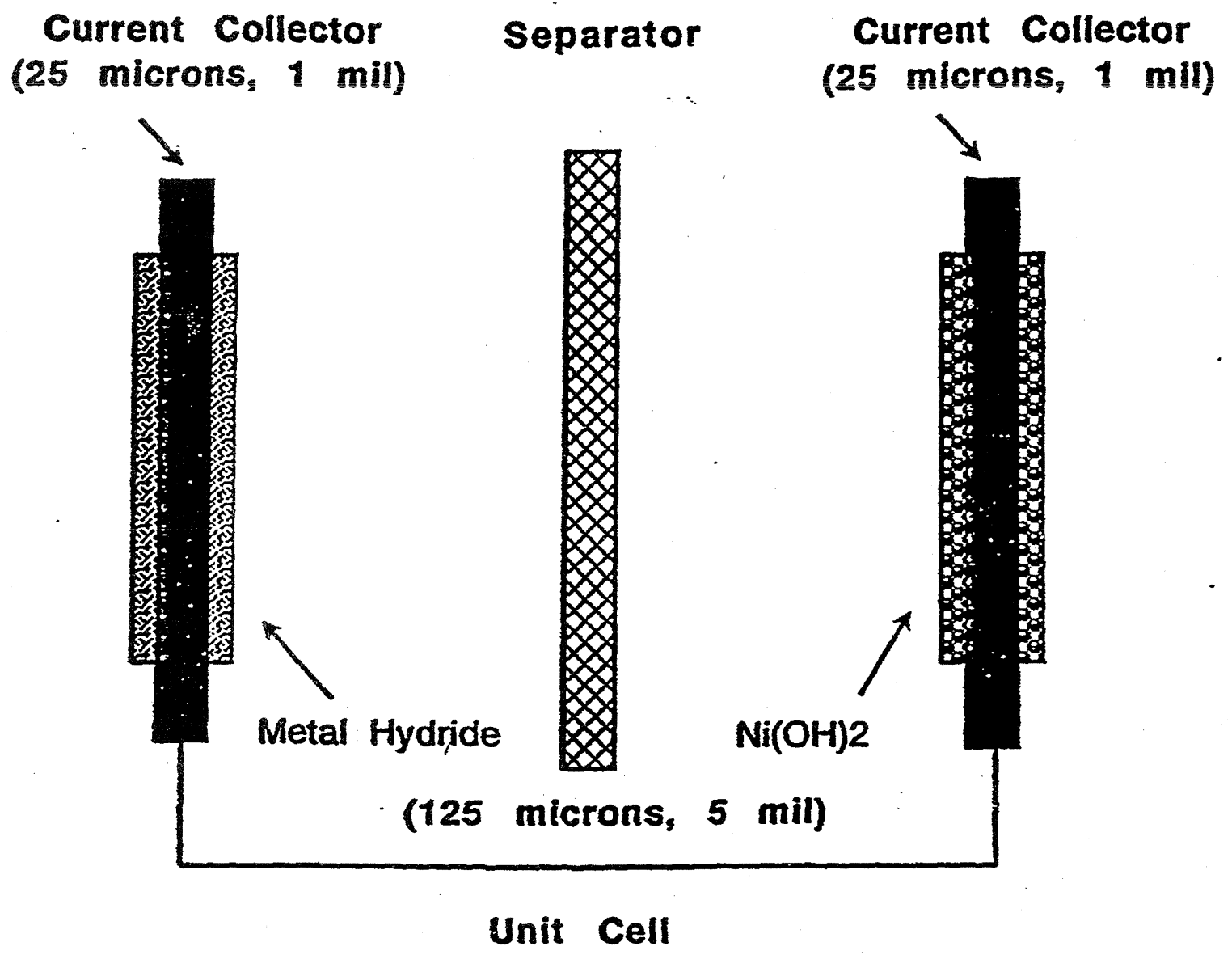

FIGURE 54 


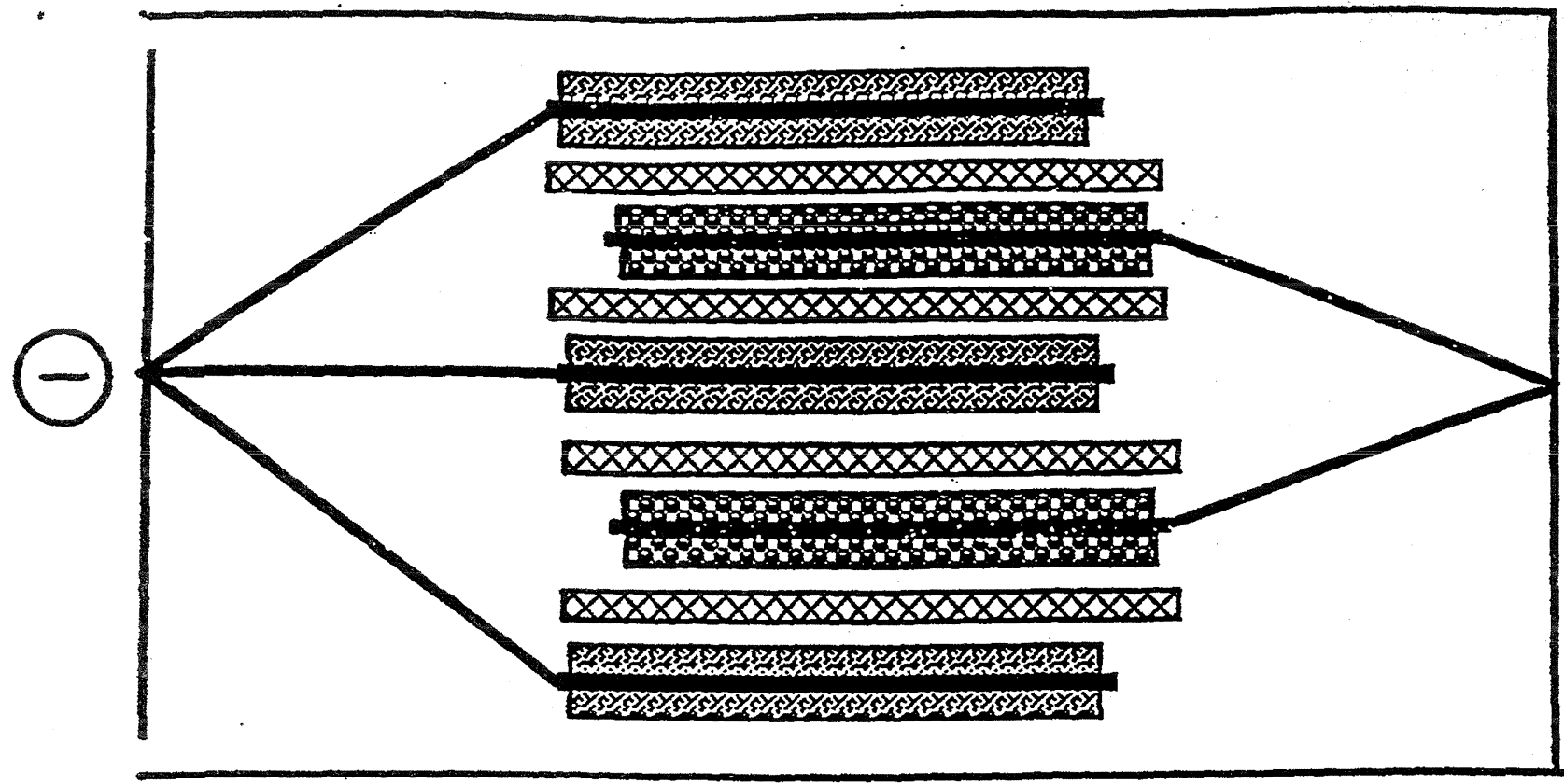

\section{Tabbed Cell}

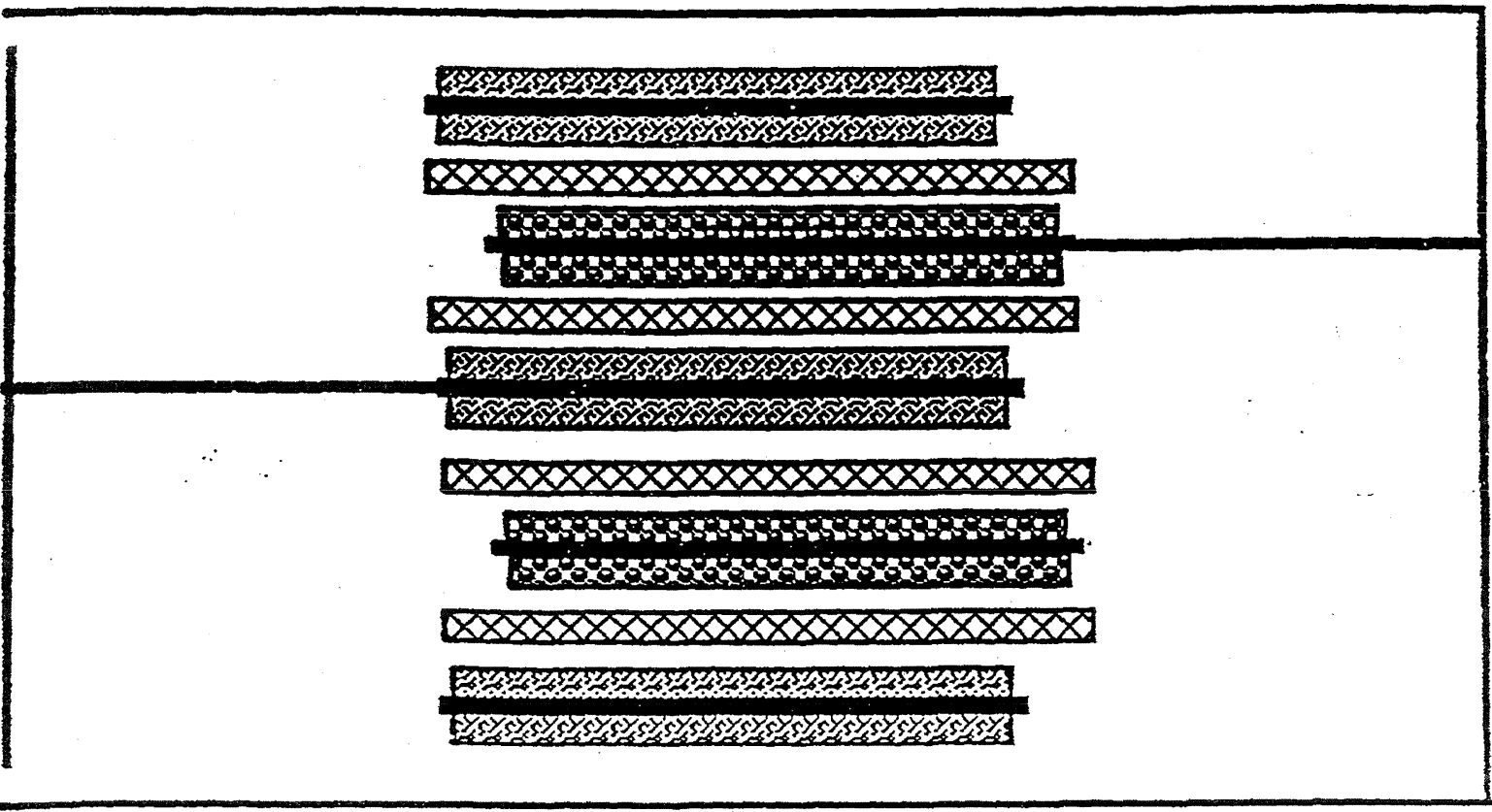

\section{Staked Cell}

FIGURE 55 


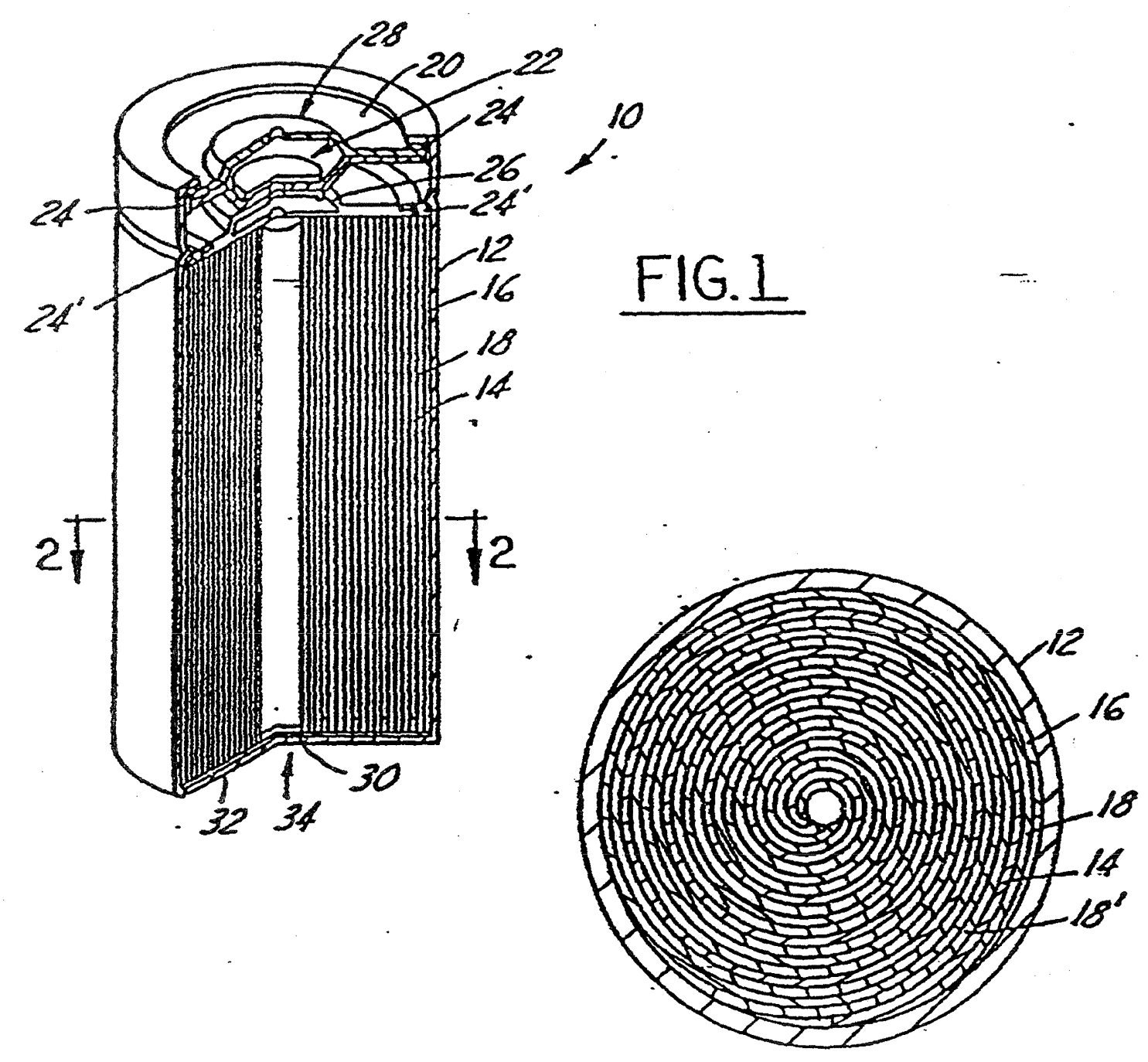

FIG.2 
IIXE

United States Patent

[19]

(ii) Patent Number:

$5,512,387$

Ovshinsky

[45] Date of Patent: Apr. 30, 1996

[54] TEMN-FIM, SOLW STATE RATTERY

BMPLOYING AN BUECTRICAULY

INSULATING, ION CONDUCTTING

RLECTROLXTE MATERIAL

[79] Inventor: Stanford R. Orshinsily, Bloomfield Fills, Mich.

[73] Assignes: Oroulc Buttery Company, InC. Troy. Mich.

(21] Appl. No.: 196,757

[22] Fed Fet 18, 1994

Related US. Application Drta

[63) Continuation-in-part of Ser. No. 155,059, Nov, 19, 1993. abendoned.

[S1] Iot. $\mathrm{Cl}^{\circ}$ BOIM 1036; HO1M $2 / 30$

[52] U.S. Cl. 429/152; 429/162; 429/178:

$429 / 191$

[58] Feld of Search 252/622; 429/162 $4291152,178,59,191 ;$ H01M 6/18 References Cited

\section{U.S. PATENT DOCUMENTS}

$4,404,268$ 9n983 Imaied al 4291191

4,810,599 3n989 Koodo et al. 4291191

$5,272,004$ U1924 Plictur at.

429191

Primary Examiner-John S. Maples

Artorny, Agent or Fim-Narvin S. Siskind: Mare I. Luddy; David W. Schumaker

[S7]

\section{ABSTRACT}

A solid staic battery comprising abstrate; le least one multilajecred electrochemical cell deposited onto the substrate, erch layer of the multalayered clectrochemical cells composing: a layer of negative clectrode material capable of eloctrochemically adsorbing and desorbing lozs during charge and dischange; a laye of positive eloctrode matcrial capable of electroctemically desorting and adsorbing ions curing charge and discharge; and a layer of insulating/ conducting material disposed between the laye of positive eloctrode material and the layer of negative cloctrode material, where the layer of insulating/conducting material is eloctrically insulating and capable of readily conducting or transporting ions from the layer positive electrode material to the layer of negative eloctrode material white the bathery is charging and from the iayer of negative electrode material to the layer of positive electrode material while the battery is discharging: and an eloctrically conductive laye deposited a wop the last of the af least one multilayered electrochemical cells, the electrically conductive laye providing one battery terminal.

18 Chims, 1 Drawing Sheet

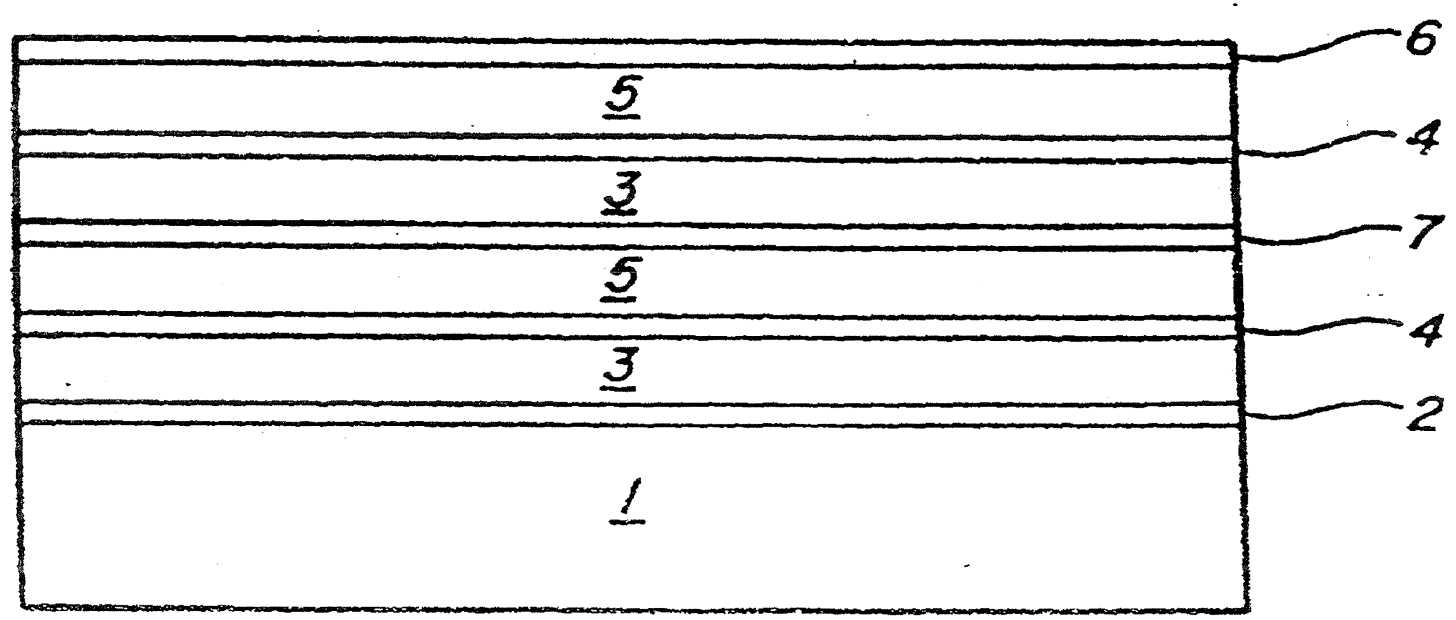




\section{Electron Beam Evaporation}

BOC Computer Program

BOC is currently operating a $2000 \mathrm{sq}$ ft/day system depositing 125 microns of alloy and operating for 3 shifts/day

$\mathrm{Ni}_{0.5} \mathrm{Ti}^{\mathrm{T} .5}$ Alloy

Program Inputs

Coating Thickness

Substrate Width

Percent Area Coated

Line Speed

Thickness Uniformity

Ni Cost (2" rod)

Ti Cost $\left(2.5^{\prime \prime} \mathrm{rod}\right)$

Substrate Cost

Electricity Cost

Equipment Cost

\# Operators/machine

Operator Cost

Hours/year/shift

Unscheduled Downtime

Equipment Amortization
40 microns

36 inches

$100 \%$

6.00 inches/min

$+1-15 \%$

$\$ 8.00 / \mathrm{b}$

$\$ 13.50$

$\$ 0.10 \mathrm{sq} \mathrm{ft}$

$\$ 0.04 \mathrm{kWhr}$ (Niagara, Boulder City etc)

$\$ 7,000,000$

1.00

$\$ 53 / \mathrm{hr} /$ day

1880

$10 \%$

10 yrs 


\section{Electron Beam Evaporation}

\section{Program Outputs}

Electron Beam Sources

Collection (coating) Efficiency

Material Cost/1000 sq ft

Substrate Cost/1000 sq it

Energy Cost/1000 sq ft

Direct Labor Cost/1000 sq ft

Equipment Cost/1000 sq $\mathrm{ft}$

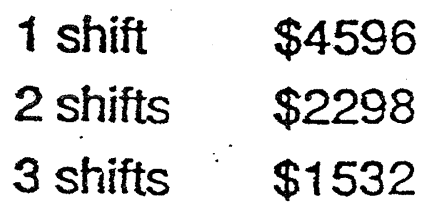

Total Cost/1000 sq ft

1 shift

2 shifts

3 shifts

Total Throughputfyr

1 shift

2 shifts

3 shifts

Total Cost/sq ft/yr

3 shifts

Total CostJAA Anode 3 shifts

Target CosUAA anode
9 (6 Nickel, 3 Titanium)

\section{$44.4 \%$}

$\$ 1218$

$\$ 100$

$\$ 240$

$\$ 656$
$\$ 6811$

$\$ 4513$

$\$ 3747$

$152,292 \mathrm{sq} \mathrm{ft}$ $304,584 \mathrm{sq} \mathrm{ft}$

456,877sq ft

( 2000 sq ft/day)
$\$ 3.74 / \mathrm{sq} f t$

$\$ 0.99$

$\$ 0.60$ 


\section{Plasma Spray Deposition}

No computer program available. Calculation is approximate at this time

Plasma Spraying has 40x throughput compared to E-beam but higher maintenance costs

$\mathrm{Ni}_{0.4} \mathrm{Ti}_{0.6}$ Alloy

Inputs

Coating Thickness

Substrate Width

Percent Area Coated

Line Speed

Thickness Uniformity

Chamber Pressure

Ni Cost ( $2^{\text {n rod })}$

Ti Cost $\left(2.5^{\prime \prime}\right.$ rod)

Substrate Cost

Electricity Cost

Equipment Cost

\# Operators/machine

Operator Cost

Hours/year/shift

Downtime

Equipment Amortization
40 microns

36 inches

$100 \%$

1-10 Torr

$\$ 8.00 / \mathrm{lb}$

$\$ 13.50$

$\$ 0.10 \mathrm{sq} f \mathrm{ft}$

$\$ 0.04$ kWh (Niagara, Boulder City etc)

$\$ 7.000,000$

2.00

$\$ 53 / \mathrm{hr} / \mathrm{day}$

1880

1 Shift (8 hrs)

$10 \mathrm{yrs}$ 
System Concept - Electron Beam Evaporation -

Síde View

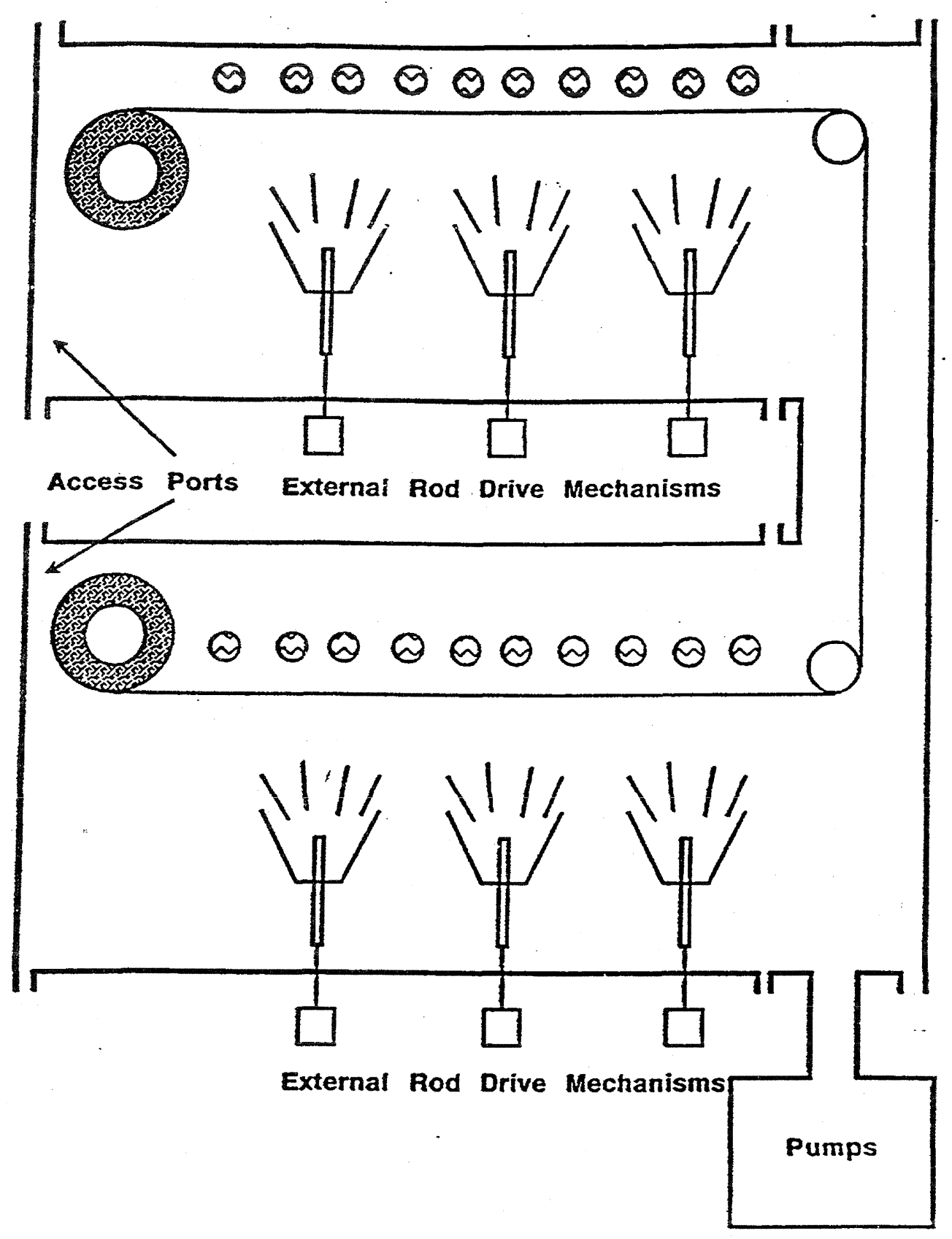

FIGURE 61 


\section{System Concept II - Plasma. Spray Deposition Top View}
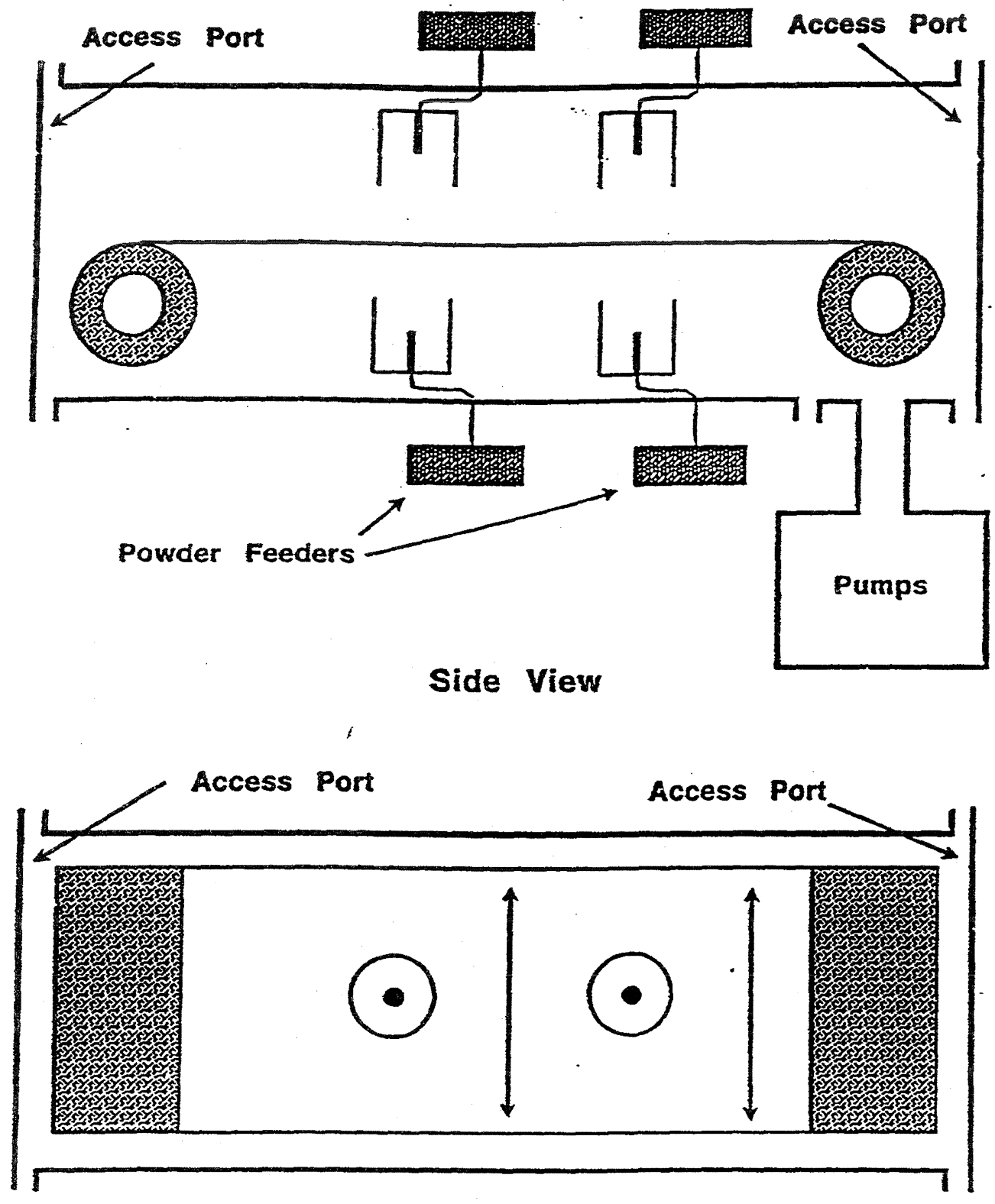

FIGURE 62 